\title{
Teachers' and students' perceptions of motivational teaching strategies in an Indonesian high school context
}

\section{Sri Puji Astuti}

A thesis submitted to the Victoria University of Wellington in fulfilment of the requirements for the degree of Doctor of Philosophy in Education

Victoria University of Wellington January 2015 



\begin{abstract}
The purpose of this multiple case study is to explore teachers' and learners' perceptions of motivational strategies. This study addresses three questions: How do teachers perceive the use of motivational teaching strategies; how do teachers implement these strategies; and how do learners' report the impact of these strategies on their motivation. The findings of this study help teachers of English understand the effectiveness of strategies that motivate their students and the impact of implementing these strategies in their teaching.
\end{abstract}

The data for this case study research were obtained from schools in a small town in West Sumatra, Indonesia. This study is underpinned by Dörnyei's (2001) work on Motivational Teaching Strategies. He identified a total of 102 such strategies, which he grouped into four phases: creating motivational components; generating students' motivation; maintaining motivation; and encouraging positive retrospective self-evaluation. These phases build on each other so that student motivation is created, generated, maintained and encouraged (Dörnyei, 2001). The underlying assumption of this framework is that teachers' behaviours and beliefs have a direct influence on learners.

This qualitative research uses case study methodology in order to contextualise the research within the real life environment of an Indonesian secondary classroom (Yin, 2003). Additionally, this approach allows different data collection techniques (Yin, 2009). These include semi-structured interviews, classroom observations, stimulated recalls, and focus group interviews.

The findings indicate that the implementation of Dörnyei's (2001) framework, motivational teaching practice (MTP), and Hall and Kidman's (2004) teaching and learning map ( $T-L$ map) are complementary. The findings reveal two groups of motivational components. The first is the teachers' rapport with students, including the encouragement given to students and the building of trust and respect with the students. The second relates to the teacher's planning decisions such as the selection of classroom activities, the way feedback is given, the management of the classroom, and the choice of learning resources. The findings also suggested that the appropriate use of $L 1$ is a motivational teaching strategy. It is unique to this study that L1 not only promotes L2 learning but also influences students' motivation. 
These findings suggest that teachers of English in an Indonesian high school context can influence their students' motivation by understanding the impact of motivational teaching strategies on students' learning and behaviour. The teachers themselves play a very important role in motivating their students. 


\title{
Acknowledgements
}

\author{
الْحَمْدُ لِلَِّ رَبِّ الْعَالَمِينَ
}

Al-hamdu lillahi rabbil 'alamin, "All the praises and thanks be to Allah, the Lord of the 'Alamîn". My deep and heartfelt thanks and gratefulness are due to Allah the Almighty.

I would like to sincerely thank many people who have contributed a great amount of assistance for me to finish my PhD journey. Having completed my study, I take with me valuable lessons and great experiences of conducting a research project that support my future learning and researching.

My greatest gratitude goes to my supervisors, Dr Carolyn Tait and Emeritus Professor Cedric Hall who have guided me with patience and lots of encouragement to finish my study. The most important thing is that they teach me how to be a selfdependent, lifelong learner.

I also wish to express my sincere gratitude to my sponsor, the New Zealand Asian Scholarship (NZAS) for presenting me with the scholarship and full support that enabled me to study at Victoria University of Wellington for more than three years.

I offer many thanks to my research participants who have shared knowledge, values, opinions and experiences. This study would have not been completed without their generous contributions and assistance. May Allah SWT grant them rewards.

Last but not least, I really thank my late father Supardi who was always proud of me, my mother, Bardini, who supports me with prayer and is looking after my children while I am completing my PhD. I thank my brother, Sugeng Hariady, and my sister, Sri Rahayu, who pray for my success. A very special thank due to my husband, Afrizal, who always supports me and patiently looked after our children while I was completing my PhD. My three children, Afifah Puti Sholihat, Muhammad Arif Ramadhan, and Alifya Aini Fauziyah, who encouraged me to take my PhD and patiently taking their turn to accompany me to New Zealand. I thank all my extended family members for their unconditional support, encouragement, prayers, and love. 


\section{Table of Contents}

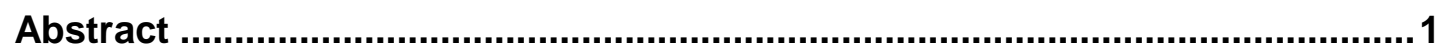

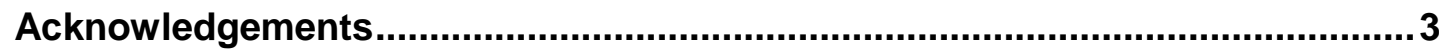

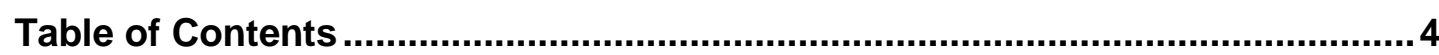

CHAPTER 1 Overview ............................................................................. 11

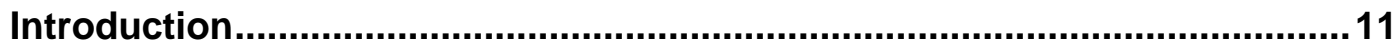

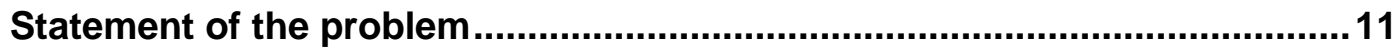

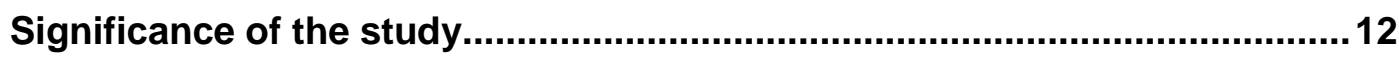

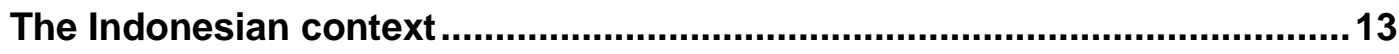

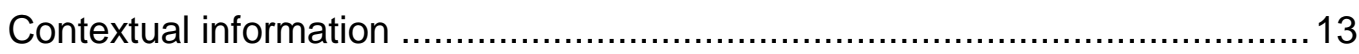

Collectivist nature of Indonesian culture .............................................. 13

Historical perspective of Indonesian education .......................................... 14

Structure of Indonesian education ........................................................ 14

English as a foreign language in Indonesia ............................................ 15

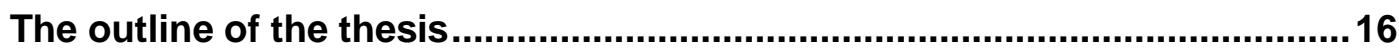

CHAPTER 2 Literature Review................................................................. 18

Teaching and learning English in Indonesian high schools.........................18

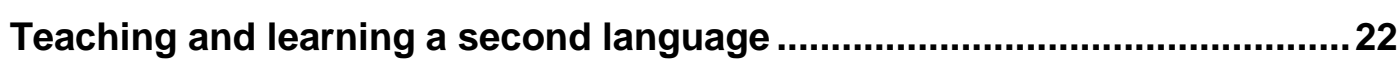

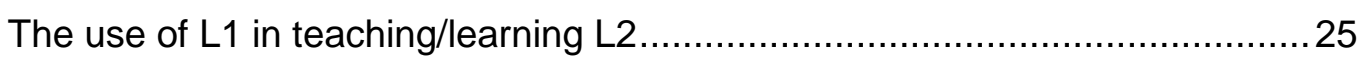

Motivation in learning a second/foreign language ........................................26

High school student motivation in learning English as a second/foreign

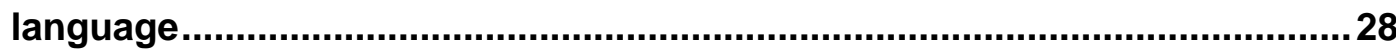

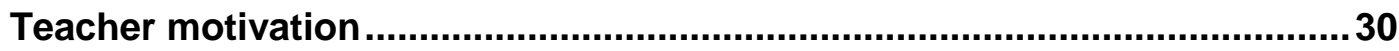

Motivation in an Indonesian EFL context..................................................... 32

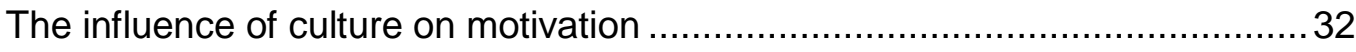

High school and university students' motivation .......................................... 32

The history of research in second/foreign language learning motivation ....34

The socio-educational period .............................................................. 34

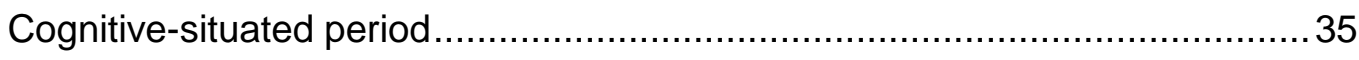

Process-oriented period ............................................................................ 36

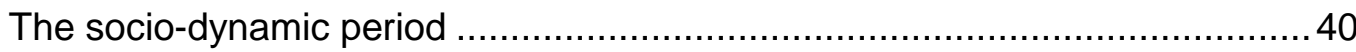

Research on motivational teaching strategies .............................................41

Teachers' and students' perceptions of motivational teaching strategies... 45

A contextual model for embedding MTP ....................................................47

Summary and research questions................................................................50 


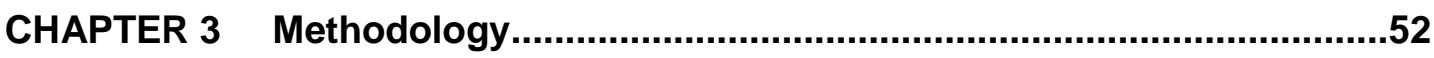

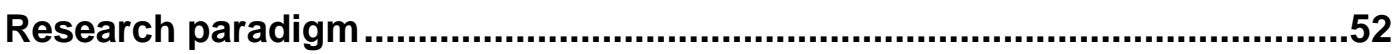

Research design: Analytical processes and contextual influences ...............53

The use of case study methodology.............................................................55

Research Procedure .................................................................................57

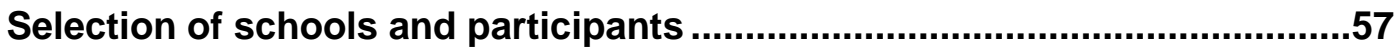

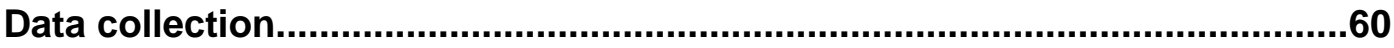

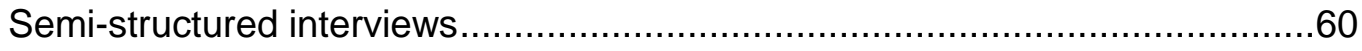

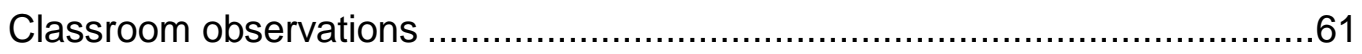

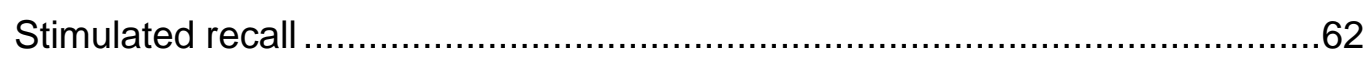

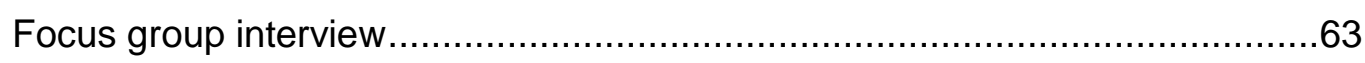

Data collection schedule .........................................................................63

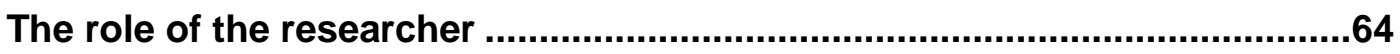

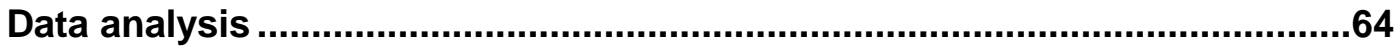

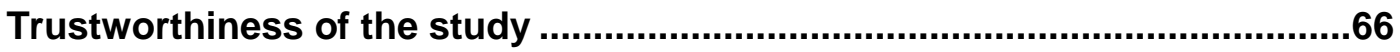

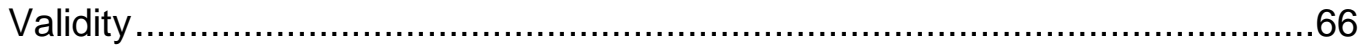

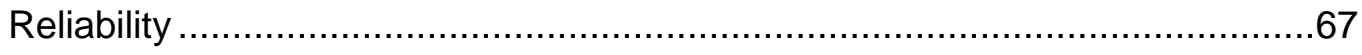

Ethical considerations .................................................................................68

Limitations and delimitations ..................................................................68

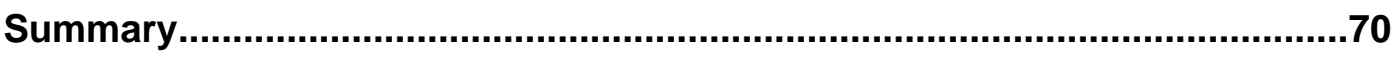

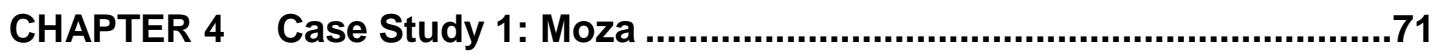

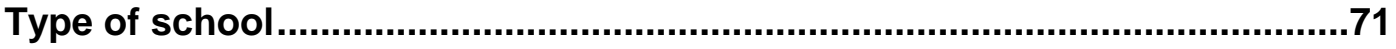

The layout and structure of the school.........................................................

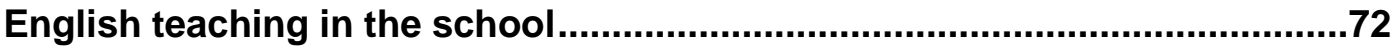

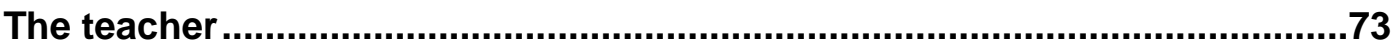

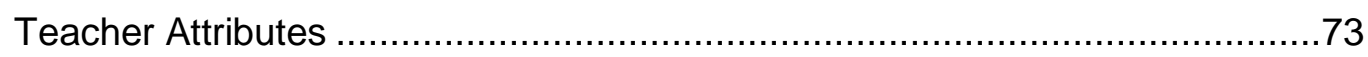

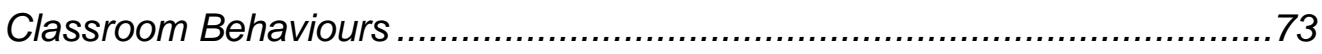

Good model of English speaking ................................................. 76

Summary of teacher attitude ................................................................ 76

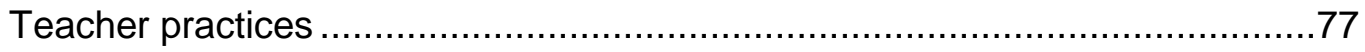

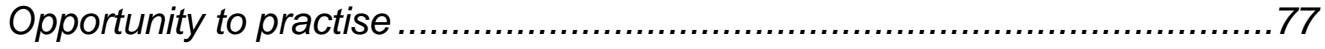

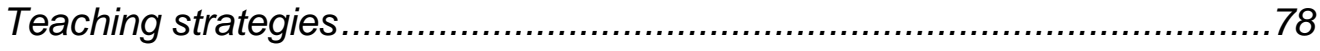

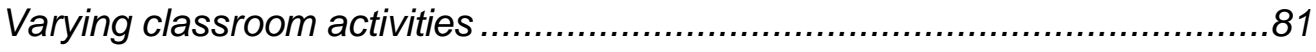

Emphasising the usefulness of English for students future ........................83

Activating students' prior knowledge .................................................83

Reading for comprehension ........................................................ 84 


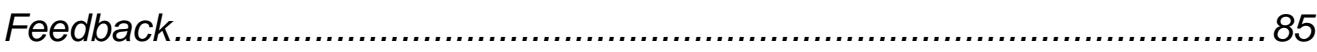

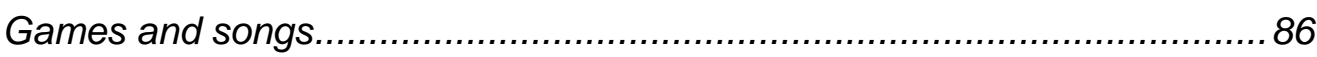

Managing unmotivated students ................................................... 87

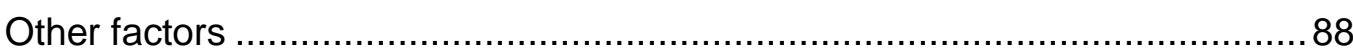

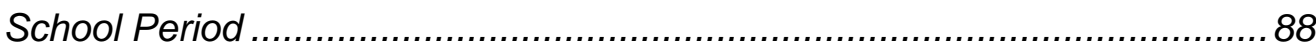

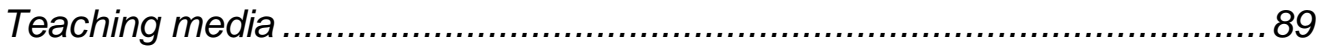

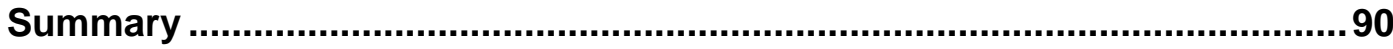

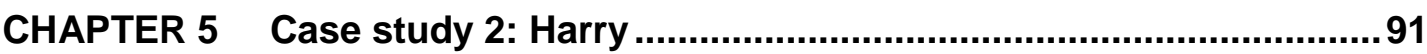

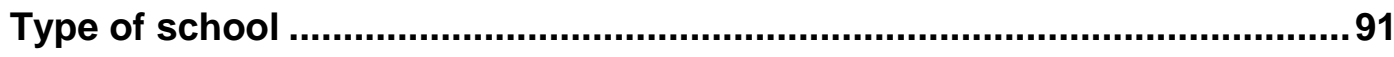

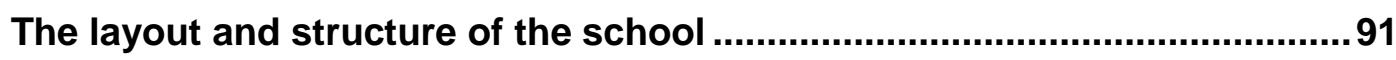

English teaching in the school ....................................................................92

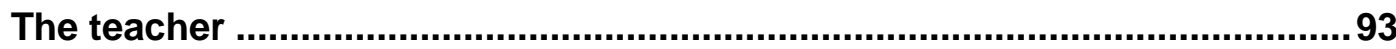

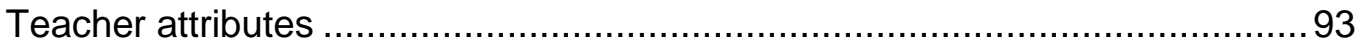

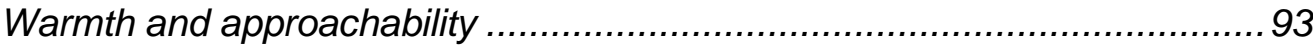

Maintaining a strong relationship with students....................................99

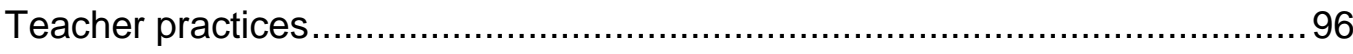

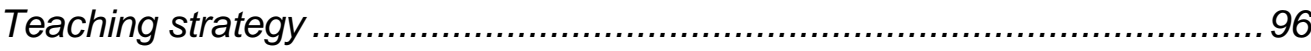

Grouping students for interaction ............................................... 97

Setting up the learning ................................................................. 98

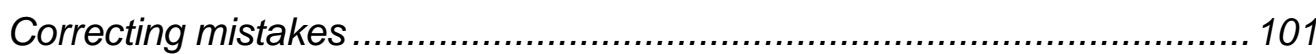

Answering student questions ............................................................. 102

The importance of English .................................................................. 103

Managing unmotivated students .......................................................... 103

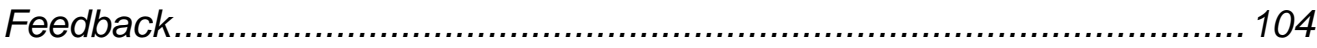

Adopting teaching strategies from other sources ................................. 105

Using English for daily communication............................................. 105

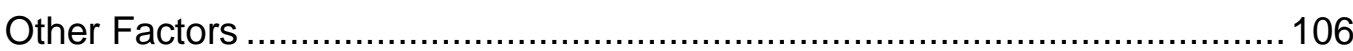

Students' academic backgrounds ................................................. 106

Classroom layout............................................................................. 107

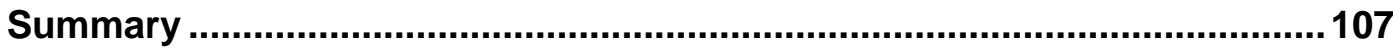

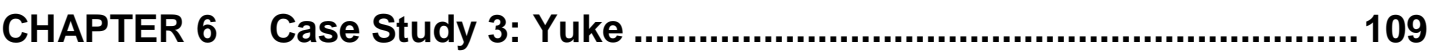

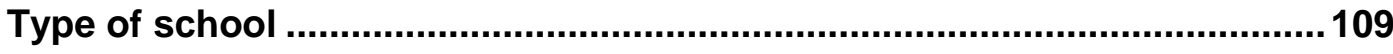

The layout and structure of the school ........................................................... 109

English teaching in the school ...............................................................110

The teacher ................................................................................................110

Teacher attributes ............................................................................ 112 


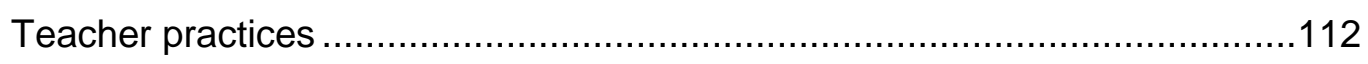

Classroom teaching and learning ................................................... 112

Grouping students..................................................................... 113

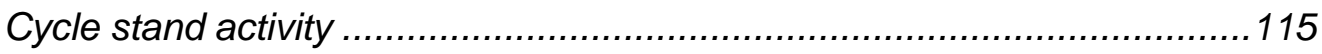

Reading Comprehension..................................................................117

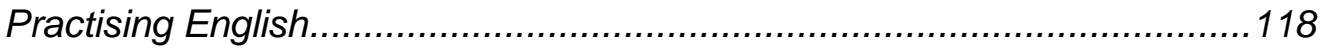

Correcting mistakes ................................................................... 120

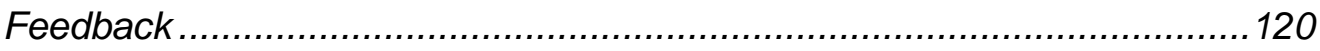

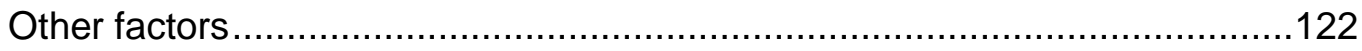

English Curriculum in Indonesia .......................................................122

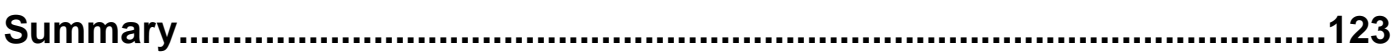

CHAPTER 7 Case Study 4: Arfan ..............................................................125

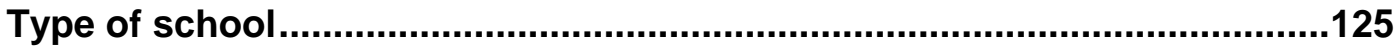

The layout and structure of the school.........................................................125

English teaching in the school...................................................................126

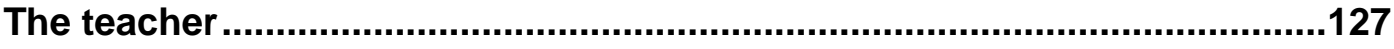

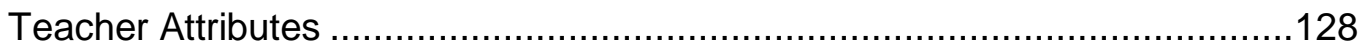

Classroom behaviours.................................................................... 128

Teacher practices .......................................................................... 129

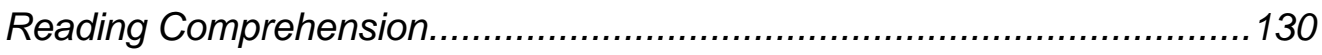

Using audio resources...................................................................130

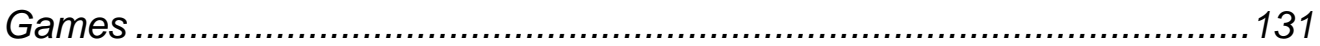

Grouping students........................................................................... 132

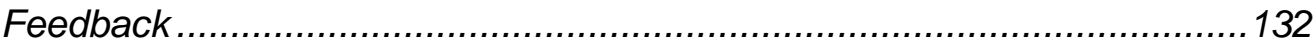

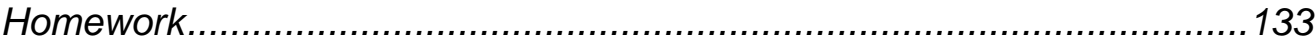

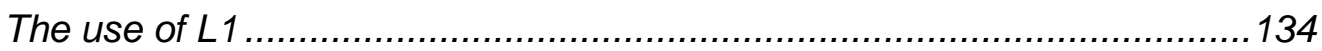

Planning the Lesson.................................................................... 135

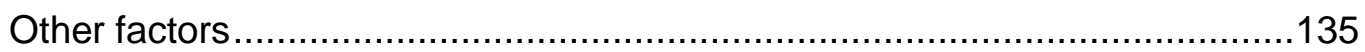

Classroom facilities ....................................................................... 136

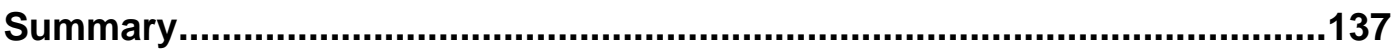

Classroom should be comfortable for learning..............................................137

CHAPTER 8 Cross Case Analysis...............................................................138

Question one: Teachers' perceptions.......................................................138

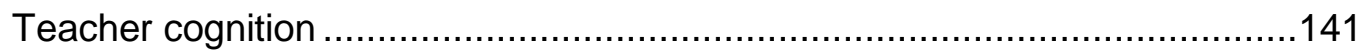

Teachers' teaching experience ..............................................................141

Teacher motivation .................................................................................. 144 
Question two: Teachers' practices........................................................... 145

Teachers' pedagogical practices ......................................................... 145

Learning resources and activities.............................................. 145

Classroom management................................................................ 146

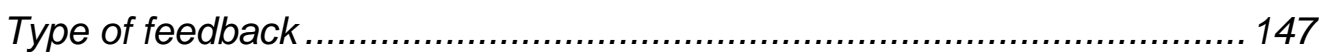

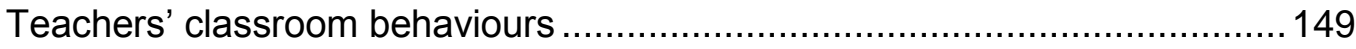

Question three: Students' perceptions of motivational teaching strategies 152

Teacher motivational strategies and Dörnyei's framework ........................153

Creating the basic motivational conditions.............................................. 153

Generating initial motivation ............................................................ 157

Maintaining and protecting motivation .................................................. 160

Encouraging positive retrospective self-evaluation ................................... 162

Further discussion of the four phases.................................................... 163

Motivational teaching practice and the teaching-learning map....................167

International context: English as a global language ….............................. 169

National context: Indonesian educational context .................................... 170

Teacher roles................................................................................. 171

Time for learning ..................................................................... 171

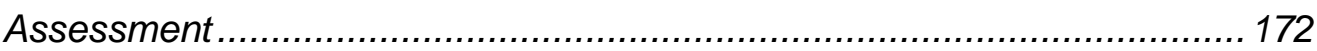

The English Curriculum................................................................. 174

National context: Indonesian educational culture ...................................... 175

Institutional context: School Context...................................................... 177

The use of English in the school context ........................................... 177

The length of a school period............................................................ 178

The timing of classes ............................................................. 178

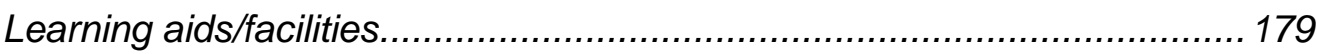

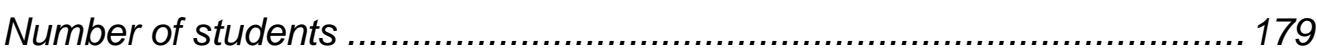

Teachers' perceptions of student learning achievement......................... 180

Classroom context: teaching-learning context ....................................... 181

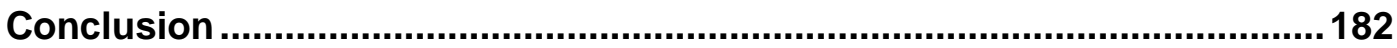

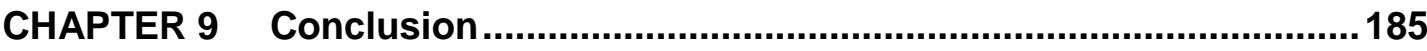

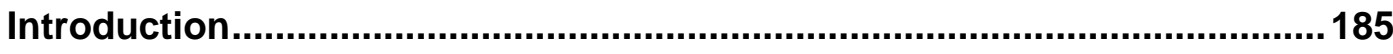

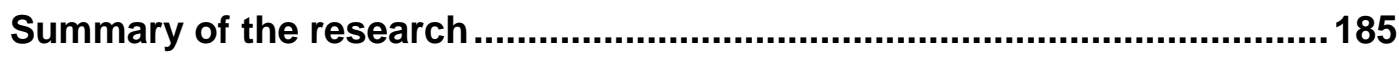

The research findings................................................................................ 187

Contribution of this study ...................................................................... 188

Contribution to the field of motivational teaching strategies ...................... 188 
Contribution to the implementation of motivational teaching strategies in

Indonesia

Understanding the Indonesian educational context

Understanding the Indonesian educational culture. 192

Contribution to classroom practices .194

Building rapport with students .194

Teachers' classroom behaviours. 194

Reducing continuous use of a textbook. 194

Introducing learning strategies 195

Regarding mistakes as part of learning . 196

Improving classroom management 196

Emphasising the usefulness of English 197

Students' perceptions. 197

Areas for future research 198

Recommendation for learners/teachers/stake holder 198

Concluding statement. 199

Limitation of the study 200

Personal reflection .201

REFERENCES .203

APPENDICES 210

Appendix A: Ethical Approval Letter 210

Appendix B: Teacher Interview Question 211

Appendix C: Classroom Observation-Possible indicative codes .212

Appendix D: Teacher stimulated recall.......................................................213

Appendix E: Student Focus Group Question............................................214

Appendix F: Student Consent ...............................................................215

Appendix G: Student consent form for classroom observation ..............216

Appendix H: Information for student participants for focus group..........217

Appendix I: Student consent form for focus group interview .....................218

Appendix J: Information for teacher participants .......................................219

Appendix K: Teacher consent ...................................................................220

Appendix L: Information for the Principal ..................................................221

Appendix M: Principal approval form ...................................................222 


\section{List of Tables}

Table 2.1: Ten Commandments for Motivating Language Learners 37

Table 2.2: The mismatch between teacher and student perceptions of motivational strategies 46

Table 3.1: Actions taken to ensure validity and reliability in the present study .67

Table 4.1: Summary of Moza's teaching attributes and practices .90

Table 5.1: Summary of Harry's teaching attributes and practices 108

Table 6.1: Summary of Yuke's teaching attributes and practices 124

Table 7.1: Summary of Arfan's teaching attributes and practices 137

Table 8.1: Motivational Teaching Practice 153

Table 8.2: Research questions and findings 184

\section{List of Figure}

Figure 2.1: Motivational Teaching Practice .38

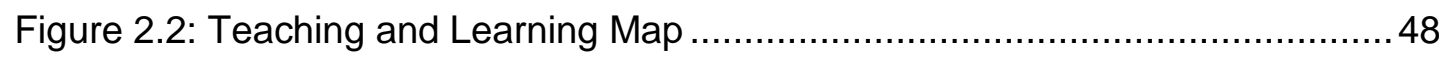

Figure 3.1: Data Collection Procedure ........................................................ 57

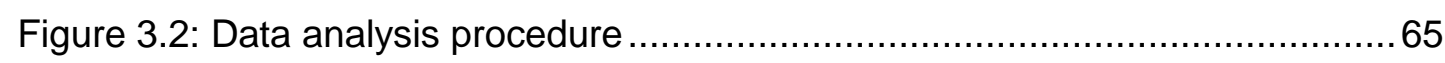

Figure 8.1: Classroom atmosphere: Main themes from the findings ................... 151

Figure 8.2: Comparison of Dörnyei's framework with the findings........................ 167

Figure 8.3: Teaching-Learning Map: The influence of context and motivation (a modified version of Hall and Kidman, 2004) 168

Figure 8.4: Assessment system in Indonesia (BNSP, 2007) .... 172

\section{Glossary}

Motivational strategies: techniques to promote one's goal-related behaviours.

Motivational teaching strategies: techniques used by teachers that are used intentionally to promote their students learning to achieve systematic and continuing positive effect.

T-L map: a way of looking at educational contexts which consist of factors that influence classroom teaching and learning. 


\section{CHAPTER 1}

\section{Overview}

\section{Introduction}

This thesis examines the motivational strategies of four teachers of English as a foreign language (EFL) in four Indonesian high schools. This study considers the motivational strategies utilised by teachers and the impact of these strategies on students' motivation to learn.

My own background includes 20 years as an English teacher in an Indonesian high school. I have noted that students often complain that learning English is daunting for them. I think that two possible reasons underpin the students' perception. They are that, first, English is one of three subjects that determine their pass or fail in the National Standardised Exam; and second, English is perceived as a difficult language to learn since it is so different from Bahasa Indonesia. Although the reasons cited here are anecdotal in nature, they provide some of the impetus for my interest in researching factors that influence students' motivation to learn English.

I have been inspired to conduct research on this topic primarily to share the benefits of this study with teachers of English in other Indonesian high school contexts. I believe that teachers' motivational strategies can help students learn English and build their motivation for lifelong learning.

The findings of this study should allow teachers of English to gain insight into the effectiveness of strategies to motivate their students and the impact of implementing these strategies in their teaching.

\section{Statement of the problem}

Two problems are addressed in this study. The first problem is how to motivate students to learn English in an EFL context. In this context, English is not an everyday language so students are not exposed to English beyond the classroom and are not expected to use English for their daily communication and future careers. Indonesian students generally fail to achieve high levels of oral or written proficiency. Achieving competency in English is a long and tedious process. Students may lose their motivation during this long period of learning (Lamb, 2007; Liando, Moni, \& Baldauf, 2005). 
The second problem relates to the context of high school teaching and learning. In high school, where students are adolescents, their motivation to learn English tends to be diminished by school factors such as the classroom learning context, negative peer pressure or teachers (Lamb, 2007). Problems with the classroom context inhibiting students' motivation include: large classes, fixed desks and chairs, insufficient supporting technology, and an absence of air conditioners. Negative peer factors occur when some students disrupt the class by talking to each other about things that are unrelated to the lesson, or when they misbehave in class. Teacher factors include; teachers' classroom behaviours (such as irritability, tension, or unfriendliness) and teachers' teaching styles (such as textbook oriented lessons, monotonous lessons, direct criticism of students, and allowing little time for students to practise) (Lamb, 2007).

This study will address these two problems by researching teachers' perceptions of motivational strategies, how teachers implement these strategies, and the impact of these strategies on learners' motivation. There are few published studies of the motivational strategies typically used in an Indonesian EFL high school context. This study aims to fill this gap in the literature.

To answer the research questions, I have adopted a case study methodology within a qualitative/interpretive research paradigm.

\section{Significance of the study}

It is expected that the research findings will contribute to an understanding of how to design a supportive but challenging teaching and learning environment that will motivate students. This understanding will inform Indonesian Ministry of Education officials and teachers of English, and other stakeholders with an interest in students learning English. For example, by understanding teachers' and learners' perceptions of motivational teaching strategies, the Ministry of Education may be in a position to design aspects of the English curriculum for Indonesian high schools. Hopefully, this will enable teachers to create a learning atmosphere that is motivating for students; "curriculum" is not simply about course content, but includes teaching strategies and practices that foster student engagement. 


\section{The Indonesian context}

To understand how English is used in Indonesia, it is relevant to consider historical, political, socio-cultural, and linguistic factors within Indonesia.

\section{Contextual information}

Indonesia is an archipelagic island country located in Southeast Asia, between two oceans (the Indian and the Pacific) and two continents (Asia and Australia). It has approximately 17 thousand islands and among these five major islands, Sumatera, Java, Borneo, Sulawesi and New Guinea. The population is approximately 250 million people (estimated at midyear 2013) (Syarifah, 2013). The country has 33 provinces, with the capital being Jakarta.

There is one official language, Bahasa Indonesia, but over 350 native languages are currently in use throughout the country (Steinhauer, 1994). Most Indonesians speak their mother tongue as their first language and start learning and using Indonesian when they begin schooling at the age of five or six years old.

English is the first foreign language that is learned by students, and is taught from Year 7 until Year 12. Some elementary schools teach English as an optional subject (Mattarima \& Hamdan, 2011a). The reason why English is taught at this level when it is not compulsory may be because of parent demand or school resources.

\section{Collectivist nature of Indonesian culture}

Indonesian culture, like that of several Asian countries, is highly collectivist in nature; that is, it places value on individuals conforming to group customs and expectations (Lamb \& Coleman, 2008). Collectivist cultures differ from individualistic ones which tend to value personal freedom. Indonesian children are raised to respect older people and community leaders. Challenging older people such as parents and teachers is discouraged.

The collectivist nature of Indonesian culture can also be seen in the lifestyle of the extended family. It is common for grandparents to live together with their children's family, and children are expected to respect older members of the family. Arguments between children and older people are not culturally valued. It is considered polite to listen to and accept what older people say. 
This feature of Indonesian culture may well influence students to listen to what teachers' say rather than ask questions. Traditionally teachers dominate class time, giving instructions and explanations during the lesson (Mattarima \& Hamdan, 2011a). Marcellino (2008) found that students were not interested in challenging their teachers; teachers act as a source of knowledge rather than as a learning facilitator.

\section{Historical perspective of Indonesian education}

Historically, Indonesia was colonised by the Dutch for over 350 years. During most of this period the majority of Indonesians were illiterate. Few Indonesians attended school; most schools were attended by Dutch children. English was taught as a foreign language at these schools (Lauder, 2008).

Indonesia proclaimed its independence on August 17, 1945 and established a republican government. The government decided that English should be the first foreign language instead of Dutch; Dutch was considered to be a colonialist language rather than an international language like English (Lauder, 2008).

However, the development of using English in Indonesia differs from that which occurred in neighbouring countries such as Malaysia, Singapore or Philippines because, unlike those countries, Indonesia was not a colony of the United Kingdom or the United States of America. If it had been, there would be a greater foundation for the use of English within official or daily communications. Instead, English was chosen as a compulsory subject in high school for the strategic advantages it offered, being the dominant language of international business diplomacy, and education. In addition, most of the international books and journals read in Indonesia are written in English.

\section{Structure of Indonesian education}

The levels of education in Indonesia consist of basic education, secondary education and higher education. Basic education is compulsory and comprises six years of elementary school and three years of junior high school. Secondary education involves three years of schooling in either a general secondary school or a vocational secondary school. Students or their family decide which secondary school suits their future. 
The general high school prepares students for university education. There are three possible streams of study in this kind of school: science, social studies, and language studies. The vocational school prepares students for skills required in the work place. Each vocational school offers a particular major subject such as economics, technology, and arts.

Law number 20, Year 2003 of the Indonesia National Education System enables foreign educational institutions accredited in their own country to open schools in Indonesia. It is also possible for central and local government to develop "International Standardised Schools". These schools are required to meet criteria which give these schools an "international" equivalence in quality. The criteria are based on academic achievement and school management performance.

The central government supports each province in establishing international standardised schools for each level of education. The local government also selects a school in each town to be an international standardised school. In each town or district, there is one international standardised elementary school, one international standardised junior high school and two international standardised senior high schools, one general school and one vocational school. Schools that do not achieve the international standardised criteria are classified as national standardised schools or regular schools.

\section{English as a foreign language in Indonesia}

Unlike other foreign languages which are optional, learning English is mandatory in Indonesian high schools. Students learn English for three years in junior high school and for three years in senior high school.

Since English is a foreign language in Indonesia, most students mainly engage with English as a language in the classroom. This places a premium on the quality of classroom teaching and learning. In line with this, students' classroom learning motivation is a central element in the teaching and learning process (Dörnyei, 2001; Oxford \& Shearin, 1994).

Teaching and learning English is mostly content-centred whereby the teacher is expected to provide the knowledge of English and how to teach it. Generally, students are motivated to learn English more to get a good mark in their academic 
report rather than to obtain language skills for real communication Therefore, teaching strategies are an important factor in enhancing students' motivation.

In conclusion, learning English in an Indonesian high school context is challenging. Some factors may decrease students' motivation such as lack of classroom facilities, teacher factors, the curriculum, or the situation where English is taught as a foreign language. Teachers' use of motivational strategies play an important role in keeping students motivated to learn English. In the following section, the chapters of this thesis will be outlined to give a clear picture of how this study investigated teachers' motivational strategies using teachers' and students' perspectives.

\section{The outline of the thesis}

This thesis comprises nine chapters. This chapter serves as an introduction to the thesis and highlights the research questions, the setting of the study, and the significance of this study.

Chapter 2 provides a theoretical background for this study through a review of relevant literature. Literature is presented on: (i) teaching and learning English in Indonesian high school; (ii) teaching and learning a second language; (iii) motivation in learning a second/foreign language; (iv) high school motivation in learning English as a second/foreign language; ( $v$ ) teacher motivation; (vi) motivation in an Indonesian EFL context; (vii) the history of research in second/foreign language learning motivation; and (viii) research on motivational teaching strategies.

Chapter 3 outlines the methodological approach used in this research. The approach uses case study methodology based on qualitative data. Data were collected using individual interviews, classroom observations, stimulated recall, and focus-group interviews. These data methods are explained. Finally, a step by step explanation of how the data were analysed is described.

Chapters 4, 5, 6, and 7 describe and analyse the findings using the research questions as a framework. Each chapter represents one case and its analysis. The analysis uses Dörnyei's (2001) framework as a basis for analysing the findings. 
Chapter 8 presents a discussion of the findings based on a cross-case analysis. The findings are analysed by looking at the themes emerging from the data in the context of evidence from the literature.

Chapter 9 revisits the objectives of this study, discusses the contributions and implications emerging from the findings, makes recommendations for EFL teachers, summarises the findings of the study, and provides my personal reflection on this study. 


\section{CHAPTER 2 \\ Literature Review}

This study explores teachers' and students' perceptions of motivational teaching strategies and the impact of implementing these strategies on students' language learning motivation. This literature review consists of four main sections. The first section sets the context of this study with a review of literature on teaching and learning English in Indonesian high schools. The second section briefly overviews some of the literature relating to teaching and learning a second language. The third section covers motivation in second/foreign language learning, high school student motivation in learning EFL, and motivation in an Indonesian EFL context. The fourth section reviews the literature on the history of research relating to motivation in learning a second/foreign language; this includes literature on motivational teaching strategies, and teachers' and learners' perceptions of motivational strategies. This positions my study in the wider field of literature on motivational teaching strategies in an ESL/EFL context. The chapter concludes with a focus on the importance of conducting research on motivational teaching strategies in an Indonesian high school context.

\section{Teaching and learning English in Indonesian high schools}

In Indonesia, English is a compulsory subject in high school. Students learn English for three years in junior high school (Years 7 through 9) and three years in senior high school (Years 10 through 12). Since English is a foreign language in Indonesia, students are only exposed to English in the classroom. Teachers often report that students lack the ability to communicate using English both orally and in writing (Mattarima \& Hamdan, 2011b).

It is difficult to relate the relevance of English to the everyday lives of Indonesian students because English is a foreign language, not a second language, in Indonesia (Liando et al., 2005). Students do not have life experience using English and they do not usually expect to be able to speak English in their future careers. Most of the time at school and sometimes at home students use the Lingua Franca, Bahasa Indonesia. Clearly, the social and cultural environment does not provide strong support for learning English (Lie, 2007). 
Indonesian learner characteristics often include low motivation. One of the causes is reported to be the large class size (Bradford, 2007; Lie, 2007). Lamb (2007) found that Indonesian high school students are initially motivated to learn but their experience of learning English at school decreases motivation.

In general, Indonesian students tend to be passive and nonverbal in class. They rarely initiate class discussions until they are called on because of the nature of the course content, teaching methods, and assessment (Bradford, 2007; Lie, 2007; Mattarima \& Hamdan, 2011b). Another reason is a lack of exposure to English outside the classroom. This is especially true for most Indonesian students who live in the rural area (Lie, 2007). These findings are supported by Marcellino's (2008) survey of Indonesian high schools. He found that students tend to be passive in the classroom for three reasons. Firstly, students have not experienced interactive classrooms. Secondly, challenging teachers by asking or talking actively is considered impolite. This is also seen to be a form of showing off to classmates. Thirdly, a lack of ability to use of vocabulary and English expressions make students shy and reluctant to use English. Hence, it is challenging for teachers to motivate students to use English.

Additionally, teachers often believe that students' fail as the result of the individual shortcomings of the students themselves-such as laziness, a lack of intelligence, or a learning disability - or deficiencies in the students' homes or communities such as excessive television-watching, a lack of parental attention, or bad reading habits (Bailey \& Ken, 2003). On the other hand, in a case study conducted in an Indonesian high school, Lamb and Coleman (2008) found that students view their teachers of English as a factor influencing their dislike of English.

To cope with the problem of teaching and learning English in an Indonesian high school context, the government has changed the English curriculum six times since independence in 1945 (Lie, 2007; Marcellino, 2008). Among the six language curriculums there are three different approaches: grammar translation (1945); audiolingual instruction (1968); and a form of teaching known as a communicative approach (1984). Grammar translation and audio-lingual instruction focus on the language itself such as grammatical rules, pronunciation, and vocabulary. On the other hand, the communicative approach to language learning emphasises a teaching and learning process that includes interaction, conversation, and language use rather than learning about the language (Lightbown \& Spada, 2006). In 2004, 
the government implemented a competency-based curriculum which was revisited in 2006 to become a school-based curriculum known as Kurikulum Tingkat Satuan Pendidikan (Depdiknas, 2006). A communicative approach is still encouraged and used in the teaching of English (Lie, 2007).

In the new curriculum, the first goal of teaching and learning English in high school is discourse ability. Students are expected to understand and produce oral and written texts in relation to four language skills: listening, speaking, reading and writing. Secondly, students are expected to comprehend and produce various texts in different genres such as narratives, procedures, description, recounts, reports, news items, analytical expositions, hortatory expositions, spoofs, explanations, discussions, reviews, and public speaking. Thirdly, students are expected to demonstrate linguistic (grammar, vocabulary, spelling), sociocultural (language expressions based on the context), strategic (problem-solving), and discourse competence (Depdiknas, 2006).

The school-based curriculum allows more freedom for teachers to select and implement teaching materials, teaching methods and strategies that suit their students' abilities and needs. Teachers are given the freedom to adopt and adapt the national curriculum based on their teaching contexts. However, the changes in the curriculum have not been followed by appropriate socialisation and teacher training (Hadisantosa, 2010). Moreover, teachers may not have the skills to create their own curriculum because they are not sufficiently trained to do so. Often teachers simply adopt the government curriculum or use textbooks offered by publishers (Yuwono, 2005).

Another problem encountered by teachers and students is the assessment of learning. In Years 9 and 12, students have to sit the English national standardised test. Even though the curriculum focuses learning on the four language skills of listening, speaking, reading and writing, the written test is usually designed to evaluate students' listening and reading skills only. Speaking and writing skills are generally evaluated by teachers, rather than in a national standardised test. Testing in this way leads teachers of English to concentrate on these two skills, especially reading, since the teaching of listening is more difficult because of limited resources and materials (Mattarima \& Hamdan, 2011b). 
A recent policy (2008) implemented by the Indonesian government categorises high schools as one of either: a regular/local school; a national standardised school; an international school; an international standardised school; or a prospective international standardised school (Hadisantosa, 2010). An international school is defined as a school run by the representative of a foreign country and approved by the Indonesian government. International and prospective international standardised schools fulfil all the national standards for education as determined by the education standards of one of the countries belonging to the Organisation for Economic Cooperation and Development (OECD) (Depdiknas, 2007).

Different types of high school use English to varying degrees during the school day and to different ends. The different school types provide different environments for learning and using English. Students in international and prospective international standardised schools use English as a medium of instruction for science and mathematics. Students in these types of school therefore have a higher motivation to learn English as compared to their counterparts in the regular high schools (Lie, 2007). In national standardised and regular/local schools, English is learned and used in English subject classes which generally meet twice a week for ninety minutes each meeting (Depdiknas, 2006).

Over time, with the changing of the school curriculum, learning conditions in Indonesian schools have started to change positively. Unfortunately, this change mostly only happens in urban schools, especially in international and prospective international standardised schools where students are more involved in the teaching and learning process. The classroom layout enables group discussion with the teacher acting as a facilitator, reflecting a movement away from a teacher-centred approach to a learner-centred approach (Yuwono, 2005). Class sizes have also changed. Classes tended to be crowded previously with about 40 students. Now, classes have been reduced to 25-35 students per class. However, national and regular/local schools classes are still crowded, possibly because of the limited availability of classrooms and teachers.

The approach to language teaching favoured by teachers is moving towards contextual and communicative language teaching to meet students' needs (Bradford, 2007). Some teachers have changed their teaching strategies from traditional approaches to a communicative approach by focusing on the four language skills: listening, speaking, reading and writing (Hadisantosa, 2010). 
However, most teachers still implement a teacher-centred approach, possibly because of insufficient professional development or training (Lie, 2007). What is clear from these changes is that if schools are to meet the expectations of the new policies, attention needs to be placed on both teachers' and students' motivation.

Before this review examines the literature around language learning motivation and motivational teaching strategies, some literature drawn from the wider context of teaching and learning a second/foreign language will be introduced to provide background to language teaching. It is also important to discuss the role of first language in second language learning.

\section{Teaching and learning a second language}

In this thesis, a second language (L2) means any other language learned after acquiring a first language (L1). In this section I will provide a brief overview of influences on second language learning, including the age of the learners, the types of approaches that have been used historically, and the role of L1 in learning a second language. Many factors, biological and experiential, influence L2 learning (Lightbown \& Spada, 2006).

Lightbown and Spada (2006) depict a broad view of second language learning; they claim that L2 learning is affected by factors such as: learner characteristics and experience, social and cultural environment outside and inside the classroom, the structure of first and second language, opportunity to interact with the target language speakers, and access for correction and grammar instruction.

Learning L2 can be difficult, especially for adolescents, because at this age the language is not acquired as readily as in childhood but adolescents have advantages in terms of linguistic background and cognitive maturity (Lightbown \& Spada, 2006). When children become adolescents, their problem-solving and metalinguistic abilities are already developed so they can become more selfconscious when learning a second language (Lightbown \& Spada, 2006). They are not prepared to take risks and hence make the mistakes that are essential for language learning. Fortunately, at this stage they already have a linguistic system, their L1, upon which they may rely when required (Hummel, 2013). 
Unlike learning a first language, acquiring L2 during adolescence may not involve predictable linguistic and cultural processes. Adolescent L2 learners are subject to a more complex learning situation than children acquiring a first language. In keeping with this, students' personal characteristics and their learning contexts influence L2 learning. The individual aspects of learning include intelligence, aptitudes, attitudes, motivation, personalities, learning styles, cognitive styles, and learning strategies (Hummel, 2013).

A foreign language learning context covers the interacting environments of classroom context, the school context, and the wider community context. Chang (2011) asserts that L2 learning can be hindered by factors beyond the control of the classroom teacher in the school and community contexts. In the school context factors include examination oriented teaching/learning, limited class hours, and large classes; and in the community contexts, factors such as lack of opportunities to practice L2, and lack of learning resources pose as impediments to learning (Chang, 2011).

A body of research suggest that there are effective methods and strategies in teaching L2. However, the methods of teaching should suit the context of the learners (Cummins \& Davidson, 2007; Ellis, 2008; Hummel, 2013; Kumaravadivelu, 2005; Lightbown \& Spada, 2006). Chang (2011) also adds that the suitability of language teaching methods in particular context may influence effective language teaching and learning for students. Hence, it is imperative that teachers select a suitable language teaching methods that is relevant to their context (Littlewood, 2007).

Language teaching methods have changed over time. The methods can be traced back from grammar translation methods which were introduced in 1780 (Harmer, 2007). Some key features of this method were: presenting students with long explanations of L2 grammar rules, memorisation of vocabulary, and translation exercises. Another method that was developed in the 1950s was the audio-lingual method which relied heavily on language drills and learners not making errors. This method has a link to behaviourist theory of learning, suggesting that learning is a result of habit formation (Harmer, 2007). Around 1950s-1960s a new method became popular: the so-called direct method characterised by the exposure to grammar through dialogues and conversational exchanges, and using the target language is a major priority. The use of $L 1$ is limited in this method. In response to 
all the methods that have been introduced, teachers and researchers have realised that students need to communicate meaning, rather than focus on grammar rules (Cummins \& Davison, 2007). For this reason the communicative approach or communicative language teaching was introduced.

Another recent approach, and one which developed together with communicative language teaching, is task-based language teaching. This approach integrates the theoretical and empirical foundations of pedagogy to promote learning in the form of 'tasks'. However, Ellis (2009) notes that there are advantages and disadvantages in using task-based language teaching. This approach offers several advantages such as promoting natural learning inside the classroom, emphasising meaning, helping learners to get a rich input, intrinsically motivating, learner-centred learning, promoting both fluency and accuracy, and working alongside traditional approach. On the contrary, he also suggests that teachers also commonly misinterpret the meaning of 'task' and language teaching methods are used inappropriately. Teachers may be tempted to use the students' L1 more than in other approaches because they want to explain the procedures associated with the task in order to maintain discipline in the classroom. This may impede communication in L2 (Ellis, 2009).

From the history of L2 teaching methods, a new perspective has developed. It is called post method teaching and is based on the view that no one method is best for all L2 contexts. Teachers are expected to use their creativity, practices, and processes of classroom instructions to develop approaches to suit their teaching and learning context (Hummel, 2013; Kumaravadivelu, 2005).

All L2 teaching methods reviewed above raise some classroom instructional issues that need to be addressed. It indicates that each teaching method has strengths and weaknesses. Such issues, however, point to two distinct teaching approaches at play, one cognitive and the other sociocultural (Hummel, 2013). The cognitive approach relates to how much L2 grammar should be taught in the classroom. Research shows that any pedagogical approach to language teaching should draw students' attention to L2 structure implicitly or explicitly (Lightbown \& Spada, 2006). The sociocultural approach relates to the importance of social interaction in L2 learning because one of the purposes to learn L2 is to be able to communicate using it. To accommodate this goal, students need to be exposed and encouraged to listen and use L2. This creates a conflict with how much L1 can be used in 
learning L2 (Hummel, 2013; Levine, 2013). Levine (2013) added that appropriate use of L1 saves time and can be more efficient for optimising L2 use in the classroom. The main question in relation to all methods since the introduction of the Direct Method is whether L2 should be used solely and for the whole lesson or whether L1 can also be used to communicate or give information (Lee \& Macaro, 2013). Research indicates that there is a link between students' use of $L 1$ and their L2 learning. Hummel (2013) and Nation (2003) emphasise that L1 use in the classroom has a role in students' L2 learning.

\section{The use of L1 in teaching/learning L2}

Although there has been a controversy in the field of $L 2$ learning about whether the use of $L 1$ is a help or a hindrance, the role of L1 in L2 learning cannot be neglected (Bingjun, 2013; G. Hall \& Cook, 2013). L1 supports L2 learning for several reasons, such as helping students with vocabulary, reading comprehension, and linguistic awareness (G. Hall \& Cook, 2013; Hummel, 2013; Nation, 2003). Linguistic awareness, such as structural differences and similarities in L1 and L2, promotes students' L2 learning (Hummel, 2013). Carson and Kashira's (2012) study of teaching English in Japanese found that the students' L1 supported their understanding of L2 vocabulary, linguistic rules, and assisted checking for comprehension. Similar findings emerged from Afzal's (2013) study which found that using L1 helped students to understand complex ideas from a text and grammar explanation. He emphasised that appropriate use of L1 did not reduce students' exposure to L2. Additionally, Ellis (2008) explained that students' L1 facilitates their L2 learning as background knowledge for acquiring $L 2$.

In the context of a German university, Campa and Nassaji (2009) investigated two L2 instructors in a 12-week semester by using interviews and stimulated recall sessions. The study focused on teachers' reasons for using L1 in L2 classroom. The finding was that teachers use L1 as one of their pedagogical techniques and if students share the same L1, it can also be used as a learning tool (Campa \& Nassaji, 2009). A similar finding emerged from a study in Saudi Arabia which involved 30 students and three teachers who learn English as an EFL in a high school. The study found that teachers preferred to use Arabic for certain situation and specific reasons such as helping low achieving students, explaining grammatical rules, introducing new vocabulary, and giving exam instructions (AlNofaie, 2010). Pakzadian's (2012) study in Isfahan which involved 60 high school students learning English as a foreign language and Liu's (2008) experimental 
research in a Chinese university also suggest similar findings that students' L1 facilitated their understanding of L2 vocabulary.

Strategic use of L1 has been found to promote vocabulary learning, grammar instruction, classroom management including discipline, maintaining relationships with the learners and reflecting on learning. Macaro and Lee (2013) undertook a quantitative study of 798 students (311 university students and 487 children from the last year of elementary school) learning English in Korea. The findings suggested that using L2 benefitted students' vocabulary learning; none of the early adolescent or university students in the study favoured the total exclusion of L1 use in the classroom. Edstrom's (2007) study supported Macaro and Lee's (2013) findings. He conducted a case study with 15 students who learned Spanish. The data were collected using 24 audio-recorded class sessions, a reflective journal, and a written questionnaire. The study found that the teacher's reasons for using L1 in L2 classroom were grammar instruction, classroom management and maintaining relationships with students. Additionally, Jindal (2013) noted similar reasons for teachers' use of L1 in L2 classrooms, such as maintaining discipline, using L1 as a resource for $L 2$ learning, metalinguistic reflection, establishing communication, and reducing social inequalities between teachers and students. Overall, Nation (2003) highlighted that the use of L1 needs to be seen as a useful tool, similar to using pictures, real objects, and demonstration but L1 should not be overused because students also need to be exposed to L2. These studies indicate that the use of L1 in the classroom can facilitate and promote students' L2 learning. It can be concluded that the studies suggested avoiding too much use of L1 and promoting L2 use.

The studies that have been reviewed provide evidence that the use of L1 not only supports L2 learning but is also useful as a teaching strategy to build rapport with students and hence may have the potential to foster L2 learning motivation. The following section will look at motivation and motivational teaching strategies in L2 learning.

\section{Motivation in learning a second/foreign language}

Motivation is interpreted in different ways by different researchers. The root of motivation is from the Latin verb, "movere" which means "to move" (Dörnyei \& Ushioda, 2011, p. 3). Researchers view motivation as the driver of human action for a special purpose (Csizer \& Dornyei, 2005; Dörnyei, 2001; McDonough, 2007; Ryan 
\& Deci, 2000). In Gardner's socio-educational model, motivation is defined as the learner's orientation to learn a target language (Gardner, 1999). Nakata (2006) states that motivation has a link to cognition, feeling and emotion, and the environment when learning languages. The view that motivation and emotion are strongly linked is endorsed by Maclntyre (2002). For the purpose of my study, I define motivation as factors or reasons that move or drive students to learn English as a foreign language.

Motivation plays an important role in second or foreign language learning success (Dörnyei, 1998). It is considered as a cause of success or failure in learning (Guilloteaux \& Dornyei, 2008). Among factors that influence success in learning a second language-such as attitudes, motivation, language anxiety, self-confidence, field independence, personality variable, intelligence, language aptitude, and language learning strategies-motivation is considered the most influential factor in second language learning. These other factors depend on motivation in order to be realised (Gardner, 2001).

It is hard to succeed in learning a second/foreign language without motivation (Ushioda, 2008). Moreover, a study found motivation correlates with achievement (Bernaus \& Gardner, 2008). According to this study, the more motivated the students the higher their L2 language achievement. Therefore, in learning a second or foreign language, motivation is considered as a determining factor for success or failure (Dörnyei, 2010b).

Language learning motivation is unique compared to motivation for learning other subjects because learning a second/foreign language also involves taking on elements of the target language community's culture, psychological identification with the second language community, and changes in identity (Dörnyei, 2001; Maclntyre, 2002). In learning a second/foreign language, sustained motivation is very important because language learning takes considerable time and effort.

Oxford and Shearin (1994) emphasised the difference in motivation to learn a language between second and foreign language environments. A second language is a language which is learned in an environment where the target language is used as a medium of communication, such as occurs for a non-English speaker learner learning English in New Zealand. So learning English in this circumstance is 
supported by the social environment that uses English as a medium of communication. A foreign language is one where that language is not used as a medium of daily communication (Dörnyei, 1990; Oxford \& Shearin, 1994). The use of the target language may be confined to the classroom and there are few opportunities to use it in the environment for communication.

It will be more difficult to learn a second language in a foreign language context where students have little opportunity for contact with the target language speakers. Accordingly, learning a second language in a foreign language context will need more motivation from students (Dörnyei, 1990, 1994; Oxford \& Shearin, 1994). In other words, foreign language learners generally need higher motivation in order to succeed compared to second language learners (Dörnyei, 1990). Additionally, Oxford and Shearin (1994) argue that foreign language learners need more emotional or psychological security. When the students do not feel psychologically secure they will not take the risk of using the target language. These studies (Dörnyei, 1990, 1994; Oxford \& Shearin, 1994) relate to the context of Indonesian high school students who learn English as a foreign language.

\section{High school student motivation in learning English as a second/foreign language}

Motivating learners to learn a second/foreign language is reported by many teachers as the most important but difficult skill in teaching after managing classrooms (Dörnyei, 2001). Studies of motivation in second/foreign language learning reveal that student motivation is influenced by other factors such as teachers, classroom climate, and assessment (Ghenghesh, 2010; Kikuchi, 2009; Matsumoto, 2009; Yeung, Lau, \& Nie, 2011). Thus, the role and the influence of the teacher in motivating high school students to learn a second/foreign language are very significant. Myburgh et al. (2004) in the South Africa EFL school context found that the teacher's role was extremely important. The study also suggested that teachers need to consider learners' experience and cultural background and parents' involvement in the learners' schooling should be encouraged.

Ghenghesh (2010) investigated 140 students studying EFL who had just entered high school, and five teachers in the Tripoli area using a questionnaire. The questionnaire consisted of 101 statements about the learning of English with 19 motivational variables. The students responded through a five-point Likert scale plus 
two open-ended statements. Twenty students and three teachers took part in a follow-up semi-structured interview. The results indicated that the motivation of second language learners decreases with age; that is, the older the learners are, the lower their motivation. These research findings indicate the importance of conducting research on high school students' motivation in other cultural/national contexts, such as Indonesia.

In the Singaporean context, Yeung (2011) surveyed 4214 high school students who studied English as a second language. The study examined motivational constructs such as self-efficacy, interest, mastery goal orientation, engagement, avoidancecoping, and effort withdrawal. The study found that high school students' English learning motivation tends to decline as they grow older. It revealed that second language teachers needed to expend more effort and use more strategies to motivate adolescents. The findings also revealed that teachers have a crucial role in influencing and enhancing students' motivation. Yeung's research is consistent with the findings of Ghenghesh's (2010) study.

Interestingly, one way to promote high school students' EFL motivation is using CLIL (content and language integrated learning). English is used as a medium of instruction to teach other subjects. Lasagabaster (2011) confirmed the benefit of CLIL for enhancing both students' motivation and language achievement. This study indicates that using English to learn school subjects can benefit students. One of the cases in my study, the international standardised school, uses English as a medium of instruction for students learning mathematics and sciences.

In contrast, Kikuchi (2009) investigated factors that demotivate high school students to learn English in a Japanese context. Forty-two students responded to a questionnaire which allowed open-ended responses so that participants could answer in their own words. The open-ended questions asked whether the students would use English for their future, whether they enjoy studying English, and what discouraged them from learning English. Five students participated in an interview. The study found five factors demotivated students: individual teacher behaviour in the classroom; the overuse of grammar translation method; tests and university entrance examinations; vocabulary memorisation; and textbook limitations. This research supports the influence of teacher decision-making on students' motivation. It indicates that teachers' decision-making can increase or decrease students' motivation. 
Even in an environment where the target language is the medium of communication in the community, language teachers are important because students need to use the language to survive in everyday life. In a survey of 119 international students who studied English in an Australian context, Matsumoto (2009) found that teachers are an important factor in student motivation. The teacher factors that influence student motivation are categorised into three groups: behaviours; personality; and teaching style. The findings signify that teachers' behaviours and the building of a positive relationship with students are motivating factors in learning English.

The studies of high school student motivation to learn English as a second/foreign language confirm the important role of the teacher in enhancing and nurturing students' motivation. High school students' motivation is associated with their teacher's motivation; they support each other (Papi \& Abdollahzadeh, 2011). At this stage of their education, the students' motivation may decrease because of the classroom environment and factors related to the teacher (Lamb, 2004b). Hence, at high school a teacher can have an impact on students' motivation to learn a second/foreign language.

\section{Teacher motivation}

When teachers are perceived by their students to be motivated, the students' own learning motivation and satisfaction are likely to be increased (Montalvo, Mansfield, \& Miller, 2007). Motivated teachers love teaching and enjoy students. If the learners sense this, the teachers are likely to be remembered for the whole of the students' lives, not because they are the most clever and skilful instructor but because of the caring relationship between them (Montalvo et al., 2007). Teachers' motivation is associated with students' motivation. These studies also imply that teachers' behaviours, especially those associated with caring, enhance students' motivation (Bernaus, Wilson, \& Gardner, 2009; Jesus \& Lens, 2005; Matsumoto, 2009; Montalvo et al., 2007). In other words, student motivation and teacher motivation are closely linked (Nakata, 2006).

Additionally, Sugita and Takeuci (2010) claim that what teachers do in the classroom influences learner motivation. This idea is strengthened by a mixed method study of motivational teaching strategies in EFL classes in Brazil. This study involved 23 teachers of English and 213 students; the results indicated that teachers and students agreed on the importance of teacher-student rapport, teacher 
characteristics, and the stimulation of interest for fostering students' motivation and learning (Xavier, 2005).

Bernaus and Gardner (2008) argue that teacher motivation is the most important variable in $\mathrm{L} 2$ teaching and learning. They claim that if teachers are not motivated the whole notion of motivational strategies is under-used (Bernaus \& Gardner, 2008). Without motivation, it is hard for teachers to implement motivational teaching strategies. Dörnyei and Ushioda (2011) also confirm the positive effect of teacher motivation on L2 teaching and learning. The implementation of motivational teaching strategies in the classroom is also related to the teacher's pedagogical knowledge, teaching experience, and beliefs (Bernaus \& Gardner, 2008; Dörnyei \& Ushioda, 2011; Jesus \& Lens, 2005; Matsumoto, 2009; Montalvo et al., 2007).

A survey in an Iranian EFL high school students found that many teachers did not utilise motivational strategies in their teaching to promote their students' English learning achievement (Khatib \& Najafi, 2012). The questionnaire was distributed to 50 students randomly. The questionnaire gathered data about the cognitive, affective and social motivational strategies used by teachers. The results were analysed statistically. The study revealed that teachers had a conception that students were responsible for motivating themselves so teachers did not need to apply motivational teaching strategies. This implies that teachers' perception of the lack of need for motivational teaching strategies influenced their teaching practice.

Borg (2003) argues that teacher cognition-what teachers think, know and believeinfluences their classroom practices. Borg (2003) emphasises that teachers' classroom practices are also shaped by the social, psychological and environmental realities of the school and the classroom. Borg (2003) classified four factors influencing teacher cognition such as schooling, professional coursework, classroom practice, and the teaching-learning context. Language teachers are also influenced by their experience as language learners. Teachers promote or avoid using particular teaching strategies based on their positive or negative experience of these strategies as learners (Borg, 2003). From the research on teacher cognition, Borg (2003) found that teachers' education at teacher training college impacted on their cognition. Teacher cognition is considered to be a powerful influence on their classroom practice. 
To sum up, second/foreign language teachers have an important role in influencing student's motivation. Teacher motivation and cognition influences a teacher's classroom practices. In turn, the teacher influences students' motivation.

\section{Motivation in an Indonesian EFL context}

This section will explore learning English as a foreign language in an Indonesian context. It considers both the school context and the cultural context.

\section{The influence of culture on motivation}

When motivation to learn a second/foreign language is discussed at school, it is important to consider the cultural context of classroom learning (Gardner, 2007). Learning a second/foreign language involves elements of another culture. It means students' motivation is influenced by their own culture and it is necessary to consider this culture.

Many Indonesian students are reluctant to speak English because of shyness. They tend to be passive and listen to teachers rather than challenging them with questions (Marcellino, 2008; Mattarima \& Hamdan, 2011b). In a survey of six classes from five Indonesian senior high schools, Marcellino (2008) found that one of the reasons why students were silent in the classroom is because of their cultural belief and values. Indonesian culture does not encourage students to challenge older people such as parents, teachers or community leaders. Marcellino's study also found that a teacher-centred approach is still embedded in the Indonesian school setting. A teacher-centred approach results in few opportunities for students to ask questions or practise their English.

\section{High school and university students' motivation}

There is some research on motivation in the Indonesian context. A major figure in this research is Martin Lamb who conducted a series of studies looking at 11 and 12 year old children's English learning motivation. At this age, children in Indonesia enter junior high school, and most of them start learning English for the first time. In elementary school, English is not a compulsory subject. Lamb used open and closed questionnaire items followed by class observations and interviews. His findings indicated that students' motivation when they entered junior high school was high. This includes both integrative and instrumental motivation in relation to English as a global language. Integrative motivation refers to learners' desire to 
interact with the speakers of a target language community and culture. Instrumental motivation is a desire to learn a target language for the usefulness of the language, such as to improve one's future employment opportunities (Gardner \& Lambert, 1959; Hernandez, 2006).) Lamb (2004a) found that Indonesian high school students had both integrative and instrumental motivation. However, the integrative motivation refers to the desire to be part of a global English culture instead of an Anglophone culture (Lamb, 2004a). Liando et al. (2005) found similarly that Indonesian secondary students display integrative motivation in considering English as a global language. Lamb (2004b) also found that Indonesian students had to be autonomous learners because the school, English curriculum, and teaching methods do not accommodate what the learners need in terms of English skills. However, Lamb (2007) found that students' motivation tended to decrease after the initial learning of English at school (Lamb, 2007). The study suggests that the English teaching methods and materials should be changed to keep the students motivated to learn English.

In his following study in Indonesian high schools, Lamb (2012) found that students' ideal L2 self was a significant factor in students' motivation in an urban or metropolitan area. In this study Lamb used Dörnyei's L2 motivational self-system as a framework (see Section The socio-dynamic period). He conducted a survey of 527 learners using a 50 -item questionnaire. An interesting finding from this study is that urban students have more L2 self-motivation compared to their counterparts in rural schools. This suggests that the teacher's role in motivating students in rural areas is a topic that requires more in-depth study.

Maulana, Opdenakker, Brok, and Bosker (2011) investigated interpersonal relationships between teachers and students in English and mathematics. The participants were 1900 junior high school students (grades 7 to 9), aged approximately 11-14 years old. The findings show that teachers perceive themselves more favourably than their students' do. The teachers perceived that they were more likeable, helpful, friendly, and understanding compared to what the students reported. Students perceive that teachers' interpersonal behaviour links with their learning motivation (Maulana et al., 2011). This implies that teachers can influence students' motivation, and teachers' behaviours have a link with students' English learning motivation. 
Bradford (2007) explored Indonesian university students' motivational orientation to learn English by administering a three-part questionnaire, with some open-ended questions, to a sample of 168 Indonesian university students. The study found that university students' motivation to learn English is mostly influenced by instrumental reasons, such as understanding textbooks, getting a highly paid job, or working for a foreign company or working abroad. Student integrative motivation in learning English was not considered to be influential.

The research on high school student motivation and university student motivation to learn English in Indonesia shows different findings. High school students display more integrative motivation towards English as a global language. They are initially motivated to learn English but this motivation decreases because of the classroom and school context which may not accommodate the students' English language needs (Lamb, 2007). On the other hand, university students can keep themselves motivated by considering the advantages of learning English for their future careers. This indicates they are influenced through instrumental motivation.

Overall, the findings in this section suggest that research on what the teacher does to motivate students in Indonesian high schools, especially outside the central urban areas, is very important. At school level, integrative motivation is evident whereas at university level instrumental motivation is a stronger form of motivation.

\section{The history of research in second/foreign language learning motivation}

Ushioda and Dörnyei (2012) have identified four broad phases in relation to the research that has been conducted on second/foreign language motivation. These phases have been described as: the socio-educational period; the cognitive-situated period; the process-oriented period; and the socio-dynamic period. This analysis also reveals that second language motivation is related to other disciplines outside of language learning.

\section{The socio-educational period}

The socio-educational period can be traced back to an early leading theory in language learning motivation; it arises from the seminal work of Wallace Lambert and Robert Gardner (Gardner \& Lambert, 1959) who studied motivation in second language learning in Canada. They classified motivation into two basic types: 
integrative and instrumental. As mentioned above, their idea of integrative motivation relates to the learner's positive attitude toward the target language community and the desire to integrate into that community. Integrative motivation is regarded as the main driver to learn a second language. Instrumental motivation, on the other hand, refers to students' goal of learning a target language because of the usefulness or reward for this learning, such as getting good mark in a test, winning a prize, or getting a good job. Instrumental motivation arises because of the linguistic benefits or practical advantages that arise from learning a target language (Gardner \& Lambert, 1959).

Many studies have been conducted based on the dichotomy of integrative and instrumental motivation (Bernaus \& Gardner, 2008; Bernaus et al., 2009; Gardner, Masgoret, Tennant, \& Mihic, 2004; Gardner \& Tremblay, 1994). However, this concept is now considered by some researchers as not broad enough to represent and explain student's motivation to learn a second language (Dörnyei, 2005; Oxford \& Shearin, 1994). For second/foreign language teachers, the issue is not only the students' desire to integrate with speakers of the target language, but how the students engage in learning tasks and maintaining this engagement in their learning.

\section{Cognitive-situated period}

The limitation of the socio-educational perspective of motivation encouraged researchers to search for other factors that may influence second language learning motivation. During the late 1980s and early 1990s, research began to focus on "cognitive-situated" influences (Ushioda \& Dornyei, 2012). The starting point for this research is the work of Crookes and Schmidt (1991).

Crookes and Schmidt (1991) suggested that motivation in learning a second language connected to the students' choice, engagement and persistence. They argued that research on motivation in learning a second language should be general, not only consider strategies that can be applied in a certain context only. Oxford and Shearin (1994) supported Crookes and Schmidt's (1991) findings that students' motivation to learn a second/foreign language is broader than the distinction between integrative and instrumental motivation only. They argued that integrative and instrumental were some of the reasons why students learn a second/foreign language. Other factors include cultural curiosity, an interest in foreign travel, and the intellectual challenge (Oxford \& Shearin, 1994). Additionally, 
Oxford and Shearin (1994) emphasised that students seek social comfort, acceptance and esteem in the classroom. However, students' motivation is not stable over time; it may change in kind and degree (Dörnyei, 1994, 2010a; Oxford \& Shearin, 1994). Consequently, the research approach has shifted to a stronger focus on the classroom; how the learning context influences learner motivation, and conversely how motivation affects the learning process. It is argued that the classroom context has a stronger effect than was previously proposed (Dörnyei, 1994).

\section{Process-oriented period}

The third phase of research on motivation is based on Dörnyei and Otto's (1998) research on second language learning motivation; this is referred to as the processoriented period. This research groups motivation into three temporal segments (Dornyei \& Otto, 1998 pp. 47-51):

- Preactional stage: in this stage motivation needs to be generated (it is also called "choice" motivation).

- Actional stage: in this stage motivation needs to be maintained and protected by providing pleasant and interesting activities or tasks so learners experience a supportive learning atmosphere. This stage is sometimes called "executive" motivation.

- Postactional stage: in this stage learners need to undertake retrospective evaluation of how the learning has been conducted; they should be able to select learning activities that motivate them to learn in order to pursue their future goals. This is also known as the "motivational retrospection" stage.

In support of the process-oriented model, Dörnyei and Csizer (1998) conducted a survey in Hungarian second language learning which identified the most important factors that teachers should consider in motivating students. The questionnaire consisted of 51 strategies, with the teachers asked to rank how frequently they used the strategies. Dörnyei and Csizer surveyed 200 Hungarian teachers of English from various language teaching institutions to establish the 51 motivational strategies and then identified how often the teachers used them in the classroom. They proposed that ten major strategies or "Ten Commandments" underpinned motivation for second language learners. These are given in Table 2.1. 
Table 2.1: Ten Commandments for Motivating Language Learners

Ten Commandments for Motivating Language Learners

1. Set a personal example with your own behaviour.

2. Create a pleasant, relaxed atmosphere in the classroom.

3. Present the tasks properly.

4. Develop a good relationship with the learners.

5. Increase the learner's linguistic self-confidence.

6. Make the language classes interesting.

7. Promote learner autonomy.

8. Personalise the learning process.

9. Increase the learners' goal-orientedness.

10. Familiarise learners with the target language culture.

(Dörnyei \& Csizer, 1998, p. 215)

These Ten Commandments offer strategies that teachers can use to motivate learners. Empirical studies have been conducted to determine whether these techniques are worth using in specific learning contexts. It is important to note that in Dörnyei and Csizer's study, the data were collected from the teachers' perspective and included no student perspectives on what constitutes motivating teaching strategies.

Based on his research on second/foreign language motivation, Dörnyei (2001) developed a total of 102 motivational strategies, called motivational teaching practice (MTP). MTP systematises the application of motivation into a circular system comprising four phases: creating motivational conditions; generating student motivation; maintaining motivation and protecting motivation; and encouraging positive retrospective self-evaluation. This cycle implies that student motivation should be built, generated, maintained and encouraged (Dörnyei, 2001). 


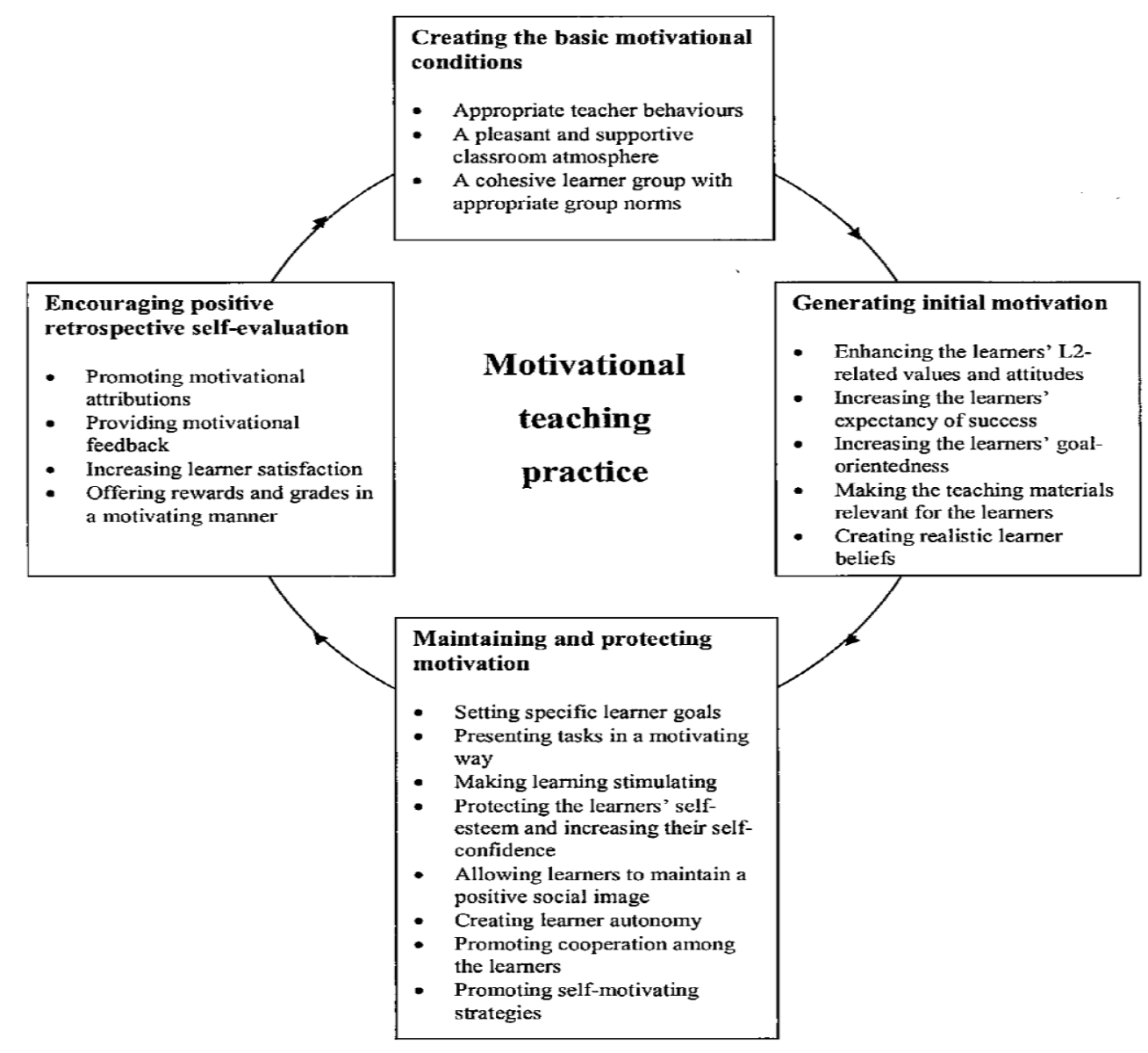

Figure 2.1: Motivational Teaching Practice

(Presented by permission from Dörnyei (2001), Figure 3, p. 29)

In the first stage, teachers need to create motivational conditions in the classroom through appropriate teacher behaviours, good relationships with students, creating a pleasant and supportive atmosphere, and providing group norms to promote cohesive group behaviour. The second stage focuses on generating students' motivation by enhancing their attitudes to learning language, increasing their goal orientedness, making teaching materials more relevant, and creating realistic beliefs. The third stage focuses on maintaining motivation by setting specific learner goals, presenting tasks in a motivating way, creating learner autonomy, and promoting learner self-motivational strategies. In the last stage, students are encouraged to build positive self-evaluation by the teacher promoting motivational attributions, providing motivational feedback, increasing the learner's satisfaction, and offering rewards and feedback in a way that is motivating (Dörnyei, 2001). 
Motivation study in middle of the twentieth century dominated by behaviourist psychology which focused on stimuli and responses based on research on animals such as Pavlov's dog or Skinner's rats. As a counteraction to the behaviourist theory, in the 1960s humanistic psychologists tend to focus their research onto human self-actualising to achieve personal capacities and talents. This cognitive approach focus on how individual's attitudes, thoughts, beliefs, and interpretations influence their behaviours (Dornyei, 2001 p.8).

The other way to view motivation is from the sociocognitive theory which underlines the important role of social process in shaping motivation. This theory argues that there is interrelationship between individual cognitive process and the environment (Bandura, 2001).

There are different approaches to students' motivation and while teachers need to understand these theories of motivation, they also seek ways to implement them within their own classrooms. Dornyei's (2001) work was intended to raise practical issues and make concrete suggestions for classroom practices by developing a motivational teaching practice (MTP) framework which drew on the theories of motivation. In a language classroom, no single motivation theory can capture the complexity (Dörnyei, 2001).

Therefore, strategies in MTP are drawn from different motivation theories. Phase one indicates how to create the preconditions that must exist so as to apply motivational teaching strategies such as appropriate teacher behaviours, a supportive classroom atmosphere, and a cohesive learner group. The other three phases are derived from different motivation theories. Some of the strategies in phase two are derived from expectancy value and goal orientation theory. For example, some strategies that teacher can apply such as inviting senior students to share their successful experience of learning L2, keeping students' goal achievable, relating L2 to everyday experience, raising students' awareness of different ways to learn L2. Most of strategies in phase three are derived from self-efficacy theory which helps students to build their "self" (self-esteem, self-confidents, self-efficacy, self-worth). The strategies that can be applied are presenting tasks in motivating ways such as using body movement, providing opportunities to success, drawing students' attention to their strength and abilities. The last phase relates to motivational attribution theory by helping students to reflect on their past learning in 
a positive way such as teaching students to attribute their failure in learning L2 as lack of effort rather than lack of ability (Dörnyei, 2001).

This framework suits the purpose of my study which looks at motivation from classroom context. The focus of my study is on motivational teaching strategies or techniques used by teachers to motivate their student to learn. This is to help teachers to implement motivation theory in classroom practices.

\section{The socio-dynamic period}

In his later research, Dörnyei $(2005,2009 b)$ broadened and elaborated on the MTP framework by introducing the L2 motivational self-system. With this development, motivation research has moved into the "socio-dynamic" phase, so-called for how it emphasises that teaching and learning contexts are made up of a multiplicity of internal, social, and contextual factors (Ushioda \& Dörnyei, 2012). This phase of motivation research is called the "socio-dynamic" phase because it emphasises that the context of the teaching and learning is made up of a multiplicity of internal, social, and contextual factors (Ushioda \& Dornyei, 2012). In this model Dörnyei proposed three main dimensions to students' language learning motivation: the ideal L2 self; the ought to L2 self; and the L2 learning experience. The ideal L2 self represents the learners' image or vision of what they aspire to be in the future. The ought to L2 self represents the learner's perception of what significant other people expect. Those people may be parents, peers, or teachers. The ought to L2 self therefore represents the external influence on the learner as perceived internally by the learner. It also deals with the attributes the learner should possess to achieve goals and avoid possible negative outcomes. The L2 learning experience focuses on the students' learning environment and experiences in that environment. The L2 learning experience covers the impact of the teacher, the curriculum, the peer group, and the experience of success (Dörnyei, 2014).

The socio-dynamic approach to language learning views motivation as the interaction of learners with their learning context, underlining the important role of social processes in shaping motivation (Ushioda \& Dornyei, 2012). Through the new framework of the L2 motivational self-system, Dörnyei (2014) argues that learners cannot be separated from their social environment. In effect the teacher needs to consider the complexity of factors impacting on a student, whether they are internal 
to the student, arising from the student's family and social context, or from the learning context itself (Dörnyei, 2014).

The difference between Dörnyei's (2001) MTP system and the L2 motivational selfsystem $(2005 ; 2009)$ lies in relation to how motivation is viewed. MTP looks at motivation from the teachers' perspective or teaching process; it involves the strategies a teacher can use to motivate their students. The L2 motivational selfsystem focuses more on the learning process of students; that is, how student characteristics and the context influence the learning process. Since my study focuses on how teachers motivate their students, the MTP framework is a more appropriate model for gathering research data in the present study.

\section{Research on motivational teaching strategies}

The techniques used by teachers to motivate their students cannot be generalised and applied to all classrooms because of culture-specific variables such as the student approach to learning, the teaching approach, learner characteristics, and other factors in the learning environment that influence student motivation. Effective motivational teaching techniques used in one country may not be effective in another country (Cheng \& Dornyei, 2007; Guilloteaux \& Dornyei, 2008; Ruesch, Bown, \& Dewey, 2011).

Research has been conducted to find out the effect of implementing motivational teaching strategies on students' motivation. Fourteen studies have used Dörnyei's MTP framework. Most of the studies were surveys, followed up by interviews or classroom observations; one study conducted a quasi-experimental design, and one case study used interviews only. These will be described and reviewed below. First international studies will be reviewed and then two studies from Indonesian will be introduced.

To investigate whether motivational teaching strategies are valid for all learning settings in terms of culture, ethno-linguistic and classroom context. Cheng and Dörnyei (2007) conducted a study in Taiwan. The researchers asked 387 Taiwanese teachers of English to rate a list of comprehensive motivational strategies in terms of how important they were and how often the strategies were used in their teaching. This study revealed some similarities between motivational strategies rated by Hungarian teachers in Dörnyei and Csizer's (1998) study. In 
other words, the study found that some motivational teaching strategies are transferable across nations but some strategies are culturally bound.

In response to this, Guilloteaux and Dörnyei (2008) conducted large scale observational research involving $40 \mathrm{EFL}$ classrooms consisting of 27 teachers and 1,381 students in South Korea. They used classroom observations to document learners' motivational behaviours and teachers' motivational teaching strategies; they also used student motivation questionnaires and observations of teachers' overall motivational strategies. They found that teachers' motivational strategies had a positive effect on students' motivation. This finding filled the gap in the literature left by a lack of empirical evidence that teachers' motivational strategies did impact on learners' motivation.

Not all strategies from MTP are found in every context, Guilloteaux (2013) conducted another study in South Korea involving 268 secondary school teachers. She confirmed her previous study with Dörnyei that some motivational strategies can be transferred across contexts. However, unlike her previous study, she found that Korean teachers rarely used motivational teaching strategies related to generating a positive classroom climate, or engaging students in group work and thereby enabling them to control student's learning (Marie-Jose Guilloteaux, 2013).

Similar findings from a study in a Saudi Arabia university showed that the lecturers utilised some motivational teaching strategies-such as demonstrating proper teacher behaviour and promoting learners' self-confidence-but paid little attention to the use of strategies that enhanced learners' autonomy (Alrabai, 2011). Motivational teaching strategies can impact on students' learning. A similar study was conducted by Papi and Abdollahzadeh (2011) in an Iranian context. The study involved 741 students and 17 teachers. The results indicated that teachers' motivational teaching strategies significantly increased the students' motivation. Classroom activities showed a strong positive correlation between teacher motivational teaching strategies and students' engagement in learning. The research findings thus indicate that language teachers can enhance student language learning motivation by implementing specific methods and techniques. These motivational teaching strategies are investigated in my study. 
Papi and Abdollahzadeh's (2011) findings are supported by the study of Sugita McEown and Takeuchi (2012), conducted in a Japanese EFL context. They found that two strategies enhanced Japanese university students' motivation, namely, starting the class on time and giving a clear explanation for helping students to prepare for class assessments and exams. The study asked for more research into whether motivation is influenced by teachers' motivational teaching strategies or simply by the teacher's likeability to students.

To find out the effect of motivational teaching strategies, Moskovsky et al. (2013) conducted a quasi-experimental study in a Saudi Arabia high school. This study involved 14 teachers and 296 students, splitting into an experimental and a control group. The study found that teachers' motivational teaching strategies clearly enhanced students' L2 learning motivation (Moskovsky, Alrabai, Paolini, \& Racheva, 2013).

There may be difficulties arising from the context which limit the use of motivational teaching strategies. Ziyuan (2004) used a mixed-method study in Jilin University with 130 students and an unspecified number of teachers. A survey was followed by interviews. The results show that some motivational teaching strategies proposed by Dörnyei (2001), such as teachers given to sharing their personal interest in second language learning with students, and showing students that the teacher cares about their progress, were not practical at Jilin University due to cultural differences and educational conditions in China.

In the Brazilian EFL context, Xavier (2005) investigated three teachers and 213 high school students. The result suggests that some motivational teaching strategies from Dörnyei's framework also applied in Brazil. In this study, Xavier asked both teachers and students to fill out the same questionnaire and followed this with interviews and classroom observations. The study found that factors from Dörnyei's research, such as promoting learner autonomy, and emphasising the usefulness of learning English, both of which enhance student language learning motivation, are underutilised in this context.

A positive relationship between teachers and students has been shown to be important in the Indonesian university context. Nugroho (2007) surveyed 43 English teachers in an Indonesian university The teachers filled out a questionnaire 
indicating how frequently they employ certain motivational teaching strategies. The findings indicated that some motivational teaching strategies were not used. These included inviting highly motivated senior students to share their learning experience, inviting English native speakers into the classroom, displaying class goals, using or displaying culturally authentic material, and using group work. However, the findings also revealed that some motivational teaching strategies such as establishing a good relationship with students, creating a supportive and pleasant learning atmosphere, giving clear instructions for learning tasks, showing enthusiasm for teaching, and varying learning activities, are transferable across cultures and linguistic contexts.

Kassing's (2011) qualitative study investigated the motivational teaching strategies used in an Indonesian university. The participants were EFL lecturers and their student-teachers. The study found that lecturers and student-teachers agreed that a caring relationship between them is a highly effective motivational teaching strategy. However, the lecturers were not aware that the strategies they used impacted on the student-teachers' motivation.

Culture may affect the perception of motivational teaching strategies. Ruesch et al. (2011) administered a survey to foreign language students in an American university. This study suggested a cross-cultural difference in perception of motivational teaching strategies. The study found that there was a different perception of motivational strategies between teachers and students when the culture of the students differs from the culture of the teacher (Ruesch, 2012).

In summary, the 14 studies reviewed here generally found a correlation between teacher motivational teaching strategies and students' motivation (e.g. Guilloteaux \& Dornyei, 2008; Kassing, 2011; Papi \& Abdollahzadeh, 2011; Ruesch et al., 2011). However, teachers were not necessarily aware that their motivational teaching strategies impacted on learners' motivation (Kassing, 2011). Furthermore, Sugita and Takeuci's (2010) study indicated that only some motivational teaching strategies have a correlation with students' motivation and the effectiveness of these strategies varied based on students' language level. Cheng and Dörnyei's (2007) Taiwanbased study reveals that some motivational teaching strategies are transferable across cultural and ethnolinguistic contexts but some strategies are culture-sensitive or even culture-dependent. This finding is supported by Nugroho's study (2007) in an Indonesian university and Xavier's (2005) study in a Brazilian high school. 
These appear to be a limited amount of published research on motivational teaching strategies conducted in an Indonesian high school context. It is important therefore to research motivational teaching strategies in Indonesian high schools to understand whether student age, the classroom context, and the wider cultural context influence student motivation. Among the 14 studies cited above, 12 were conducted by using survey research followed by interviews; one case study by interviews only; and one study by experimental research. My research contributes to this literature in that it is a multiple case study conducted in secondary school classrooms across different kinds of schools. There is a need for this research so that Indonesian teachers of English may understand the source of students' motivation and help enhance their motivation by implementing suitable motivational teaching strategies.

\section{Teachers' and students' perceptions of motivational teaching strategies}

In a second/foreign language context teacher and students may have different perceptions of what they consider to represent effective motivation in teaching and learning. The mismatch of such perceptions may well decrease students' motivation (Brown, 2009).

Language teachers who teach in an EFL context may have constraints that limit their attempts to motivate their learners. In this context, students learn English in the classroom but have very little time for practice through exposure to English outside the classroom. This situation is likely to decrease students' motivation to learn English (Sugita \& Takeuci, 2010). There is a positive relationship between students' perceptions of their teacher's motivational strategies and their own learning motivation (Matsumoto, 2009, 2011).

As mentioned, teachers may believe that their teaching strategies will enhance students' learning motivation, but this is not always true. Sugita and Takeuci (2010) did a qualitative study in a Japanese high school and found that only a few of the teachers' motivational strategies had a significant impact on students' motivation. This finding is supported by Bernaus and Gardner (2008) who also found a mismatch between students' and teachers' perception of motivational strategies. The teachers reported that some strategies were effective, but the students reported that these same strategies did not enhance their motivation. A similar study in an 
Iranian context produced similar results (Shishavan, 2010). Shishavan investigated 59 teachers and 215 students to identify effective English language teaching strategies. Again, teachers and learners had different views about such strategies. It is evident from the above studies that teachers and learners of English can have different perceptions of effective motivational teaching strategies (Bernaus \& Gardner, 2008; Shishavan \& Sadeghi, 2009; Sugita \& Takeuci, 2010; Sugita McEown \& Takeuchi, 2012).

Table 2.2: The mismatch between teacher and student perceptions of motivational strategies

\begin{tabular}{|c|c|c|}
\hline Motivational strategies as presented in the findings of four studies & $\begin{array}{l}\text { Teacher } \\
\text { perceptions }\end{array}$ & $\begin{array}{l}\text { Student } \\
\text { perceptions }\end{array}$ \\
\hline \multicolumn{3}{|l|}{ Bernaus \& Gardner, 2008} \\
\hline Making students do grammar exercise & $\mathrm{v}$ & \\
\hline Addressing question to the whole class & $\mathrm{v}$ & \\
\hline Asking students to work in small groups & $\mathrm{v}$ & \\
\hline Asking students to do project work & $\mathrm{v}$ & \\
\hline Laying down the norms to be followed in class & $\mathrm{v}$ & \\
\hline Emphasising communicative competence over discourse competence & $\mathrm{v}$ & \\
\hline Supplementing textbooks with other materials & $\mathrm{v}$ & \\
\hline Surprising students with new activities to maintain interest & $\mathrm{v}$ & \\
\hline Evaluating students by using tests & $\mathrm{v}$ & \\
\hline Giving students questionnaires to evaluate teaching & $\mathrm{v}$ & \\
\hline \multicolumn{3}{|l|}{ Shishavan \& Sadeghi, 2009} \\
\hline Assigning homework & $\mathrm{v}$ & \\
\hline Integrating group activities & $\mathrm{v}$ & \\
\hline Using lesson plan & $\mathrm{v}$ & \\
\hline Asking about lesson preparation & $\mathrm{v}$ & \\
\hline Using L1 & & $\mathrm{v}$ \\
\hline Mastery of the target language & $\mathrm{v}$ & \\
\hline Good knowledge of pedagogy & $\mathrm{v}$ & \\
\hline Teacher caring behaviour & & $\mathrm{v}$ \\
\hline \multicolumn{3}{|l|}{ Sugita \& Takeuci, 2010} \\
\hline Applying continuous assessment rather than pencil-paper test & & $\mathrm{v}$ \\
\hline Teacher sharing own personal interest in L2 learning (e.g. learning strategies) & & $\mathrm{v}$ \\
\hline Accepting mistakes as part of learning process & & $\mathrm{v}$ \\
\hline Providing regular feedback & & $\mathrm{v}$ \\
\hline \multicolumn{3}{|l|}{ Sugita McEown \& Takeuchi, 2012} \\
\hline Circulating around the classroom & $\mathrm{v}$ & \\
\hline Positive rewarding and praising the students & $\mathrm{v}$ & \\
\hline Bringing humour into the classroom & $\mathrm{v}$ & \\
\hline Performing in a friendly manner & $\mathrm{v}$ & \\
\hline Displaying enthusiasm & $\mathrm{v}$ & \\
\hline
\end{tabular}


The mismatch between teacher and student perceptions of effective motivational teaching strategies is presented in table 2.2. It should be noted that the table covers only mismatches. The symbol " $\mathrm{v}$ " in the table identifies whether the strategy relates to the perception of teachers of the perception of students. The appearance of " $v$ " in a column indicates a positive perception by a particular group, teacher or students.

In contrast to the preceding evidence, a study by Tuan (2012) in a Vietnamese high school involving a survey of 290 students and seven teachers of English, found that students were motivated and had positive perceptions regarding most of their teachers' motivational teaching strategies. However, other factors were found to influence students' learning motivation as well, such as students' personal learning strategies and the nature of the English curriculum. This finding is supported by Sakui and Cowie (2012) who found that both the institution and the educational system influence learners' motivation. The latter study also found that rapport between teachers and students had a positive effect on students' motivation. However, certain student characteristics relating to attitudes and personality were found to impact negatively on their learning motivation; these included anxiety, lack of interest, shyness, and lack of confidence in learning a foreign language.

\section{A contextual model for embedding MTP}

The previous section reviewed research which is consistent with an ecological model (map) of teaching and learning proposed by Hall and Kidman (2004). This model is depicted below in Figure 2.2. Although the model is based on teaching and learning research conducted at the tertiary level, the authors report evidence of the application of the map to school level (Hullena, 2008). The feature of the map is that it organises contextual influences in a way that has some parallels with the ecological model of human development proposed by Bronfenbrenner (Bronfenbrenner, 1979, 1994).

Bronfenbrenner argues that human development process is influenced by environmental factors which consist of four layers: microsystem, mesosystem, exosystem, and macro system. The microsystem consists of three points that influence a person's development: individual activities, roles, and interpersonal relationship. The mesosystem embraces the relationships and process taking place between two or more setting (e.g. the relations of school and home, school and work place). The exosystem highlight factors that are not directly relate to individual but 
could influence his/her development. The biggest system in this ecological model, macrosystem, embraces the smaller of lower order systems (Bronfenbrenner, 1979).

Hall and Kidman (2004) proposed a model that also organises contextual influences in a way that has some parallels with the ecological model of human development proposed by Bronfenbrenner. Moreover, Hall and Kidman teaching and learning map (T-L map) specifically portrays education environments (wider community, institutional community, and the direct context of teaching and learning in the classroom). Additionally, this model pictures classroom context in more detail. Therefore, this model suits my study better than Bronfenbrenner's framework since I am looking at the classroom context specifically teachers' motivational teaching strategies and the environmental factors that influence the implementation of these strategies.

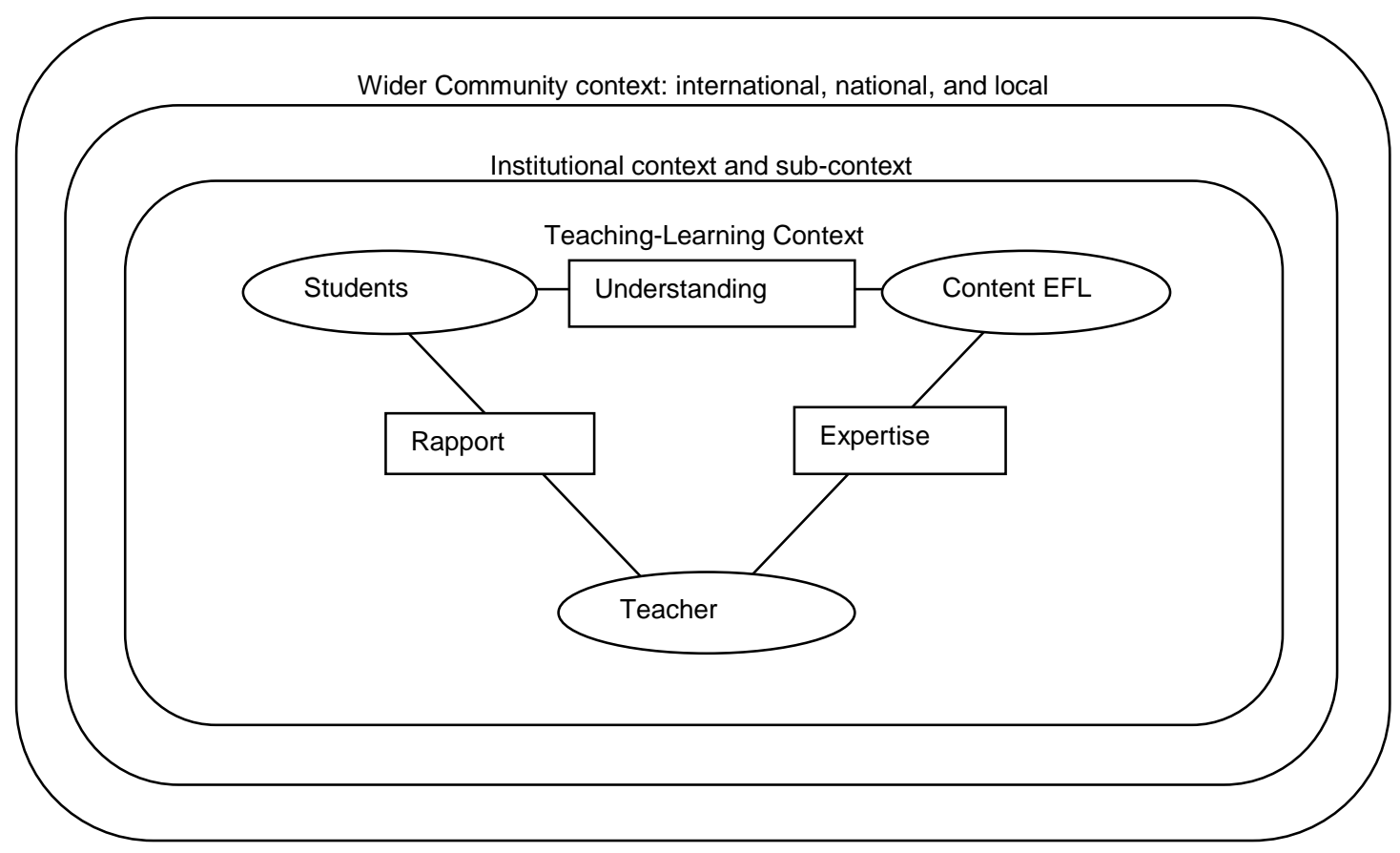

Figure 2.2: Teaching and Learning Map

(Taken from Hall and Kidman, 2004, with permission)

The model proposed by Hall and Kidman identifies three significant contextual levels that influence students' performance in university education. At the micro level are the teaching-learning contexts typically represented by specific courses that students undertake. Within such contexts there are three key elements: the students; the teacher(s) of the course; and the particular subject matterknowledge, skills and values-that make up the content or curriculum within the 
course. There are also three key relationships depicted by the concepts of "rapport" (between teacher and students), "expertise" (between the teacher and the contentthe teacher must have expertise of both the subject matter and how to teach the subject), and "understanding" which recognises that students must be active in building their understanding of the content.

Within the teaching-learning context, Hall and Kidman stress the importance of factors that motivate and help students build their understanding. For example, the "rapport" between students and teachers comes about by the teacher's respectful treatment of students, being available outside of class to answer questions, making lessons interesting and challenging, encouraging group work to support students in their learning, and so on.

At an intermediate level of context, the Hall and Kidman model identifies the importance of the institutional context in supporting (or inhibiting) teachers in their work within the teaching-learning context. Institutional support covers matters such as the availability of resources, professional development opportunities for teachers, library support for students, computer facilities and other technologies that help teachers and students, and learning support and counselling for students that is over and above that provided in a specific teaching-learning context. The institutional context supports (or not) the motivational teaching strategies of teachers and the goals of students for their learning and future aspirations.

The remaining (widest) context recognises influences on teaching-learning that arise from the wider community context: international, national, and local. For example, the availability of student loans and part time employment for students impacts on the time that students have available for study and the way students must learn to prioritise their life in order to be successful.

The significance for the present research of the Hall and Kidman model is that it provides a complementary framework for Dörnyei's MTP model. In a sense, the Hall and Kidman model is the equivalent of an "atlas"-it provides the bigger picturewhereas Dörnyei's model is the equivalent of a street finder; it provides the detail of motivational teaching strategies that teachers can bring to the teaching-learning context. 
This research will examine the impact of motivational teaching strategies within the complementary conceptual frameworks provided by Dörnyei (2001) and Hall and Kidman (2004).

\section{Summary and research questions}

Motivation plays an important role in learning a second/foreign language. It is even more important in learning a new language in a foreign language context where students are generally exposed to a target language in the classroom. Moreover, the age of students also influences their motivation to learn a new language.

Teacher's roles in motivating their students are crucial since it has been that teachers' motivational teaching practice can influence students' motivation. Teachers' implementation of motivational strategies is influenced by two main factors: teacher motivation and teacher cognition.

In relation to research on motivational teaching strategies, it can be concluded that to some extent that teachers and students have different perceptions as to which teaching strategies are motivational (Bernaus \& Gardner, 2008; Shishavan, 2010; Sugita \& Takeuci, 2010; Sugita McEown \& Takeuchi, 2012). It is also evident that the implementation of motivational strategies depends to some extent on the context (Sakui \& Cowie, 2012; Tuan, 2012). There is a need for empirical research on these literature findings to determine whether, or to what extent, they apply in high school classrooms in Indonesia. My study contributes to filling this gap in the literature.

Among several available frameworks on motivation, Dörnyei's MTP most suits this study's aim. The current study focuses on strategies that can be used by teachers to motivate their students. It was found that the implementation of MTP was influenced by context. The importance of context for teaching and learning is depicted well by Hall and Kidman's (2004) teaching and learning map (T-L map).

This study investigates teacher perceptions of motivational strategies, how the strategies are implemented, and how learners report their motivation. This study should help teachers and educational practitioners understand how teachers motivate students in learning English as a foreign language in Indonesian high schools. It will also inform research on the social and cultural factors that influence 
foreign language learning. In support of these objectives, the research questions that frame this study are:

1. How do Indonesian teachers of English in high schools report their perceptions of motivational teaching strategies?

2. How do teachers implement motivational teaching strategies in the Indonesian EFL classroom context?

3. How do students report their perceptions of the motivational teaching strategies used by their teachers? 


\section{CHAPTER 3}

\section{Methodology}

This chapter includes descriptions of the research paradigm, the research design, the case study methodology, the research procedure, the participants and setting, my role as the researcher, and how the data were collected and analysed. The trustworthiness of the study, ethical considerations, and the limitations and delimitations of the study are also considered.

\section{Research paradigm}

A research paradigm is similar to a world view; it represents the researcher's understanding of the nature of the world within which the research problem is located. It is a set of basic beliefs that guides a researcher in conducting a research (Guba \& Lincoln, 1994; Lincoln, Lynham, \& Guba, 2011). Lincoln et al. (2011) categorise research paradigms in education and social research into two main types: positivism, and interpretivism or constructivism. Within these two types there are some variants.

The positivist paradigm is based on the belief that there is an objective reality to the world which is best approached through the use of methods that prevent or minimise human contamination (Lincoln et al., 2011). In its extreme form, this paradigm assumes that there is an absolute truth to knowledge (Creswell, 2009). A positivist believes that the relationship between research variables is best analysed using empirical methods that are objective and quantitative in nature (Silverman, 2005). This belief has been criticised because within education and the social sciences answers to research questions are usually complex in nature and not easily reduced by quantitative analysis to numerical answers (Creswell, 2009).

The interpretivist/constructivist paradigm focuses research on participants, the interactions between participants, the need to understand social knowledge through critical analysis, and the need to recognise the active construction and co-creation of such knowledge through human consciousness (Lincoln et al., 2011). This paradigm assumes that individuals explore and try to understand the world where they live and work (Creswell, 2009). The meaning of a social phenomenon is determined by the "actors", the research participants. The different ways that actors interpret the world are not constant but change over time. The role of the researcher is to present the beliefs of the actors and the way they construct meaning. It implies that 
knowledge continues to develop over time (Bryman, 2008). Because reality is socially constructed within a constructivist framework the focus of research is on the multiple perspectives that participants bring to the phenomenon under study. A social constructivist worldview recognises that knowledge and truth are created rather than discovered (Richards, 2003). Social constructivism relies on the participants' view of the phenomenon and their interpretation of the research context (Creswell, 2007).

The focus of my qualitative research is to gather information about teachers' perceptions and experience of implementing motivational teaching strategies in their classrooms. The underlying assumption is that teachers use particular strategies to motivate their learners. I want to explore and analyse how the EFL teachers perceive motivational teaching strategies and how they implement such strategies in their classroom. Social constructivism allows me to understand how the teachers of English motivate their students and why they conduct particular actions to motivate their students because constructivism places priority on the context of the study. Constructivists study how the participants construct meanings and action in a particular context (Charmaz, 2006). It should also be emphasised, in line with a constructivist paradigm, my own teaching background, professional context, experiences, and prior understandings also influence the interpretations that I will make. These factors may also influence the research participants' interpretation, conception and implementation of motivational teaching strategies.

The data allowed me to gain insight into how motivational teaching strategies are implemented and why teachers employ particular strategies. My focus was on identifying and interpreting patterns in teachers' behaviours that reflect their own knowledge, experiences, and theoretical orientations (Creswell, 2009).

\section{Research design: Analytical processes and contextual influences}

As indicated, to answer research questions about how teachers report their perception of motivational teaching strategies and how students report the impact of the strategies on their motivation, a qualitative design is appropriate. Qualitative study is characterised by collecting data in a naturalistic setting where participants experience the issue of the study (Creswell, 2009). Qualitative research uses strategies characterised by inductive, constructive, and interpretive analytical 
processes, although researchers do not always implement all three features (Bryman, 2008).

Inductive analysis is one way of understanding the relationship between theory and research (Bryman, 2008). I used inductive analysis in my study; my intention was to use Dörnyei's (2001) MTP as a framework and examine its implementation within an Indonesian high school context through interviews with teachers and students and classroom observations of teaching practice. Dörnyei's MTP framework was established largely through quantitative analysis; my approach is to gather qualitative data. As noted in the previous chapter, of the fourteen published studies which utilised Dörnyei's framework, thirteen collected largely quantitative data. The current research therefore provides a unique contribution to Dörnyei's framework. In qualitative research, the context and the participants' views contribute "rich" or "thick" descriptions of the phenomenon under study that is not available from traditional positivist approaches to research.

Although Dörnyei's framework influenced the data collected through the construction of questions that participants in the present research were asked, it is still important to recognise that participants construct their view of the research topic based on their own experience and knowledge. The context, which includes the research site, also influences the perceptions and thinking of participants. In general, the more open-ended the interview questions the better for enabling the researcher to focus on participants' perceptions and actions in their life or work setting (Creswell, 2009). Consequently, I used semi-structured interviews and stimulated recall from videos of classes to gain teachers' perspectives of what happened in their classroom; these methods were used to support and clarify the observational data I collected from classroom lessons. In this research, therefore, I identified and interpreted motivational teaching strategies from my research participants' reports and actions. In addition, by using student focus groups, I was able to see the impact of the teachers' actions through the eyes of their students.

The qualitative design used in this study is person-centred in approach and is appropriate for the field of language teaching. Qualitative researchers focus their research on the socially constructed nature of reality including the relationship of the researcher to the research topic and the influence of situational factors within the research site that shape the inquiry (Denzin \& Lincoln, 2008). The collection of rich 
data allows the researchers and the readers of the research to understand the context in which teachers implement their teaching strategies.

In summary, a qualitative methodology guides the selection of research procedures including the selection of participants, the data gathering strategies, and the analysis of case study data. The description and interpretation is strongly influenced by the research context. How the teachers report their perceptions of motivational teaching strategies is heavily influenced by their classroom and school contexts. The context for my study involves researching four classrooms, each from a different high school in a town within Western Sumatera, Indonesia. Further information on the research sites is given later in this chapter.

\section{The use of case study methodology}

This research uses a case study methodology. In brief, four teachers from four different schools were selected and their teaching strategies investigated in relation to the "phenomenon" under study, namely "motivational teaching strategies". Each teacher represented a separate case. The data comprised my observations of their teaching, their perceptions of their use of motivational teaching strategies, and students' perceptions of the impacts of these strategies. Each school met a different set of standardised criteria based on quality assurance standards for high schools as determined by the government. The schools selected were an international standardised school, a national standardised school, and two local schools.

Unlike experimental studies, case study research is a naturalistic approach that does not involve any kind of treatment (Nunan \& Bailey, 2009). A case study approach is suggested when the researcher deliberately wants to consider contextual conditions within a real life situation (Yin, 2003). Additionally, case studies enable different data collection techniques to be used (Yin, 2009). They allow the researcher to collect detailed, in-depth data, using multiple sources of information. In this study the data were gathered from semi-structured interviews, classroom observations, stimulated recall, and student focus group interviews. The analysis of the data enabled each case to be described and themes to be identified.

Case study research focuses on a case or cases as complete entities that exist within real life contexts (Johnson \& Christensen, 2008). As already noted, a case study seeks a holistic interpretation of the research problem in its context (Merriam, 
1988); that is, each case to be studied is a unit that is embedded in a context or background (Stake, 2008). To understand a case, it is necessary to present rich, thick descriptions of the context and phenomenon under study.

Yin (2003) identified three types of case study research: explanatory, descriptive, and exploratory. The research questions influence the type of case study to be used. 'What' research questions tend to be more suited to exploratory case study research. When the aim of a study is to describe a phenomenon or to predict the outcomes, the research is better suited to a descriptive case study. On the other hand, "why" and "how" research questions are more likely to align with an explanatory case study (Yin, 2003). The research questions in my study focus on how the four teachers of English report their perceptions of teaching strategies that are motivating for students, how they implement these strategies, and how students report their perceptions of the impact of the teachers' behaviours and actions. For this reason, this research aligns with the notion of an explanatory case study. The focus is on operational links between teachers' actions and students' responses rather than particular incidents.

Because this study involves four cases, it can be described as a "multiple case study". For such research, the investigator should first describe and explain each case in turn. The themes from a case should be looked at in relation to the case's own context and background. Once this is done, a thematic analysis across case studies, called cross-case analysis (Creswell, 2007), should be undertaken. In line with this methodological approach, my case study analysis first focuses on each case in its own right, and then moves to a cross-case analysis. 


\section{Research Procedure}

The following diagram outlines the data collection procedure:

Selection of four year 11 teachers: Semi-structured interviews were conducted with the four teachers by using open ended questions.

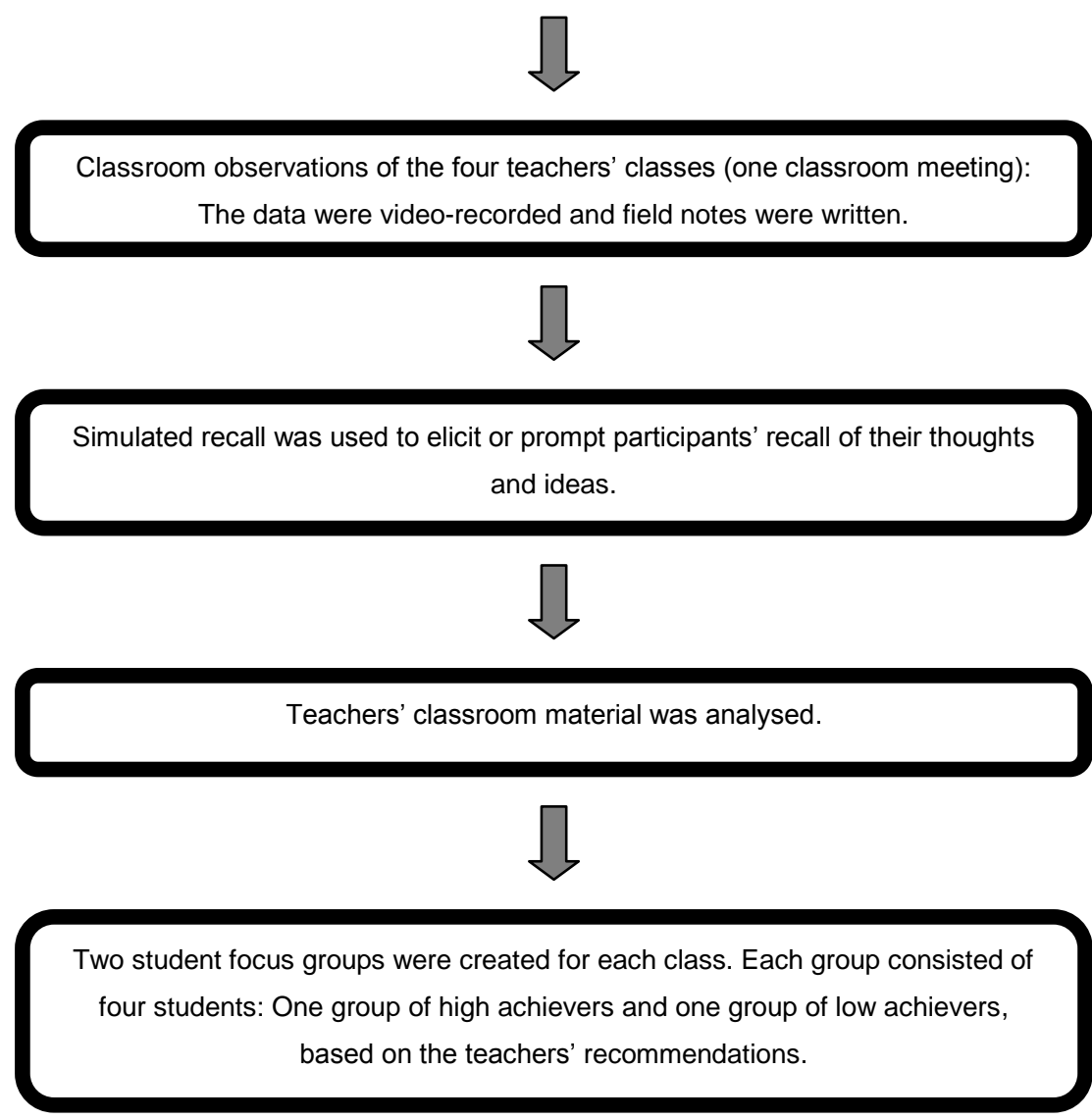

Figure 3.1: Data Collection Procedure

The sequence is explained more fully below.

\section{Selection of schools and participants}

For this research, I used purposive sampling to identify my participants. In qualitative research, samples are not usually selected randomly (Creswell, 2007). Purposive sampling requires that participants are selected strategically to ensure that those best-positioned to provide answers to the research questions contribute their views and knowledge (Bryman, 2008).

In Indonesia (excluding international schools under another country's authority) high schools are classified into one of four groups: international standardised schools; prospective international standardised schools; national standardised schools; and regular/local schools. The international and the prospective international 
standardised schools use English to teach mathematics and sciences such as physics, biology, and chemistry. The other two categories do not use English as a medium of classroom instruction in mathematics and science classes.

In the research site, there are four high schools. One of these is an international standardised school, one a national standardised school, and the other two local schools. In addition to mainstream subjects, each of the two local schools has a different focus. One focuses on arts and the other one focuses on sports. The population living in the communities supporting the four schools comprise mainly indigenous people from the Minang ethnic group. Ninety percent of the population are Muslim and generally from a farming background. Most of the students are from low to middle income families.

In line with ethical requirements (see Ethical Considerations on page 68) I contacted the principal of each school seeking permission to conduct my research in their schools. In order to facilitate the appropriate selection of participants, I requested each principal to recommend a year 11 teacher of English. There were two or three teachers of English who teach year 11 in each school. The aim of this selection process was to include cases where there was a range of motivational teaching strategies used to enable rich data to be gathered.

As noted that in Indonesia, high schools are categorised into three types: international standardised, national standardise, and regular/local schools. The teachers in this study consist of one teacher from an international standardised school, one teacher from a national standardised school and two teachers from local schools. They are likely represented schools' conditions (physical conditions and how much English use in the school). The research site was in a rural area which has about seven to eight hundred inhabitants. It was a homogenous town where Minang ethnicity was a majority. The inhabitants mostly believed in Islam.

These teachers were nominated by the headmaster because they were effective teachers in motivating their students. They were representative of teachers who knew how to motivate students appropriately rather than being typical of all teachers. The study used purposive sampling because I wanted to see what was regarded as effective practices in motivating the students. 
An initial meeting with each participant was conducted to discuss the research process and address any questions that the teacher might have about the study. I attempted to develop trust with the teachers by building rapport through the initial meeting. It should be noted that I know all the high school teachers of English in my hometown since we have an English teacher association; I am a member of this association as are most English teachers. This created a problem because when I informed participants of my research topic they expected me to give them information about how to motivate students to learn English. It took some time to make clear to them that what I needed was information from them rather than them receiving advice from me on English teaching. Teachers were assigned pseudonyms to ensure their confidentiality. I made it clear to teachers that the study findings would not have any effect on their personal assessment and future career. (See Ethical Considerations and Appendix A)

One class taught by each teacher was observed and a selection of his/her students interviewed in a focus group. The teacher selected the class session to be observed by the researcher. This was to ensure that they felt comfortable with respect to being observed. Each class session lasted for ninety minutes. I sat at the back, and video recorded the class; the main focus for my observation was the way the teachers motivated their students.

For the focus group discussions, eight students from each class were invited to participate. Each group was divided into two; this selection was made according to students' English learning achievement based on their teachers' recommendation. High achieving students formed one group and low achieving students the other. Grouping the students in this way allowed them to be more confident contributing opinions; I did not want high achievers to dominate group discussions.

Year 11 is the second year of high school so students have already experienced learning English in high school for more than a year. They are aware of the teaching and learning process in English so they were expected to be able to describe the effects of teachers' motivational teaching strategies. At this level teachers have more freedom because they are not under pressure to prepare the students for the final exam which happens at Year 12. Year 12 teachers of English focus more on helping their students pass the English national standardised test held by the government throughout the country. Teachers at Year 12 are more focused on giving students practice on previous exam samples in order to familiarise their 
students with the exam questions. Hence, year 11 teachers of English were selected because they have more scope to choose their teaching strategies.

\section{Data collection}

Case study research accommodates various forms of data collection. For my study, the data were collected by using semi-structured interviews with teachers, classroom observations, stimulated recall with teachers, and focus group interviews with students.

\section{Semi-structured interviews}

Four teachers were selected for individual interviews and classroom observations. The four teachers participated in semi-structured interviews twice to obtain information on their motivational teaching practice. The first interview was conducted prior to the classroom observation. This interview took about one to two hours and aimed to obtain detailed information of the teachers' perceptions of the nature of motivational teaching strategies. During the first individual interview, I discussed with each participant the schedule for a classroom observation. The second interview was conducted during the stimulated recall. In this interview, I intended to obtain the thinking process of each teacher which could not be captured in the observation. This interview was shorter, taking about one hour. I wanted to find out why teachers used particular strategies at different times in the classroom to motivate their students. With each teacher, I watched and discussed aspects of the video recorded during the lesson and discussed the teacher's thinking in relation to the motivation of their students. The interviews were audio-recorded and I also took field notes.

Interviews are a data collection technique that are appropriate for qualitative research (Hesse-Biber \& Leavy, 2006). Questions should relate closely to the research topic (Nunan \& Bailey, 2009). The relationship between the researcher and the interviewee should be positive and friendly but should not result in the researcher leading the participants into giving particular responses (Johnson \& Christensen, 2008).

In some research contexts it is appropriate to use semi-structured interviews. For example, the literature supporting the research may direct specific questions. In this research, classroom observations guided the direction that my questions should take, hence I used a semi-structured interview format. The initial questions asked 
were generally open-ended in nature, allowing participants the freedom to talk about their interests or allow the researcher to follow up on topics that were important to the participants. In line with recommended practice, I allowed conversations to flow naturally so participants had a chance to express their own ideas (Hesse-Biber \& Leavy, 2006). I used probe questions to clarify participants' responses.

All interviews were conducted in Indonesian. The interviews were transcribed by the researcher and the main points were discussed in person with the participants to ensure that the transcription represented their voices. Quotations from participants were carefully translated into English to maintain, as far as possible, the literal meaning intended by the participants. The use of Indonesian in the first instance was to ensure that participants could express their views without the hindrance of using a second language. There exists a risk that the translation does not fully capture the intended meaning of the respondent. This, therefore, represents a limitation in data presentation. However, on balance, the researcher believes that a more accurate representation of participants' perceptions was obtained than attempting the interviews in English.

\section{Classroom observations}

Classroom observation is a data gathering technique where the researcher directly documents activities inside the classroom by watching, listening, and recording (Nunan \& Bailey, 2009). Classroom observation enables the researcher to understand the participants' behaviour within the research setting.

Observation is important because people do not always behave in line with how they say they behave (Johnson \& Christensen, 2008). The use of classroom observations enabled me to record what teachers actually did in their classroom to motivate students. One risk, however, is that teachers may act differently when they know they are being observed (Johnson \& Christensen, 2008). To minimise this, I observed quietly from the back, built a positive rapport with the teachers prior to the observation, and assured them that the data I gathered was only for my research and would not be used in any other way, such as evaluating their performance.

During the observations, I videotaped the teacher and watched what was happening. Field notes were taken later, when viewing of the video tape. I found that this approach helped me focus more clearly on how teachers motivated their 
students. For classroom observations, I used a coded observation system (Appendix C) based on MOLT (motivational orientation of language teaching) as developed by Guilloteaux and Dörnyei (2009); MOLT is a modified version of Dörnyei's (2001) motivational teaching strategies. The coding system involves identifying instances of the specified teaching strategies and creating tallies for each strategy. Tallies of individual strategies were not used in this study. Rather, MOLT served as a guide to record field notes of incidences of the motivational strategies that the teachers used during classroom observation.

\section{Stimulated recall}

Stimulated recall involves asking a participant to review an event, for example, as captured on video tape, to recount what they were thinking during the event (Nunan \& Bailey, 2009). The participant is asked to explain what they were thinking when they acted in a particular way so as to access their internal thoughts or the thinking processes that were occurring (Grass \& Mackey, 2000).

As classroom observations on their own cannot capture mental processes, the use of stimulated recall in this study helps to elicit relevant information on teachers' use of motivational teaching strategies (Grass \& Mackey, 2000). Stimulated recall provides data that are hard to obtain by other means (Nunan \& Bailey, 2009). There is a danger, however, that the teacher may not give a completely accurate picture of why they acted in a particular way during the classroom observation. This problem is alleviated to some extent through the use of triangulation from other data resources, for example, field notes taken from video data.

After each classroom observation, I conducted a stimulated recall session by replaying part of the video recording to the relevant teacher and asking him/her what was happening during the selected event. I selected events based on my field notes and with reference to the MOLT tallies I recorded (see previous section).

The use of stimulated recall should endeavour to capture the participant's thinking as soon as possible after the observation. For case 1 (Moza), the stimulated recall took place one day later. For cases 2 and 4 (Harry and Arfan), the process took place on the same day as the observation. However, for case 3 (Yuke) the stimulated recall could not be carried out for a week because of the need to accommodate Yuke's teaching schedule. 


\section{Focus group interview}

This section further explains the use of focus groups in this research. As already noted each teacher nominated eight students to participate in a focus group discussion which examined students' perceptions of the impact of their teachers' motivational strategies.

The literature (e.g. Nunan \& Bailey, 2009) on the use of focus groups identifies several strengths in their use. First, they are efficient in their use of time; individual interviews would take a lot longer to conduct and analyse. Second, group discussions often promote thinking by participants based on the thoughts or comments of other members of the group. Third, participants often feel more secure when they are discussing their thoughts in the safety of a group than individually with an interviewer. However, the interviewer needs to ensure that all participants have plenty of opportunity to contribute their views.

Each focus group interview took about one hour; I conducted them in a cafe so the students could eat and drink after the interview session. I assured them that there was no risk that the focus group interview would impact on their marks; their teachers would not be given access to their responses. The students were given information about the questions and they signed the relevant consent form. I started with general questions about the students' views on their experience of learning English. This was to create a warm and relaxed atmosphere. When the students looked ready for a discussion, I started asking the interview questions. The indicative theme questions can be seen in Appendix B.

\section{Data collection schedule}

\begin{tabular}{|l|l|l|l|l|}
\hline & Moza & Harry & Yuke & Arfan \\
\hline $\begin{array}{l}\text { Semi structured } \\
\text { interview }\end{array}$ & $18 / 1 / 2012$ & $1 / 2 / 2012$ & $27 / 1 / 2012$ & $23 / 2 / 2012$ \\
\hline $\begin{array}{l}\text { Classroom } \\
\text { observation }\end{array}$ & $17 / 2 / 2012$ & $8 / 2 / 2012$ & $3 / 2 / 2012$ & $7 / 3 / 2012$ \\
\hline $\begin{array}{l}\text { Stimulated } \\
\text { recall }\end{array}$ & $18 / 2 / 2012$ & $8 / 2 / 2012$ & $10 / 2 / 2014$ & $7 / 3 / 2012$ \\
\hline $\begin{array}{l}\text { Focus group } \\
\text { interview }\end{array}$ & $18 / 2 / 2012$ & $11 / 2 / 2012$ & $10 / 2 / 2014$ & $14 / 3 / 2012$ \\
\hline
\end{tabular}




\section{The role of the researcher}

Creswell (2009) identifies the researcher in qualitative research as "the instrument" of the study. In a qualitative research, the researcher purposefully selects both participants and research sites to help her understand the research problem and research questions. The researcher undertakes the data collection based on strategies such as observations, interviews, and field notes. In this role, it is important that I recognise my own biases and worldviews and take steps to word accurately the perceptions, words, actions, and behaviours of my participants. For a sensitive topic, I also need to mask the names of participants, places and activities.

In line with this perspective I transcribed the participants' words and checked the main points of the transcriptions with the participants. I kept a research journal to reflect on the process of gathering data, selecting data for analysis, and analysing data. I offered pseudonyms for all participants and the research sites.

\section{Data analysis}

The answers to the first two research questions: "How do Indonesian teachers of English in high schools report their perception of motivational teaching strategies?" and "How do EFL teachers implement motivational teaching strategies?" are informed by data gathered from the semi-structured interviews with teachers, classroom observations, and stimulated recall. The third research question "How do students report their perception of motivational teaching strategies?" is answered by data gathered from the student focus groups.

I transcribed the data from the semi-structured interviews with teachers. I then triangulated the data from the interviews, observations, and stimulated recall. The themes that emerged from each case were identified and coded. The data from each student focus group were also integrated when I collated the data for their teacher. I compared the data from each case with Dörnyei's MTP framework. The framework for data analysis is presented in the following diagram: 
The raw data (transcript and field notes) from semi-structured interviews,

observation and stimulated recall were transcribed for each teacher.

The themes emerged from each case were identified.

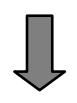

The data from the student focus group discussions were transcribed.

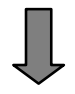

The data from the teacher and their students were merged.

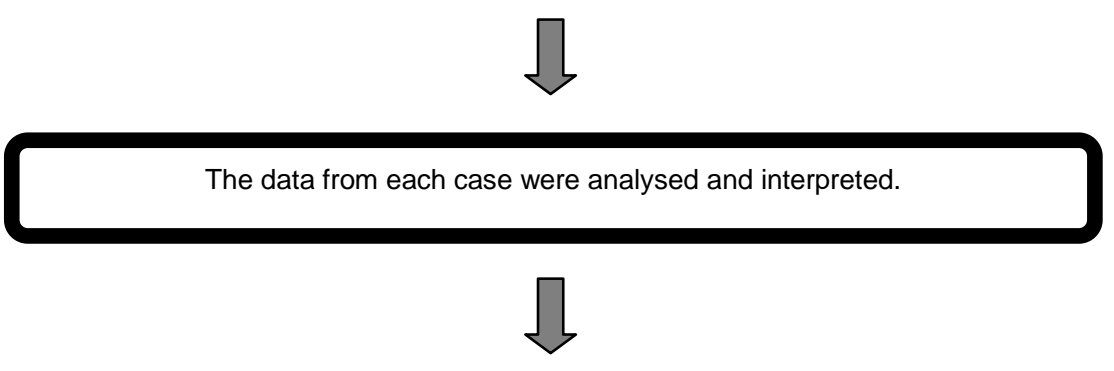

The findings are discussed as a cross-case analysis, see chapter 8.

Figure 3.2: Data analysis procedure

The data from each teacher (semi-structured interviews transcriptions, observation notes, and stimulated recall transcriptions) was coded. A code was an idea that identified by the teachers as being important. These codes were then sorted into patterns - these were determined by the responses of the teachers in relation to the different behaviours/tasks they were undertaking in the classroom. The patterns were then sorted into themes and this was achieved by linking similar patterns together that encapsulated an overall theme. I merged the data from each teacher and her/his students and considered them within the case. Then, I identified and translated indicative quotes to support the themes from teachers' and students' data. The themes that emerged from each case were analysed using Dornyei's framework. Finally, the findings were discussed as a cross-case analysis. 


\title{
Trustworthiness of the study
}

\section{Validity}

All research, quantitative and qualitative, needs to satisfy the concept of validity; that is, research should be "fit for purpose" (Hall, 2007, p. 5). According to Hall, the notion of fitness for purpose is equivalent to the concept of "trustworthiness" in qualitative design.

\begin{abstract}
A research is trustworthy if the results can be relied on because of: coherence of the overall design in relation to the research questions (fitness for purpose again); the use of appropriate methods, strategies and data analysis techniques; clarity and detail of information about the research process; evidence of appropriate or reasonable interpretations; and clarity of reporting (2007, p. 5).
\end{abstract}

Consistent with the view of Hall, Creswell (2009) identifies a range of strategies important for achieving validity in qualitative research. For example, triangulation is conducted by examining evidence from different sources. Triangulation is a way of giving confirmation and validation by looking at the data interpretation from different sources (e.g. between different teachers, and between teachers and students). Triangulation includes the use of multiple perceptions to clarify meaning.

Member checking is another technique for helping to establish validity. This strategy involves participants confirming that the data they supply represents an accurate picture of their perceptions and thinking. Where appropriate, participants should also be given the opportunity to comment on the interpretations of the researcher. This last step was impossible for the practical reason that I had returned to New Zealand by the time I analysed the data. However, the analysis of the material was presented to Indonesian teachers at two seminars on teaching and learning English in an Indonesian context (Astuti, 2013). This acted as a check on the credibility of the interpretations.

The use of rich or thick description to convey details of the research is another key element of the validity or trustworthiness of qualitative research. This involves giving all important information about the research process (e.g., the purpose, literature, methodology, data, and interpretations). This enables readers to judge the quality of the research in all its facets. 
Peer examination is also an important component of validity. In this study my supervisors cross-examined or challenged me on aspects of the process and data interpretation.

\section{Reliability}

In qualitative research the traditional concept of reliability ("consistency" or "replication") requires modification if it is to be used appropriately. Hall (2007) points out that qualitative research does not usually allow for replication; for example, the very act of conducting the research changes the context and participants' perceptions so replication is not possible. Hall argues that the key idea underlying reliability is "accuracy"; that is, data should accurately reflect the participants' perceptions, and interpretations should accurately reflect those perceptions. According to Hall (2007), accuracy in qualitative research is operationalised as "dependability"; that is, the data can be relied on (depended on) because of the procedures that the researcher has used. This requires that the researcher provides a rich or thick description of the research process and that triangulation is used to confirm findings; reliability also involves member checking to confirm data, and incorporates double coding of a sample of the data with a relevant person (e.g. a supervisor) to check consistency of coding. These processes should be declared by the researcher and made available for audit.

For the present research, the actions taken to address validity and reliability are summarised in Table 3.1.

Table 3.1: Actions taken to ensure validity and reliability in the present study

\begin{tabular}{|l|l|}
\hline Triangulation & $\begin{array}{l}\text { Sample of coding checked by the researcher's supervisors } \\
\text { Comparing data from each teacher's interview and observation } \\
\text { Observations supported by stimulated recall } \\
\text { Voices of teachers and students compared } \\
\text { Use of field notes to support interpretations of data } \\
\text { Cross case analysis of data }\end{array}$ \\
\hline Member checking & $\begin{array}{l}\text { Interviews: teachers confirm the transcription of their } \\
\text { interviews }\end{array}$ \\
\hline Rich, thick descriptions & $\begin{array}{l}\text { All details of the research, including the analysis of data, } \\
\text { written up with attention to detail }\end{array}$ \\
\hline Reliability/dependability & $\begin{array}{l}\text { Use of rich, thick description to allow readers to audit the } \\
\text { processes used } \\
\text { Member checking } \\
\text { Double coding of a sample of data } \\
\text { Triangulation of data }\end{array}$ \\
\hline
\end{tabular}


Unlike quantitative research which emphasises the notion of "generalisation"- that the findings can be generalised to suit other contexts-qualitative research emphasises the notion of "transference". This requires that all details of the research and its findings are presented in a way that enables the reader to decide if the findings transfer to their own context (Creswell, 2009; C. Hall, 2007).

\section{Ethical considerations}

There are a number of ethical issues to be addressed. In all studies, concerns about ethics are as important as concerns about validity and reliability. Not only should the study be valid and reliable, it should also be conducted in an ethical manner. Ethical issues tend to occur during the design of the study, during data collection and in the dissemination of findings.

In order to anticipate ethical issues that may arise during and after the study, the following actions were conducted. First, I gained ethics permission through the Faculty of Education Ethics Committee at Victoria University of Wellington. Second, appropriate information was provided and permission was asked from the local department of education within Indonesia. Third, permission was sought from the principals whose schools were involved in this study. Fourth, teachers were given a choice as to whether or not they wished to participate. Both teacher and student participants were invited to be part of the study. Fifth, since the ongoing support of the teachers and students was critical to the success of the study, they were informed of the approximate amount of time required for their involvement. Sixth, the participants were given the right to withdraw before the data were analysed. Finally, during data collection and any writing-up of the research, the names of the participating teachers, students, and schools were altered to protect confidentiality. Appendices $\mathrm{F}$ to $\mathrm{M}$ provide copies of the various information sheets, permission letters, and consent forms used in this research.

\section{Limitations and delimitations}

The timeframe for the data collection was clearly not sufficient to capture a full or long-term picture of how teachers motivate their students. The research is a snapshot for catching the motivational teaching strategies used by teachers and their impact on students' motivation during data collection. Some strategies actually 
in use may or may not have been apparent within the time-frame of the data collection.

The sample of teachers for this study is only four; this sample size does not represent Indonesian teachers of English in Indonesian high schools. However, in line with qualitative methodology, teachers who read this research should be in a position to judge for themselves whether the findings transfer to their own contexts.

There was only one classroom observation for each teacher; this would not have captured all motivational teaching strategies implemented by each teacher. However, in the interview and stimulated recall the teachers were able to talk more deeply about their perceptions of motivational teaching strategies, allowing a fuller picture to be revealed.

The interview and stimulated recall were conducted in Indonesian so that I could catch fully the teachers' perceptions of motivational strategies. This also enabled teachers to express their perceptions better without thinking of expressing ideas and opinions in English. However, there is a possibility that minor inaccuracies might have occurred during the translation process.

A delimitation of this study is that the teachers were purposefully selected. The school principal was asked to recommend his/her teacher of English who was considered effective in motivating their students. This purposeful sampling strategy was intended to gain relevant data on the implementation of motivational teaching strategies. However, this sampling technique only includes motivated teachers, not a full representation of all teachers of English in Indonesian high schools.

The student focus group interviews were conducted with two groups from each teacher. The groups were high achieving students and low achieving students. The voice of middle achieving students was not included because of the need to ensure that the amount of data to be analysed was not excessive. This may have influenced the study findings on the impact of motivational teaching strategies on students' motivation, however, the belief is that high achieving and low achieving students were most important in ensuring that the data captured as wide a range of views as possible. 


\section{Summary}

This chapter has discussed the research paradigm which positioned this study as a social constructivism. A qualitative research design was used. Case studies were used. Rich data collection was collected from interviews, observations, stimulated recall and focus groups. The trustworthiness was taken into account carefully by using triangulation, member checking, and thick/rich descriptions. My role in this study was as an instrument to collect data and interpreted them based on the participants' point of views. The ethical aspects of the study were considered by explaining to the participants the research goals and obtaining a signed consent from those who agreed to participate. Real names were not used. There were some limitations/delimitations of the study such as the data was only a snapshot of the practices of four teachers who were purposely selected. However this enabled different types of context to be investigated. 


\section{CHAPTER 4 \\ Case Study 1: Moza}

This chapter and the other three chapters that follow will discuss the cases, one-byone. These chapters will start by describing the school conditions, then discuss teaching and learning English in the school, the teacher' attributes and practices, and other factors that influence teachers' decision making. Each chapter ends with a summary of the key factors that characterise the teachers and their teaching. The first case is that of Moza, a teacher in a general high school.

\section{Type of school}

The school is a senior high school in a small town in the province of Western Sumatera. The school is a general high school, meaning that the school prepares students for university education. The school has 30 classes consisting of ten groups of Year 10, ten groups of Year 11, and ten groups of Year 12 students. The school is highly desirable because of its "A" accreditation. The school has gained an International Standard Organisation (ISO) certificate. In Indonesia this school is categorised as an International Standardised School.

In this school, science and mathematics are mostly taught in English. The school has more than a thousand students with about 80 teachers. Entry to the school is competitive, attracting high achieving students from the surrounding junior high schools. Conveniently for students, the school is located in the city center.

\section{The layout and structure of the school}

The school's physical environment reflects the facility's level of resourcing, with students charged higher fees than the students of other schools in this town. The school has a two-storey building with some classes upstairs. The teachers' staffroom, administration office, deputy principals' office, principal's office, and library are downstairs. The school building has been refurbished so it is modern in its appearance. The front yard has a colorful flower garden. In the middle of the school yard there is a sports field where students play basketball, volleyball and badminton. The principal's office, the deputy principals' office, and the school administration office are next to each other. The school is tidy and well-presented. Three canteens are available and most students buy their lunch. 
The principal is assisted by five deputy principals. Each deputy principal has a main management job such as student administration, school facilities, school quality assurance, social relationships, and school administration.

The school is a government school so it is funded mostly by the government but parents are expected to pay a school fee. Parents need to pay a monthly school fee and an annual fee. The school fee is about NZD 15 per month and the annual fee is about NZD 150. This is an average fee for this type of high school in Indonesia. However, schools usually exempt poorer students from the school payment (Field note, January 2012).

\section{English teaching in the school}

The classroom layout is typical for an Indonesian school: the teacher's desk and chair are at the front and the students' chairs in rows facing the front. The students' chairs are able to be folded and include a small table for writing; this enables students to form small groups for team work. In the front of each class, there is a whiteboard and the school provides whiteboard markers. Most teachers have their own laptop. The school supports the teachers' acquisition of laptops by lending them money which is paid back monthly (Field note, January 2012).

Based on my observations in the school and also in the classroom, the study of English is not a major problem for many students (Classroom observation, 17 Feb 2012). They speak English with their teachers and classmates. However, some students reported that English is still a problem for them especially in answering the final national standardised test (Focus group B, 18 Feb 2012). Many students complained that they have limited vocabulary so it is hard for them to answer the test questions, especially for reading and listening.

Students' academic achievement is assessed each semester through the school semester examination, with marks determined by the students' daily participation in the learning process, a block test, a mid-semester test, and the semester test. Students sit the national final examination at the end of their studies or in the last semester of Year 12.

Although it is an international standardised school, its teachers of English reported that motivating their students to use English remains a challenge (Interview, 18 Jan 
2012). The national curriculum for English states that students are expected to be able to gain knowledge and communicate in English fluently for daily communication (Depdiknas, 2006).

\section{The teacher}

Moza had taught in this school for 32 years. She graduated from a teachers' college with a degree as her teaching qualification which allowed her to teach in a senior high school. She was a very experienced teacher of English. Her students liked to study with her because of her classroom personality and teaching style (Focus group, 18/2/2012).

\section{Teacher Attributes}

\section{Classroom Behaviours}

Moza said that she usually smiled when she entered the classroom and also when she was teaching her students. She believed that by smiling she would make her students feel comfortable and not afraid to study English. Smiling also made her feel confident entering and teaching in the classroom.

I come to the classroom with a happy face, and I usually smile when I enter the classroom. I keep smiling when I teach. I think it becomes my habit in the classroom. I try to keep smiling to my students to make them feel comfortable. I do not smile when I tell a sad story but instead show a sad expression. The students sometimes cry listening to my sad stories (Interview, 18/1/2012).

The students in the focus group also reported that they liked the teacher's smile. It made them feel accepted and free to express their ideas and opinions.

She smiles a lot. It makes me feel comfortable, and unafraid to make mistakes. Previously my English teachers were very strict, making English a very difficult subject for me. I was afraid to talk in the classroom (Focus group B, 18/2/2012).

Moza said that she almost never got angry with her students. She argued that if a teacher appeared to be angry in front of the class the learning period would be wasted, and students who wanted to study and behave well would not get any advantage. 
If they make fun of something I laugh with them. I do not get angry, because if I am angry they cannot keep laughing. After some time, I ask them to stop and tell them it is time to study. If you get angry you create distance with your students, and they will lose interest in learning English (Interview, 18/1/2012).

Moza's classes were warm and lively. She built an encouraging relationship with her students. She established a boundary as a teacher between herself and her students, but she also built a close and friendly relationship with students in the classroom (Field note, January 2012). She explained:

You have to build a relaxed classroom atmosphere. Do not make students afraid. Make them feel free to express their ideas in your class. (Interview, 18/01/2012).

Moza believed that she needed to respect her students by listening to their ideas and opinions. She said that if the students were aware that the teacher did not listen to them, they would not participate in the classroom and they would not enjoy the subject she taught. She believed that the teacher must:

Never look down on the students, even if their answers are wrong. If you underestimate the student or make them embarrassed in front of their peers, they will be so disappointed with you and the side effect is they will hate your lesson. (Interview, 17/1/2012)

The students seemed enthusiastic to learn and were happy doing the tasks given (Field note, 17/2/2012). Moza also looked enthusiastic teaching her students. She stated that:

The key is your relationship with the students. The students will be enthusiastic to learn if you appreciate them and their opinions or ideas. I tell them that English is not only required for their high school marks but also for their future lives. If using a strategy is not working I change to another strategy or I ask them to ask me questions, especially about the parts they do not understand (Interview, 18/01/2012).

She gave freedom to her students by allowing them to select discussion topics. This motivated her students to speak actively in the classroom because they liked the topic of the discussion. 
I sometimes ask the students to decide upon the discussion topics. If they like the topic they will actively participate in the discussion. If the students are unfamiliar with the topic they will be unmotivated and keep silent (Interview, 18/01/2012).

As indicated, Moza encouraged her students to express ideas freely in the classroom. She built trust and set up rules at the beginning of each semester. Moza understood that building trust between her and the students was an important component for building a strong teaching and learning process. As she elaborated:

Yes, you have to make your students trust you. You have to tell your students that what they say in the classroom-especially in discussions or during activities-will not be exposed outside the classroom. Make them trust you so they feel free to express their ideas in your class (Interview, 18/1/2012).

Moza believed that a positive relationship with her students was a key for successful teaching. She said that the teacher could make the lesson interesting with her/his personality and the teacher could also make the lesson boring. The students reported that they liked Moza's personality and her teaching methods. Not only high achievers but also weak students enjoyed learning with Moza. They stated:

She is open and warm which makes us feel comfortable, unafraid of delivering our ideas. She does not get angry if we make mistakes. She listens to our opinions and expressions. The lessons are so interesting (Focus group B, 18-2-2012).

Moza believed that when she had a personal problem and felt uncomfortable entering the classroom, her students usually could sense this. She felt that teaching and learning during such periods was not successful:

When I have a personal problem, I think my teaching is not so successful. I can feel it and I think my students know this, but they are usually reluctant to ask questions about it. But sometimes a student asks if I am sick or something (Interview, 17/1/2012).

It seems that Moza's warm and enthusiastic classroom manner encouraged students to learn. The way she respected the students created relaxed learning conditions. This is important in teaching and learning environments, especially in language learning where students often have chances to make mistakes. Moza had 
a bond with her students; she could feel that her students appreciated and understood her approach in the classroom.

\section{Good model of English speaking}

Moza considered another important point in teaching English to be the teacher's pronunciation. Moza said that if a teacher's pronunciation was not clear students became confused:

I think the important point in teaching a foreign language is the teacher's pronunciation. It makes English more interesting for students. If the teacher's pronunciation is unclear, English sounds strange to students. Nowadays, most students access English outside the classroom too. Some of them take English courses in a qualified English school (Interview, 17/1/2012).

She added that:

Especially for the language teacher, pronunciation determines the teacher's performance in the classroom because the students imitate the teacher's language. They need examples before practising the language. They will get confused if there is no model. It really depends on the teacher to make the students feel like practising the language (Stimulated recall, 18/2/2012)

Moza believed that one of the most influential factors in determining a successful language teacher is their clear pronunciation. The teacher's skill in English is considered an important model for students learning the language.

\section{Summary of teacher attitude}

The data from Moza and her students suggested that the key point of successful teaching and learning English in their classroom was the warm and supportive relationship between teacher and students. Moza thought that there should be a bond between teacher and students in order to make the learning successful. Additionally, Moza argued that teacher pronunciation was a key factor in motivating her students to learn English. She mentioned that the trust between teacher and students made students feel free and safe to express their ideas and opinion in the classroom. 


\section{Teacher practices}

While a teacher is able to make learning interesting by his/her classroom manner, she or he can also motivate learning by designing or selecting excellent classroom materials and using an effective teaching style. Moza stated, based on her experience, that an important factor influencing students' learning motivation was the quality of the teaching materials. She believed that:

Teachers should know when particular learning materials do not work for their students, and that they should then find other materials (Interview, 17/1/2012).

Moza was more likely to select teaching materials that she considered motivating. She said that if she found a learning material did not work well in her teaching then she would not use it again in her other classes.

\section{Opportunity to practise}

From the students' point of view, a factor that helped them enjoy learning English was having enough time to use the language. The students stated that they liked learning English with Moza because she gave them time to practise. According to the students, a teacher needs to explain the lesson followed by a chance to use the language. One student observed that:

The teacher is interesting for how she gives us many chances to practise. She explains and gives examples and after that gives us opportunity to practise (Focus group A, 18-2-2012)

Another student added:

I enjoy practising a lot. I understand English when my teacher explains clearly and gives examples. After that she allows us to practise in pairs or groups (Focus group A, 18/2/2012).

Moza provided time for her students to practise their English in the classroom and provided interesting learning materials. These strategies appeared to help her students' motivation to learn. 


\section{Teaching strategies}

Moza liked to start the lesson by telling a story. She believed that stories can be used as ice breakers and as pre-teaching activities. Through stories, the lesson topic may be easily introduced. Moza often told stories without looking at the book so the students had to listen to her carefully. It was usually more interesting for students to listen to the teacher's story rather than listen to the teacher reading a story. If a teacher read a story from a book it seemed less likely students will pay full attention. As Moza reflects:

As far as I know the students like it. The students are more interested in listening to my stories rather than those I could read from the book. If I read a story from the book they may talk with their friends or do other things. When I tell them stories they seem enthusiastic and listen to me carefully (Interview, 17/1/2012).

The students in the study confirmed their interest in Moza's story-telling approach. One reported that:

The teacher tells us interesting stories and sometimes the endings surprise us. She usually starts the lesson by telling a story. I think some of the stories are her real life experience (Focus group, 18/2/2012).

Moza said that she obtained stories from books, magazines, and life experiences, or else she created her own story related to the learning topic. She said that a story was a good way to start the lesson so as to engage students in the learning process. Her students sometimes asked whether her story was her real experience or she had made up the story:

When the story is very funny or surprising, my students ask whether I really experienced it or was it just a story. I am inspired by what I hear and see around me and hence I make up stories. Sometimes, the beginning of the story is real but I make up the ending (Interview, 17/1/2012).

Another student commented:

When she tells a story she uses facial expressions and good intonation. It is so interesting. I will listen more seriously when the teacher tells a story rather than reads one from the textbook. The stories in the textbook contain many difficult 
words. They are hard to understand. I do not really like reading (Focus group A, 18/2/2012).

Moza's teaching style received a positive response from her students. The students said that they liked learning with Moza. In a focus group interview a student said:

I like the teacher because we learn from many resources and do different activities. I also like listening to her stories. They are amusing (Focus group A, 18/2/2012).

Another student also mentioned that he enjoyed learning with Moza because of her way of explaining the lesson. He said that Moza used simple sentences that were easy to understand:

I like the teacher because I understand her language. She does not use difficult words. I can understand what she is saying or explaining in the classroom (Focus group B, 18/2/2012).

Moza gave examples of sentences from real life situations (observation, 17/2/2012). This motivated her students who could see a purpose for learning English:

The teacher makes sentences that are easy to follow and close to our world. She gives examples from real life and gives us time to make our sentences (Focus group B, 18/2/2012).

This contrasted with an approach that mainly focuses on grammar out of context. As an example of how she made students aware of real world use of English, one day she told them that her husband had asked her to stop teaching. She went on:

I told the students that it made me very sad and I almost cried. I made a sad face and the students were sad too. Then I wrote all my sad expressions on the board. That's how I started teaching the topic "Expressing Sadness" (Interview 18/01/2012).

However, within her class there were a few students whose English was weak and they had poor communication. Even though these weak students enjoyed learning with Moza, it was hard for them to be involved in classroom activities (Field note, 17/2/2012). Moza recognised this situation; she noted that these students usually 
understood the main information that she taught but when they were asked to perform a learning task they usually asked their friends what was expected from the tasks. Moza said:

They ask questions of their friends, but mostly I can see from their eyes that they are confused. Their eyes look blank (Interview, 18/1/2012).

This problem may have occurred because of the language barrier that the students encountered. Moza tended to use English in her teaching. She only used Indonesian for some sentences when explaining the important points of the lesson (Classroom observation, 17/2/2012). One student reported:

I like when the teacher explains the lesson in English but not all the time because it is hard for me to understand long sentences. I want the teacher to use Indonesian too (Focus group B, 18/2/2012).

Moza stated that in the classroom she mostly used English because she wanted her students to be exposed to English as much as possible (Stimulated recall, 18/2/2012). She said that it was expected from the curriculum that a teacher of English needs to give examples of how to use the language for communication.

Mostly in teaching I use English. I only use Indonesian when I feel or see my students do not understand. I want them to listen to English as much as possible so it will encourage them to use English (Interview, 17/1/2012).

This implied that Moza also used code-switching in her teaching, especially when she realised that her students looked confused and did not understand what she was explaining.

She argued that she needed to find ways to make a difficult lesson interesting by linking her teaching with the students' lives. She gave many examples of sentences and expressions relevant to teenage life to make it easier for her students to understand the expression or the sentence pattern (Interview, 17/1/2012). As one student stated: 
I can understand English more easily when my teacher explains clearly and gives a lot of examples. I like simple examples from my daily life context (Focus group A, 18/2/2012).

Another student added that they liked Moza's teaching style:

The teacher has a special trick to make the lesson interesting. She explains the lesson, writes examples from real life activity on the board and lets us practise (Focus group B, 18/2/2012)

Based on the above quote, it appears that Moza implements a three-step teaching process by explaining the lesson, giving examples, and then giving students time to practise. She also begins a class with a story and draws on it later.

\title{
Varying classroom activities
}

Moza used different activities in her teaching (Classroom observation, 25/2/2012). She stated that if the students did one activity for too long they would be bored and could become sleepy in the classroom. She also modified her teaching strategy.

\begin{abstract}
Sometimes when I teach reading, instead of asking them to answer comprehension questions, I ask them to create a short drama based on the text. I give them time to practise and then present it in front of the class. This strategy was successful, and my students enjoyed it. Teachers should know that if particular strategies do not work for their students they should find other strategies (Interview, 17/1/2012).
\end{abstract}

Moza stated that the level of her students' English competency was one of the considerations in her selection of a teaching strategy. She taught different classes at different levels of English competency. She applied different strategies for different levels of student English competency.

Based on my experience of teaching high school students, the students' level of English also determines the strategies I use. I use different strategies for different students depending on their English ability. For example, in the class of mostly weaker students I spend more time helping them with vocabulary (Interview, 17/1/2012) 
Other factors determining the teaching strategies used in the classroom were the text genre and language skills the students needed to achieve.

The text types and language skills to teach also influence the strategy I use. Teaching language expressions is always interesting and makes students happy because I give them free time to express themselves (Interview, 17/1/2012).

In teaching various text types, she sometimes modified her teaching strategy, as, for example, in teaching narrative text, where, instead of asking the student to tell the story alone she asked the students to work in groups.

Sometimes instead of telling the story alone I ask them to work in groups so they can tell the text in a form of a short drama or role play. It varies the teaching strategy and it is a lot of fun for students (Interview, 17/1/2012).

When she found that a teaching strategy was uninteresting she would not use it again but if it was successful she would apply it again in another class.

One day, I asked the students to tell a narrative story in front of the class one by one. To make them listen to their friends' stories I told them that at the end I would ask them to answer several questions based on all the stories. But the students did not listen to their friends' stories. They were too busy preparing their own stories to present in front of the class. When I asked questions they worked together, helping each other by sending paper message to each other to find out the answers to the questions. So this strategy does not work and I never use it anymore (Interview, 17/1/2012).

She found that discussion was generally more interesting than debating for her students. In a discussion, students could position themselves to agree or disagree with the discussion topic. In a discussion students worked in groups and helped each other but, in a debate, they had to sit in a team of two or three and argue against another team. In a debate a team takes the position of being a negative or affirmative team in relation to the theme of the debate.

Sometimes I change the strategy and procedure of a debate. To make it more lively I change it to a discussion instead so students have more freedom to express their ideas and arguments (Interview, 17/1/2012). 
Moza stated that when she found her students still had a problem understanding a lesson she used other strategies to explain it.

I can tell if my students have ongoing problems understanding a particular lesson. In that situation I will try to repeat the lesson using other strategies (Interview, 17/1/2012).

Moza showed that she was an experienced teacher in making the learning interesting by implementing a range of teaching strategies. She knew ways to make the classroom environment warm and lively for her high school learners.

\section{Emphasising the usefulness of English for students future}

Moza said that one of the ways to motivate her students was by telling them how important English was in their lives. She said that English was not only important for them as high school students but also for their university study and future careers.

I tell them how important English is for their future and their lives. I advise them that for the university entrance test and for their university lives English is important. If they can answer the English and Indonesian part of the university entrance test they can pass the test and enter university. I also emphasise that most university textbooks are written in English, and translations are hard to find. I tell them the example is my son. $\mathrm{He}$ is not really good at other subjects but he can answer Indonesian and English questions in the university entrance test, so he passed the test. This motivates the students. They try to get good marks for their English and study hard (Interview, 17/1/2012).

She thought that it was important to tell her students about the usefulness of English. By knowing the reasons for learning English, the students would understand that they should master English as an important international language. The students needed to know that their English achievement influences their academic credit in the university entrance test. She said that this helps motivate them to learn English in the classroom (Interview, 17/1/2012).

\section{Activating students' prior knowledge}

To activate students' prior knowledge, Moza used strategies such as asking her students to brainstorm the topic of the lesson. First, she wrote down a word on the whiteboard. Then she asked her students to think of what they had in their minds 
when they read and thought about the word. She wrote down all the students' opinions. Then she asked her students to read a short article dealing with the topic. She asked her students what they had found in the article related to the words they had mentioned and written on the whiteboard (Interview, 17/1/2012).

The students found this activity challenging because they had to think and guess. They said that they were happy when they had a good guess and could do the exercise well.

I work harder when the topic is interesting. I am so happy if I can do the exercises well or answer the teacher's question (Focus group A, 18/2/2012).

Moza had a special strategy when she taught middle to low achievement students.

I teach one of the average cohorts this semester, and I spend more time activating their prior knowledge. I take a long time in my pre-teaching. I usually tell a funny story or share some personal experience. Once the students look happy and enthusiastic, ready to learn, I start teaching the learning topic (Interview, 17/1/2012).

Moza enhanced her students' motivation by activating their prior knowledge before she started the lesson. This helped her students' readiness to learn.

\section{Reading for comprehension}

Moza tried to help her students master English by implementing challenging and fun English in the classroom. She said that in teaching reading comprehension she used the following activity:

\footnotetext{
Sometimes I ask them several comprehension questions, or I ask them to say one sentence that they remember from the text, or I ask them to tell me the conclusion of the text. These exercises help them to get information quickly from what they have read (Interview, 18/01/2012).
}

Moza sometimes started reading comprehension by writing the key words of the text on the board. Then she asked the students to think of the words' meaning and to find related words. After that she asked the students to skim the text and find the words. She said that she also used other strategies in reading. 
I ask the students to read the text and then say one sentence about the text, but they are not allowed to repeat what their friends have already said (Interview, 17/1/2012).

She stated, however, that she wanted her students to listen to their friends' ideas and opinions so they would respect each other.

I want them concentrate and focus more on the language use in the examples of what their friends say. I use the book only as additional material. I do not want them to repeat what their friends have said so they have to listen carefully. I hope they can learn from treating their friends' sentences as examples (Interview, 17/1/2012).

Moza helped to make the reading comprehension session interesting by combining reading and speaking. This appeared to help students comprehend a text more easily since they did it together in pairs or in groups.

\section{Feedback}

The assessment of student learning was not based solely on examination achievement. The assessment covered students' competency, classroom participation, and classroom learning attitude. The mark for each student's academic report was calculated from their marks in classroom participation, a block test, a mid-semester test, and end of semester test. Some teachers focused more on the semester test rather than the learning process assessment, which was unpopular with some students. As one said:

I like the way my teacher evaluates us. She does not just consider the test but also our classroom participation (Focus group B, 18-2-2012).

Another said that she was motivated when she found her classmates were better than her:

I will be very motivated to try harder when I find out one of my classmates is better than me. I want to beat them and be better than them. At least I want to be as good as them in English (Focus group A, 18-2-2012). 
Moza did not directly correct students in her class as she thought that this would make students unmotivated to talk. When her students practised or talked she just listened and made corrections at the end of the learning period. She picked up the important mistakes and made general corrections.

I do not correct their mistakes directly. I usually write down their mistakes on a paper, and at the end of the lesson I write their mistakes on a board without telling whose mistakes were whose. The class discusses the mistakes and tries to reach the correct answer (Stimulated recall, 18/2/2012).

During the class, Moza walked around to make sure that her students understood the task. Sometimes she asked questions to make sure that they knew what to do with the assignment. She explained that she liked to do this to be satisfied that all students achieve the learning goals of each meeting.

I want to make sure that they can do the task. Sometimes weak students are too shy to ask questions. When I come to them they usually ask me to help them with the difficulties they face. They trust me enough to share their ideas or opinions with me (Classroom observation, 17/2/2012).

Her students also gave a positive response here. They liked it when Moza came to them and asked whether they were on task or not.

I will be on task because the teacher actively invites me to practise and supports me with encouraging comments (Focus group B, 18-2-2012).

In summary, students liked Moza's way of evaluating the learning. It seemed that she used formative assessment more than summative assessment. Consequently, the assessment process did not judge the students' ability only, but also built students' confidence and involvement in the process.

\section{Games and songs}

However, the students also wanted her to play more games in the classroom. Some students also wanted to listen to English songs to increase their vocabulary. 
I like songs or games in the classroom. It increases vocabulary and the learning will be lively and warm (Focus group B, 18-2-2012).

The students thought that songs could make the learning atmosphere relaxed and friendly. Songs could also update students' knowledge of popular and well known songs from around the world. However, students reported that songs were not played in the classroom. In the focus group interview, students said that:

We like listening to English songs in the classroom as part of our learning and classroom ativities. Since the beginning of the academic year my teacher did not play any songs in the classroom (Focus group B, 18/2/2012).

Moza seemed to understand that her students liked songs but she did not say why she did not use them as one of her teaching strategies.

\section{Managing unmotivated students}

If Moza thought one of her students was misbehaving, she approached this student and talked with them confidentially. She believed this would avoid making other students feel uncomfortable or disturbed by her anger towards one of their classmates. She explained:

I usually advise misbehaving students personally, and usually it works. But if they do not change their behaviour I do not look at them many times. It will influence my mood in teaching and this will affect other students. Sometimes I motivate misbehaving students by telling them that I cannot help them with their marks, so they have to help themselves. I tell them that their activeness and participation in the classroom will be considered and influence their mark and this motivates them to behave (Interview, 17/1/2012).

She said that if such a student did not listen to her and still misbehaved she did not want her teaching to be influenced. She tended to ignore this particular student during her teaching.

Moza reported that when she experienced difficulties motivating her students in ways that were usually effective, she would use her last strategy, telling her students that she would evaluate the tasks at the end of the class period. She hoped that 
students would perform the tasks and feel motivated because they wanted to get credit for their classroom participation. She said:

I tell them that their exercises today will be marked and considered as a part of their classroom participation credit. This will motivate them (Interview, 17/1/2012).

If she found her students remained unmotivated, perhaps due to shyness in front of their classmates, she usually gave these students the opportunity to participate towards the end of a period. She hoped that witnessing their classmates' performance would help them prepare.

I give all students a chance to participate and if, at the end, there are still some who are not, I invite them gently to join in. Usually they feel like joining in because all their classmates have already participated (Interview, 17/1/2012).

Moza did not think that she was a clever teacher but she was confident in saying that she was good at motivating students to learn English in the classroom.

I don't think I am a clever teacher but I am good at motivating students to learn. I want them to love English and to provide them with activities they like. Most students do not like textbook learning. They like to practise so I give them enough time to do this. I give them the model and then let them practise using the language (Interview, 17/1/2012).

It seems that Moza knew her students well so it was easy for her to handle her students who were misbehaving. She also looked confident in her motivating strategies.

\section{Other factors}

\section{School Period}

The timing of the school period also influenced students' motivation. When Moza taught in the morning all students looked enthusiastic and happy to learn. However, when they studied in the late afternoon she thought they looked tired and hungry. She usually took more time warming up students for the afternoon period. After the students seemed engaged then she started the lesson. Most of the time she used 
jokes or told a funny story that made her students laugh and forget their tiredness. Then they were ready to study (Interview, 18/1/2012). She said that:

The period of teaching also influences my teaching strategy. Teaching in the early morning and the early afternoon will be different. More time warming up or doing pre teaching activities is required in the late afternoon classes. If I teach at the end of the school period I use more time to warm up the class before starting the lesson. The atmosphere should be relaxed (Interview, 17/1/2012).

The students reported that they preferred learning in the morning. They felt fresh and ready to learn. The weather was also still cool. Learning in the afternoon was tiring and they felt sleepy.

I like to learn in the morning. The weather is still fresh and cool. In the afternoon I usually feel sleepy and hungry too (Focus group, 18/2/2012).

Moza said that when she taught in the afternoon session she preferred to review the lesson rather than explain a new topic. She usually only explained or reviewed language expression and gave the students time for practice.

I usually spend more time reviewing the lesson in the afternoon class. I invite the students to express their ideas and opinions on a topic. In the afternoon it takes a long time to engage them in a learning atmosphere. I do not teach difficult lessons in this session (Interview, 17/1/2012).

The timing of the school period was something beyond teacher authority. Instead of complaining about this, Moza worked with the situation by giving more time for students to settle and practise the language that had been learnt.

\section{Teaching media}

Moza said that she had a problem teaching language listening because the school did not have a language laboratory and nor did the school provide a tape recorder.

I have a problem teaching listening because the school does not provide me with a tape recorder. For listening practice I just use my voice. I read the dialogue or 
monologue and the students listen for comprehension or general information (Interview, 17/1/2012).

Moza said that she had to provide her own teaching aids-such as a tape recorder. She sometimes used her own voice for listening practice. She did not comment as to whether this was a big problem for her.

\section{Summary}

Table 4.1 below provides a short summary of the key factors that characterise Moza's teaching. This material is used in the cross case analysis in Chapter 8.

Table 4.1: Summary of Moza's teaching attributes and practices

\begin{tabular}{|c|c|}
\hline Attributes a & Illustrations \\
\hline $\begin{array}{l}\text { Attributes } \\
\text { - Warm classroom manner } \\
\text { - } \text { Respecting students } \\
\text { - Clear pronunciation }\end{array}$ & $\begin{array}{l}\text { Smiling and showing a happy face when entering the } \\
\text { classroom. } \\
\text { Listening to students' ideas and opinions. Building trust by } \\
\text { assuring students that classroom discussion is confidential. } \\
\text { Having clear pronunciation and using simple sentences. }\end{array}$ \\
\hline $\begin{array}{l}\text { Practices } \\
\text { - Giving time to practice } \\
\text { - Interesting materials } \\
\text { - Telling stories } \\
\text { - Using English } \\
\text { - Earying activities } \\
\text { - } \text { - Activating students prior } \\
\text { knowledge } \\
\text { - Reading for } \\
\text { comprehension } \\
\text { - Miving feedback } \\
\text { - Managing unmotivated } \\
\text { students } \\
\text { Motivating strategy }\end{array}$ & $\begin{array}{l}\text { Allocating plenty of time for students to practise in pairs or } \\
\text { in groups. } \\
\text { Relating materials to students' lives, giving many } \\
\text { examples. } \\
\text { Telling stories related to learning topics and teenagers' } \\
\text { lives. } \\
\text { Using English when explaining lessons. } \\
\text { Using various activities in each meeting. Text genre; } \\
\text { language skills covered; and students' levels of English are } \\
\text { taken into account. } \\
\text { Reinforcing the advantages of English for university study } \\
\text { and careers. } \\
\text { Brainstorming a topic, leading students with questions. } \\
\text { Writing key words from texts, skimming, and oral } \\
\text { summarizing. } \\
\text { Giving feedback on students' learning throughout the } \\
\text { learning process. } \\
\text { Approaching students in person. Setting up classroom } \\
\text { rules at the beginning of the semester. } \\
\text { Evaluating tasks at the end of the day's period. }\end{array}$ \\
\hline $\begin{array}{l}\text { Other factors } \\
\text { - Teaching period } \\
\text { - Teaching media }\end{array}$ & $\begin{array}{l}\text { Taking more time to warm up students in the afternoon } \\
\text { period. } \\
\text { Using her own tape recorder or her voice for listening } \\
\text { activities. }\end{array}$ \\
\hline
\end{tabular}




\section{CHAPTER 5 \\ Case study 2: Harry}

\section{Type of school}

The school is located in the same town in Western Sumatera as the previous case. This is a general government high school which prepares students for university study. Two majors are offered in this school, science and social science.

Students study in the morning from 7.20 am until $1.20 \mathrm{pm}$. The students also have some extra classes in the morning and the afternoon, especially in Year 12. It is a common practice for high schools in Indonesia to give extra lessons to Year 12 students in order to prepare them for the final state examination. Year 10 and 11 only run extra classes for students who need them. The parents usually talk to the school principal if their children require extra lessons. The school then organises extra classes with the parents' financial support.

The students' parents come mostly from middle to low incomes. Besides its academic focus on science and social science, the school also specialises in arts. The school holds a youth band festival every year (Interview, 1/2/2012).

Many parents want to send their children to this school because it is a government school and the location is not far from the town centre. Some parents and their children also choose this school because there is more opportunity to obtain a learning promotion to enter a government university. In Indonesia, high school students can be automatically accepted into a government university based on their academic achievement in the first five semesters in senior high school. The school ranks students' academic achievement and sends students to their choice of university based on the ranking (Field note, 27/1/2012).

\section{The layout and structure of the school}

The school is convenient for students and their families. It is about two and a half kilometres from the town centre. Rice fields are situated in front, while houses and a midwifery college are to the side. It is a quiet area which is good for learning. The school is not on a regular public minibus route, but in the morning and afternoon there are some public minibuses to take students to and from the bus terminal. Most students ride motor bikes to school. Some students use an "ojek" as their 
transportation to school. This is a motorcycle driven by someone who takes a paying passenger. It follows a flexible route like a taxi. The fare depends on the distance of the route and is negotiated with the rider.

The school building is only one storey, with the field and playground in the centre. The classrooms surround the field with a flower garden in the front of each classroom. It is a colourful school with many kinds of trees and flowers. The parking area for teachers, school staff and guests is in the front. Students park their motorcycles inside the school parking area.

The main building of the school consists of the principal's room which is beside a deputy principals' room, school administration office, and the teachers' staffroom. The school building is like a square with the sports field in the middle. The classrooms and other buildings surround the sports field.

There are 21 classes of students. There are seven groups of Year 10 students, seven groups of Year 11 students, and seven groups of Year 12 students. There are approximately seven hundred students and sixty teachers in this school. The principal is assisted by four deputy principals. Each deputy principal has a specific job such as managing school administration, curriculum, social relationships, and students.

\section{English teaching in the school}

There are four teachers of English in this school. Each teacher teaches about five classes twice a week.

Teachers of English reported that they need to work hard to motivate students. Some students have high motivation but most are not so motivated to learn English. English is still considered to be a difficult subject and few students are able to use English satisfactorily in the classroom or daily communication.

It is hard to motivate them to learn, especially in English which they find so difficult. So I try to make them happy in my class in the hope they will shift their mind-set toward English. When they look happy, when they are laughing and enjoying the learning atmosphere, then I start the lesson (Interview, 1/2/2012). 
It seemed that Harry understood his students' mood. He started the lesson when the students were in the right mood.

Students' perceived English as a very hard skill to gain. Teaching English was a big challenge for teachers in this school. The facilities for learning English as a foreign language were limited and there is no language laboratory. The school provided teachers with a tape recorder for listening practice. If a teacher wanted to use computer-based learning materials, he or she needed to borrow a data projector from the school and bring it to the classroom. Some classes had electricity supplied and some do not. Teaching facilities were therefore limited in classrooms with no electricity. Teachers needed to shift the students to a multipurpose room or the library (Interview, 1/2/202012).

\section{The teacher}

Harry had taught in this school for 15 years. He graduated from a teachers college with a degree to teach at high school. Harry said that most of his students were motivated to learn when he told jokes and gave advice. He believed that the important thing in teaching and learning in the classroom was his relationship with students. When students felt comfortable learning in the classroom, the learning process would run well. However, when students felt afraid and under pressure, learning will not happen (Interview, 1/2/202012).

\section{Teacher attributes}

\section{Warmth and approachability}

Harry was friendly and very easy going. He appeared to build a strong relationship with his students. He was an outgoing teacher. His students liked to study with him because he was warm to talk to; the students felt comfortable talking to him inside or outside the classroom. He is easy to approach.

I like the teacher because he has a great sense of humour and he encourages us with his advice. I can ask him questions or chat with him outside the classroom (Focus group, 11/2/2012). 
Harry was clear about what he thought his students needed. He said that students needed someone to motivate them to learn and they needed a warm and lively classroom.

Before starting each lesson I set up the students with some advice, I put myself forward as a motivator for my students. I use songs, jokes and games (Interview, $1 / 2 / 2012)$.

The students mentioned that for them the most important thing in learning English was the teacher. Even though the material was interesting, if the teacher's personality was not warm, the learning would not be interesting.

I think the first thing in classroom learning is the teacher. Other things will follow if the teacher is nice and interesting (Focus group, 11/2/2012).

It seemed that Harry's behaviour inside and outside the classroom is the same. $\mathrm{He}$ was warm and approachable both inside and outside the classroom. His students were able to give feedback or talk with him about the learning experience outside the classroom (Field note, 27/1/2012).

\section{Maintaining a strong relationship with students}

Harry said that to engage his students in learning, he chose examples that were close to his students' lives. He created stories or examples by using students' names or told them about an event that was familiar to them. This helped them understand the lesson more easily. If they felt unsafe Harry thought students would pretend to understand because they were afraid of asking questions or showing their confusion.

I involve the students in learning by making examples that are close to them. I use their names in my sentences. When I make example sentences or expressions on the board I use their names, and I also use their names in my exam questions to help remind them of what I have taught. The important thing is that they are encouraged because their names or their friends' names are used (Interview, $1 / 2 / 2012)$. 
Harry built a close relationship with his students. He stated that inside the classroom he greeted his students by using nicknames. Outside the classroom he tried to remember his students' names and greeted them using their nicknames. By doing this, he maintained a friendly and informal relationship with his students inside or outside the classroom.

I want my students to feel free to talk to me. I am not such a formal person so they do not need to treat me as though I am the big boss. I sometimes chat with them in the school canteen or if they meet me in the market or somewhere else (Interview, 1/2/2012).

In Indonesian culture knowing and calling a person by his or her nickname means a lot. It means that there is a close and understanding relationship. A common practice is to call a person by their first name. A nickname is a name that a person likes and only close relatives and friends use this name.

Harry's way of addressing his students' by their nicknames was an attempt to build rapport with his students. He also shared power with his students by describing his relationship as a brother, not as a person with high authority.

His students also liked him. They liked his friendly and warm personality. He built an understanding and respectful relationship with students:

I like studying English because I like the teacher, especially the way the teacher interacts with us. He makes jokes but we still respect him as our teacher. I do not like teachers with serious faces or no jokes at all (Focus group, 11/2/2012).

The students in a focus group stated that Harry's actions motivated them. They said that:

The first factor is the teacher, the activities and the material. I think the teacher is the first influential factor. I like humorous teachers so I enjoy learning English in the classroom with him (Focus group, 11/2/2012). 
Harry also gave advice to help his students study hard. He taught his students to respect their parents' hard work which supported them financially and allowed them to attend school. He believed that giving advice is a part of his role as a teacher.

\section{Teacher practices}

\section{Teaching strategy}

Harry reported that he also used songs in his classroom. He sometimes modified a song by using his students' names in the words and lyrics. His students enjoyed this and would laugh and tease each other. He sometimes brought his guitar to the classroom and played English songs as one of his teaching strategies.

I use songs by playing them on a tape recorder, or sometimes I sing a song myself and change the lyrics to use the students' names. I also use poems and use their names in my poems. The key is making my students happy so the classroom is lively and warm. I also build a friendly and warm relationship with my students so they feel like I am their brother, and aren't afraid of me (Interview, 1/2/2012).

His students enjoyed songs, games and varied learning activities. In the focus group one reported:

I like songs and games but in my opinion the classroom activities should be varied. Any activity that we do too much in the classroom makes us bored. So far I enjoy learning English in the classroom (Focus group, 11/2/2012).

One student mentioned that she liked learning English grammar followed by practice. She thought that grammar was also needed in learning a foreign language.

I really enjoy activities that help me practise speaking English. I feel English grammar is also important, but compared to practise; maybe it should be more balanced. I would say $40 \%$ language knowledge and $60 \%$ practice (Focus group, 11/2/2012).

In the focus group a student stated that: 
I want to learn more vocabulary from the learning activities to help my English fluency. English is an international language I need it very much (Focus group, 11/2/2012).

One of the students even said that he needed to practise with a native speaker.

I want to practise my English and talk directly with English native speakers (Focus group, 11/2/2012).

In summary, Harry understood the preferred activities of his students in learning English, hence he played songs and games, told stories, and read poems as part of his teaching strategies. He used a variety of classroom activities to engage his students in learning.

\section{Grouping students for interaction}

Harry said that he usually managed classes by putting students in pairs or groups. He argued that by doing pair-work or group-work his students would support each other. These learning activities helped students build their self-confidence and team skills because they would present the work as a group rather than as their own work.

I design my class mostly by putting the students in groups. After I explain the lesson I ask the students to sit in groups. Then I ask each group to explain and discuss their work in front of the class (Interview, 1/2/2012).

When Harry arranged group membership he ensured that each group contained at least one high achiever who could act as the leader of the group. He assigned groups with projects so that students knew there was a purpose for group discussion and that they had the responsibility to present their group report.

Yes, they feel confident if someone can lead the discussion. If all students in a group were weak they would feel confused, not knowing what to do and say in front of the class. So I make sure that one student in each group can be the moderator (Interview, 1/2/2012).

He added that: 
I train them to be brave enough to use English in front of other people. Beforehand, they are afraid to use English. By putting those students in groups their confidence with English will grow. Sometimes they can discuss and write the answers before they talk (Interview, 1/2/2012)

The students reported that they liked to work in a group. By working in a group the students could ask their friends if they did not understand something. Sometimes students were shy about asking the teacher in front of their classmates. Harry believed that mixed-ability group composition benefited his students more.

I enjoy working in a group because if I have problems, I can ask my friends for help. It is easier to understand my friends' explanations (Focus group, 11/2/2012).

Both Harry and his students enjoyed pair-work and group-work classroom activities. Harry helped build his students' self-confidence with English through this activity. However, students were held responsible for finishing the assigned project.

\section{Setting up the learning}

Harry put in place learning regulations at the beginning of the semester. He built commitment and understanding from his students with these regulations. By doing this, both teacher and students know the boundaries for class behaviour. Students understood their classroom rights and obligations.

I speak frankly to them. What I want them to be and to do in my classroom. I understand their situation but they have to be disciplined and stick to what we have agreed on. I set up the rules at the very beginning, when they start learning with me at the beginning of the semester. The goal of the learning is to develop English skills to the point where they have the capability to use English. I also tell them my life experience and how I learned English when I was at school. I learned to use English and practised my broken English every time I met westerners (Interview, 1/2/2012).

He usually reminded his students at the start of a lesson to study hard. He took 10 to 15 minutes to warm up the learning atmosphere by delivering advice before he started teaching the lesson (Classroom observation, 8/2/2012).

I remind my students that their parents work hard. Most of them keep silent when I remind them about their parents. I think they can feel that it is really true that their 
parents have had to work hard in farms or rice fields to pay their school fee (Interview, 1/2/2012).

Harry believed that the teacher needed to set up the learning conditions before starting a lesson. If a teacher directly jumped to the lesson without a pre-teaching activity, students would find it hard to concentrate. He said there was no point in starting the lesson when the students were not ready.

I start with advice, giving an Islamic lesson or telling jokes. I remind them how important English is for their life, how hard their parents work to support them financially. They listen to me seriously. They feel it in their hearts, and they are ready to study. I start the lesson when my students are ready (Interview, 1/2/2012).

In Western Sumatera's culture, giving advice based on Islamic values is common and important. Being a good Muslim is part of being a good person in general. Students accept this. At the beginning of the semester, Harry usually found out if any non-Muslim students were in his class and explained that although his advice was based on Islamic values it would be of use to Muslims and non-Muslims alike.

Harry stated that he needed to change his students' mind-set towards English. The students should not think that English is a "scary" subject. Students should understand that English could be fun and enjoyable to learn. It was not a difficult language to learn if the learning atmosphere supports it.

I teach English in a relaxed atmosphere, I often use games and songs to make English interesting. The important thing is that I prepare students to be ready to study, so the pre-teaching activity is crucial. My students have to learn in an encouraging atmosphere, not under pressure, otherwise they will think that English is a language from another planet (Interview, 1/2/2012).

Harry argued that giving advice to his students is part of his pre-teaching activity. He intentionally did this

... especially when I see the students are lazy or sleepy. But I can say that it is my habit. I feel happy to do it and I am sure my students need it (Stimulated recall, 8/2/2012). 
Harry was also flexible about class time. In the afternoon period he allowed his students to take their time for about ten minutes to eat before coming to his class. $\mathrm{He}$ thought that his students could not learn properly if they were hungry. A ten minute break to have a quick lunch was refreshing for them.

It is really important to prepare students to learn by offering advice or telling a story with a moral lesson or religious message. I have to make students feel ready to start. Even if my period is at morning tea time, I let my students eat for ten minutes. It is better to give them time to eat rather then ask them to come to my class hungry. But I tell them that having given them time to eat there are no more excuses to leave the classroom during my lesson (Interview, 1/2/2012).

The students enjoyed learning with Harry because they did not feel any pressure within the classroom environment. The students reported that Harry is a great teacher and easy to deal with.

I like the way the teacher interacts with us. He has a great sense of humour. We laugh a lot in the classroom, it is very relaxed. I do not like serious teachers. I am too afraid to talk when the teacher is too strict (Focus group, 11/2/2012).

Another student supported this opinion.

I like the teacher; he advises us and gives religious advice. I like his personality because he makes the classroom atmosphere lively. We have time to share ideas (Focus group, 11/2/2012).

However, in the focus group interview one student said that she did not like too much fun in the classroom. She complained that if there was too much joking and laughter there would be little in the lesson that she could learn.

I like humour but not too much. I want to make sure that for each period of learning I will gain knowledge. I want the teacher to explain the lesson and for this to be followed by practice. I need to practise more (Focus group, 11/2/2012).

Another student added that she liked jokes but she also wanted to learn. 
I enjoy the way the teacher explains the lesson, he is relaxed. But I do not like if it is too much jokes because I also want to learn (Focus group, 11/2/2012).

In summary, most of Harry's students enjoyed his humour but, as noted above, one did not like too much humour; especially when her friends tried to make use of the learning time by inviting the teacher to tell more jokes. She thought that the teacher had to keep control of this and make students aware that there was time to share humour and there was time to study.

Harry believed that in his classroom the important thing was a relaxed atmosphere. The students needed to feel comfortable in the teaching-learning process. The learning would not run smoothly when students felt stressed or anxious in the classroom.

\section{Correcting mistakes}

To motivate his students to talk and participate actively in the classroom, Harry did not do any direct correction of mistakes. He always told his students that mistakes are common in learning. He said that the more you make mistakes the more you learn; mistakes are part of learning a second or foreign language.

At the beginning I told them that my motto is "the more mistakes, the more you learn". I told them that we learn from the mistakes. Once we make a mistake, we can take a new lesson from it. This idea trains the students to be brave in expressing their ideas and opinions in front of their friends. I also tell them that when they present their work in front of the class, I will listen at the back and not judge them for their mistakes. I will evaluate them from their activeness in the classroom. I correct mistakes after all the students have presented their work, and I pick up only important mistakes to be corrected without telling whose mistakes were whose (Interview, 1/2/2012).

Harry did not use feedback as a way to look down on or judge his students. He used feedback as a tool of learning. From feedback, the students learn, and Harry kept reminding his students of this.

His way of correcting mistakes and his view toward mistakes made students feel free to talk. Even with their half-English and half-Indonesian, they talked actively in 
the classroom. Harry appreciated and encouraged his students' attempts to communicate in English. His students enjoyed this opportunity too.

I like the opportunity to speak English. To be fluent in English is my learning goal. The teacher really supports me. He does not laugh at any mistake. He even reminds my classmates not to laugh at others' mistakes. The learning atmosphere is really fun and relaxed (Focus group, 11/2/2012).

Harry said that he would not correct students' directly. He let his students practise. He encouraged his students to try to use English in the classroom and without thinking of mistakes.

I deliver my comments and talk about mistakes after all the groups have presented their work. In this way, the groups presenting later are not bogged down by the mistakes and feedback of earlier groups. Presenting is a big jump for these students. In the first semester, they do not want to come to the front. Giving them freedom to express their ideas gives them confidence, even though they use broken English (Interview, 1/2/2012).

Harry reported that at the beginning of the semester his students were too shy to speak. As he taught them, he let them express their ideas without direct corrections. He reminded his students not to tease their classmates' mistakes; consequently, they began to speak more freely.

In summary, Harry's way of correcting mistakes supported his students' participation in classroom discussion. Students felt they did not need to be afraid of making mistakes. Harry told his students that mistakes are common in learning a new language. He also reminded his students that they could learn from their mistakes.

\section{Answering student questions}

When a student asked a question, Harry often asked the class to respond. He wanted to give the other students a chance to provide an answer. One student did not like it when Harry passed her question to other students to answer. She wanted the teacher to answer her question too. 
I like the teacher but I don't like it when he doesn't answer the questions. When I ask a question, the teacher asks other classmates to answer but doesn't give his answer. Which is the correct answer remains uncertain (Focus group, 11/2/2012).

It seems that the student wanted to receive a direct answer from Harry. She needed to know which answer was correct, but the teacher encouraged students to find out the answer for themselves. It is the nature of classroom learning in Indonesia that many teachers directly answer students' questions.

\section{The importance of English}

Harry presented himself as a model for his students. He talked about his life experiences so that students could learn from them. By understanding that his success owed to his ability to use English, students might be motivated to study hard and practise their English.

I tell them of the advantages I've gained from the ability to use English. I can work in many different fields. I have worked as a tour guide and I worked in a foreign company too before I decided to be a teacher of English (Interview, 1/2/2012).

By talking about his work experience, Harry expected that his students would be more motivated to learn English.

I let my students know that English is one of the skills they need to gain along with computer skills. If they know English and computers they will be equipped in the global competition for jobs (Interview, 1/2/2012).

Harry told his students that they need to be able to use English, especially for communication. This skill would help them compete for good jobs.

\section{Managing unmotivated students}

Harry also motivated his students by asking them to identify their difficulties in learning English. He offered help to his students experiencing problems. He approached students and talked in person.

For his unmotivated students Harry had a particular strategy: 
I ask them to make sentences themselves. If they still seem unmotivated I ask them to write the sentences on the board. I keep telling them the more mistakes, the more you learn, and remind them that mistakes are common because English is not our mother tongue. If they're still struggling I approach him or her individually, in their seats, and I ask them where they are having difficulty. Then I explain and give examples. Sometimes I use a dictionary to help. Some students have problems with vocabulary and don't know how to use a dictionary effectively. They don't know how to read the phonetic symbols designed to help with pronunciation. I keep telling them that I evaluate them more on the process of learning rather than the result of learning (Stimulated recall, 8/2/2012).

Harry seemed to understand his students and had a clear strategy for managing his students who were less motivated.

\section{Feedback}

Harry emphasised that he evaluated students from the learning process not from the learning result only. He expected that this helped students to be more motivated in the classroom. He usually sat at the back when the students presented their group work.

Harry also got feedback from his students about his teaching style. Since he had a close relationship with his students, he could talk to them and ask if they enjoyed the learning or if there was something that they were concerned about. He was confident and sure that his students liked his teaching style and his classroom personality.

The students are enthusiastic when I use certain strategies. They tell me that they like some strategies. In general, students like learning in a relaxed atmosphere where they feel no anxiety and are free to express their ideas and opinions (Interview, 1/2/2012).

Harry received feedback from his students through the way they responded to learning activities. Some students also told him directly which strategy or activity they liked and which they did not like. 


\section{Adopting teaching strategies from other sources}

Harry said that he learned how to teach English from many different resources. One of them was a magazine called English Teaching Forum. He liked to adopt the teaching strategies from English Teaching Forum because these strategies have been tried out by other teachers in classrooms. He was quite sure that these strategies worked in his classes too.

I learned some teaching strategies at the teacher training institute where I gained my teaching degree. I have also gathered strategies from the magazine, English Teaching Forum. The strategies here have been tried by other teachers, and are published in the magazine so other teachers may use them too. I have also adopted some other teaching strategies based on my life experience (Interview, 1/2/2012).

Harry appeared to provide quality learning materials to his students. His decision to use strategies from English Teaching Forum reflected that he was selective in using learning materials for his students.

\section{Using English for daily communication}

Harry encouraged his students to use English for their daily communication. He started to invite his students to use English by introducing some sentences and expressions that were used for daily communication. He asked his students to use these expressions especially when they were learning in the classroom.

I suggest the students use English for daily conversation in the classroom, starting with simple expressions like "excuse me", "sorry I am late", "can I go to the toilet", or "sorry I do not understand". Using daily expressions helps familiarise students with English (Interview, 1/2/2012).

Harry helped his students understand that English is not only for academic purposes in high school but also a skill for life. He emphasised the use of English as a medium of communication. The students had to practise simple expressions that they would use in their lives.

During classroom observations, I noticed that Harry's students used Indonesian words when they did not know the English words. Harry helped them translate some 
Indonesian words into English. This strategy indicated that the role of L1 needed to be considered in foreign language classes (Classroom observation, 8/2/2012).

\title{
Other Factors
}

\section{Students' academic backgrounds}

Harry said that his students were not high achievers. He needed to work hard to motivate his students to learn English. His students did not have a strong basic understanding of English. Harry thought that to make them enjoy learning English was challenging.

\footnotetext{
The students who come to this school are not clever students. Most clever students will enter the international standardised school. I understand this, and that's why I have to be flexible and understanding. Teaching high achievers, the teacher need not work so hard to motivate them. They are already motivated. But students need to be encouraged to learn, especially to learn English. Maybe this is because they do not have a strong base of English (Interview, 1/2/2012).
}

Harry reported why there were many middle to low achievers in the school. However, he understood this situation and tried to adapt to this in his classroom.

\begin{abstract}
Students who enter this school are weak. This is because of a political policy. Parents go to the mayor to get their kids accepted into the government school. It is hard to motivate them to learn, especially English which they think so difficult. So I make them happy in my class. I hope they will shift their mind-set towards English. When they are ready to enjoy learning English, I start the lesson (Interview, $1 / 2 / 2012)$.
\end{abstract}

He mentioned that his students' understanding of English also influenced the choice of teaching strategy. Teaching high achievers is different to teaching middle to low achievers. Mostly low achievers need the lesson to be explained to them in detail. Sometimes, if they did not understand the basics of English grammar and vocabulary, Harry needed to explain the point of the lesson again in brief (Interview, 1/2/2012). 


\section{Classroom layout}

The classroom layout in Harry's class was similar to the layout in most schools in Indonesia. The teacher's desk was in the front and the students' tables and chairs were in rows facing the front. Some students commented that they wanted to learn in a different setting.

I have a dream to learn outside the classroom, in the school park maybe. I think learning outside the classroom would be nice and we would have a different learning atmosphere (Focus group, 11/2/2012).

Another student wished that she could learn English in a language laboratory.

I think learning in a language laboratory would be interesting. It would be a new experience. I imagine we could practise our listening skills (Focus group, 11/2/2012).

Some of the students wanted to experience learning with an English native speaker.

It will be cool if we could learn with an English native speaker, or at least practise talking with them (Focus group, 11/2/2012).

In summary, the students wanted a variety of learning environments. They expected to experience learning in an open area such as the school playground. They were also eager to know how to learn listening skills in a language laboratory, and they would like to practise their English with English native speakers.

\section{Summary}

Table 5.1 below provides a short summary of the key factors that characterize Harry's teaching. This material is used in the cross case analysis in Chapter 8. 
Table 5.1: Summary of Harry's teaching attributes and practices

\begin{tabular}{|c|c|}
\hline Attributes and practices & Illustrations \\
\hline $\begin{array}{l}\text { Attributes } \\
\text { - Enthusiastic classroom } \\
\text { manner } \\
\text { - Strong relationship with } \\
\text { students }\end{array}$ & $\begin{array}{l}\text { Maintaining a warm and approachable relationship with } \\
\text { students. } \\
\text { Using students' names in his sentence examples, stories, } \\
\text { poems, and songs. Addressing students' by nicknames. }\end{array}$ \\
\hline $\begin{array}{l}\text { Practices } \\
\text { - Interesting activities } \\
\text { - Grouping students } \\
\text { - Setting up learning } \\
\text { - Correcting mistakes } \\
\text { - Answering students' } \\
\text { - Euestions } \\
\text { - Mmphasising the } \\
\text { - Managing of unglish } \\
\text { - Givining feedback } \\
\text { - Adopting teaching } \\
\text { strategies } \\
\text { - Using English for daily } \\
\text { communication }\end{array}$ & $\begin{array}{l}\text { Placing one high achiever in each group. } \\
\text { Giving advice before starting lessons. Giving a ten-minute } \\
\text { break before afternoon period. } \\
\text { Correcting students' mistakes indirectly. Reinforcing that } \\
\text { mistakes are part of learning. } \\
\text { Encouraging the class or other students to answer. } \\
\text { Reinforcing the advantages of English skills. Using himself } \\
\text { as a role model. } \\
\text { Directly addressing misbehaving students. } \\
\text { Assessing students' learning through the learning process. } \\
\text { Using teaching strategies from English Teaching Forum } \\
\text { magazine. } \\
\text { Inviting and encouraging students to use English for daily } \\
\text { communication. }\end{array}$ \\
\hline $\begin{array}{l}\text { Other factors } \\
\text { - Students' academic } \\
\text { backgrounds } \\
\text { - Classroom layout }\end{array}$ & $\begin{array}{l}\text { Students' English achievement in their previous learning } \\
\text { hinders their learning at senior high school. } \\
\text { Students wanted to learn in a language laboratory, the } \\
\text { playground, and from English native speakers. }\end{array}$ \\
\hline
\end{tabular}




\section{CHAPTER 6 \\ Case Study 3: Yuke}

\section{Type of school}

The school is a senior high school in the small town in Western Sumatera. It is a government high school. There are two streams in this school, science and social science. The school is in demand because of its academic achievement. The school is categorised as a national standardised school. Students study in the morning from 7.15 am until $1.15 \mathrm{pm}$.

Yuke has taught in this school since she started her career as an English teacher. Entry to this school is competitive so students in this school are middle to high achieving students. The school is about three kilometres from the city centre.

\section{The layout and structure of the school}

The school is surrounded by rice fields at the back and houses in front. The air is fresh with little noise from the traffic. The building is only one storey high with the sports field and playground in the centre. The classrooms surround the field with a flower garden in the front of each classroom. The school campus is green and colourful with many kinds of trees and flowers.

The principal's office, the deputy principals' office, the school administration office and the teachers' staffroom are next to each other. The sports field is in the middle of the school. The school has a very convenient layout, allowing each classroom to be reached easily from the main administration building.

Most of the students and teachers come to school by motorcycle. Public transport is available in the morning when school starts and the afternoon when school ends. The school location is not convenient but it is in a quiet area which is good for learning. The students' parents come from a range of economic backgrounds, most from middle and low income families (Field note, 23/1/2012).

There are 21 classes consisting of seven classes of Year 10 students, seven classes of Year 11 students, and seven classes of Year 12 students. There are 
approximately eight hundred students with seventy teachers in this school. The principal is assisted by five deputy principals.

\section{English teaching in the school}

English is not spoken much in this school; it is not a medium of instruction in the teaching and learning process. The students generally use English only during their English classes. Students learn English twice a week for 90 minutes in each meeting (Field note, 27/1/2012).

Students seem to understand the benefit of learning English for their future. They appear to study hard to improve their English. They realise that they need English for their university study and their future career. One of the students in the focus group commented:

I realise that I need English for my future career and university study, motivating me to learn English. My brother told me that at university level, textbooks are mostly written in English (Focus group, 10/2/2012).

However, some students thought that English is difficult to learn. As one commented:

I like English but I still find that it is hard for me to learn. I know it is important and I do not understand why it is so difficult for me. Some of my friends enjoy learning it (Focus group, 10/2/2012).

Most students learn English in the classroom only; this does not support their English communicative skills both in spoken and written language (Field note, 23/1/2012).

\section{The teacher}

Yuke had taught in this school for 23 years. She graduated from a teachers' college with a degree to teach at high school. She continued her study and obtained a Masters degree at the local university. 
She often used action research to solve problems in class. She said that she wanted to help her students communicate in English. She has completed two action research projects in her classroom. Her first project focused on helping students improve their writing skills and the second on motivating students to enhance their speaking skills. She was eager to help her students gain more knowledge and skills in English (Interview, 27/1/2012).

Yuke indicated that she was keen to find ways of teaching English effectively. She has attended seminars and conferences to learn more about teaching English. She is enthusiastic about helping her students and her colleagues. She was highly empathetic to those around her. She was sought after by colleagues for ideas and opinions on teaching issues and other, more general 'life' problems as well (Field work, 27/1/2012).

Yuke has a distinctive style of dress at school. In this town, there was a regulation relating to work clothes. The dress was formal and women should wear a suit. However, she was not comfortable with a skirt, so she wore pants instead. She knew it was against the rule but she said that she was not confident wearing a skirt when teaching in the classroom. As she explained:

I do not mind who the headmaster of my school is. I just need someone who understands my style of dressing. I do not feel confident wearing a skirt at work. If I wear a skirt I will be more concerned with that rather than my teaching. (Interview, 27/1/2012).

Yuke had a warm and outgoing personality and this made it easy for her students to communicate with her. She did not create a distance between her and her students. She told jokes to her students inside and outside the classroom. The students respected her but were not afraid of her (Field note, 27/1/2012).

Yuke was involved actively in the English teacher association in the school and in the town. She was happy to shares ideas and teaching experiences with her colleagues. She was liked by her students and also by her colleagues. Her students and her colleagues felt happy to be with her (Field note, 27/1/2012). 


\section{Teacher attributes}

Yuke was one of the most popular English teachers in the school. During the observation, she displayed a warm personality and came into the classroom enthusiastically, smiling and greeting her students warmly. The classroom looked inviting and lively. She encouraged her students to speak by helping them with vocabulary and language expression. She let her students speak English and when the students did not know an English word she helped them by translating the word (Field note, 27/1/2012).

In the focus group, a student responded to her teaching and classroom personality:

I like studying English with my teacher. She arranges various activities in the classroom, avoiding the monotonous. As a result, I am not afraid of speaking English (Focus group B, 10/2/2012).

Yuke built a close relationship with her students. She smiled, told jokes and explained the lesson in a relaxed atmosphere. When I observed her class her students were free to express their ideas and ask questions. She did not get angry with wrong answers or mistakes made by her students.

She encouraged her students to use English both inside and outside the classroom. She communicated mostly in English with her students outside the classroom, an uncommon practice in Indonesian high schools (Classroom observation, 3/2/2012).

\section{Teacher practices}

\section{Classroom teaching and learning}

Before starting her lesson, Yuke usually reviewed the previous lesson. She said that she needed to do this to help the students settle and be ready for the new lesson.

Students need to understand the previous lesson before continuing. I usually review the previous lesson to make sure it has been understood (Field note, 3/2/2012).

Yuke's teaching approach involved explaining the lessons, giving examples, and giving students time to practise. Students were allowed to practise alone, in pairs or 
in a group. Yuke thought that by giving students time for practise, they would gain English skills faster. She said:

My students enjoy practising English. I give them a lot of time to practise speaking with their classmates. In our large classes I usually put them to work in pairs or in groups. I seldom ask them to speak in front of the class alone. I don't think that's very interesting for them. When I ask them to deliver a speech most of them memorise the script (Interview, 1/2/2012).

Yuke implemented a three-step approach as part of her teaching strategy: presenting, practising, and producing. The students liked this strategy because it helped them obtain more skills in English. As one student explained:

I like any activity that makes me use English, but I don't like it when the teacher asks me to do an activity or task without explaining how to do it (Focus group B, 10/2/2012).

The students reported that they felt relaxed when they studied with Yuke. They said this helped them to understand and use English. One stated:

I like it when my teacher speaks English with me. She doesn't force me. She invites me to speak and if I have a problem with vocabulary she allows me to use Indonesian and then helps me with the English words I don't know (Focus group A, 10/2/2012).

It seems that Yuke understood her students' preferences for learning; she applied strategies that suited her students' needs. The students felt relaxed when studying with her. It made students more engaged in their learning.

\section{Grouping students}

Yuke often asked her students to work in a group. She thought it was more effective to group students and give them time to share ideas rather than work alone. She said it took time if she asked the students to work alone and then perform the task in front of the class one by one. Her classes generally consisted of more than 30 students. She said: 
Our classes are large. Usually one class consists of 35 to 40 students. I usually put them in pairs or in groups. I think asking students to work in pairs or groups gives them more time to practise and help each other. I usually put a clever student in each group and appoint her or him to be a chairman of the group (Interview, $1 / 2 / 2012)$.

Yuke usually organised her students in five to seven groups. She made sure that each group had at least one high achiever to help the group activity run smoothly. She identifies a chairperson for each group. She said that her students needed someone to give examples and to make sure the group task is accomplished:

For all the classroom activities I select active and smart students and share them around the groups. These students are the motivators for their group. They play a role as group chairman and start the activity. They help to motivate others to complete the activity (Stimulated recall, 3/2/2012).

The students enjoyed working in groups. However, some students said that they felt a litle bored when weak students could not understand the activities and did not want to practise in the group. As one student said:

I feel upset when my friends do not know what they should do. It is tiring to explain if they do not understand (Focus group A, 10/2/2012).

Another student in the focus group stated that she does not really enjoy working in a group. She said that some of her friends did not use the time to practice. When she explained and gave an example of how to do the task her friends still did not understand.

I do not like if my friends in the group do not understand the task. I give examples but it is difficult for them to understand. Sometimes they are too lazy to practise (Focus group, 10/2/2012).

Yuke controlled each group by walking around the classroom to make sure that every group could do the task properly. She offered help if the group needed it. She said that it was important to cover each group. Sometimes students were not confident asking questions in front of their classmates. The students usually asked her questions when she came to their group. 
My students are sometimes too shy to ask questions but when I come to them they usually ask questions. Maybe they just want to make sure that they are doing the task properly (Stimulated recall, 3/2/2012).

In addition to group work activity, Yuke often asked her students to work in pairs. She asked her students to work with the person who sat next to him or her. She understood that most of her students sat with the friend they felt comfortable working with.

I ask my students to work with their peers. It is usually a friend who sits next to him or her. My students really depend on their friends (Interview, 1/2/2012).

Yuke seemed to know her students; she grouped her students based on ability so they could share ideas and help each other. She offered help to make sure that each group or pair could do the task properly.

\section{Cycle stand activity}

For one group work activity, Yuke used a cycle stand exercise. In this kind of activity students were asked to work in groups of five to seven. One student started by standing up and saying one sentence or expression based on the topic of the lesson. After saying the sentence he or she posed a question to the next student. The second student would answer the previous student's question and ask a question for the next student in the group. This activity usually ran for about ten minutes before moving to the next activity based on a different expression (Classroom observation, 3/2/2012). Yuke found the activity successful. As she said:

I have written my classroom action research on the cycle stand activity. I am sure that this activity works well in my classroom. I can tell that many students benefit from this activity (Interview, 1/2/2012).

Yuke found the cycle stand activity helped her students and she believed it was useful for not only speaking practice but also grammar (Interview, 1/2/2012).

I find that the cycle step strategy works very well in my classroom. I ask students to work in groups of five to seven. Each student takes a turn to stand and say one sentence or language expression, and then ask the next student a question. For 
example: "I feel happy, how do you feel today?" The next student does something similar, and so on, until everyone has had a chance to use English in that cycle. If I see a student with a problem expressing a sentence or language expression, I approach the group and help (Interview, 1 /2/2012).

The students reported that they liked this activity and felt it helped improve their ability to use English. As one said:

I enjoy practising English in class. I like the cycle stand activity because it is new to me. I usually practise language expressions by making a dialogue and performing it in front of my classmates (Focus group, 10/2/2012).

Another student also commented:

I like the cycle stand and other activities that make me use English. The cycle stand activity is interesting because everyone shares ideas. For me, it was a new way to practise English (Focus group, 10/2/2012).

Yuke's students mentioned that they liked activities involving body movement; the cycle stand activity was effective for them because students moved their bodies when standing. They enjoyed activities like games or drama. They said:

Drama or role play activities make the classroom lively and relaxed. We can use our own sentences (Focus group, 10/2/2012).

Yuke realised that her students liked physical activities so she used these in the classroom. She understood that it was important to implement a range of classroom activities. She indicated that she was sure the cycle stand activity was effective, having conducted a form of action research. She knows that her students like to work together rather than alone (Interview, 1/2/2012).

Yuke said that she has to work hard to coax her weak students to express their ideas or ask questions during the learning process. She said she tries to do so:

$\ldots$ by giving the students attention. Building a positive relationship with students is really important. Do not get angry with them if they make mistakes. Mistakes are 
natural in learning English. When they do not behave, I go to them and talk (Interview, 27/1/2012).

In summary, from the classroom observation, it appeared that the cycle stand activity helped weak students build their confidence to practise. When I observed the classroom, weak students began to hear and look at examples from their friends in the group which they then practised themselves (Classroom observation, 3/2/2012).

\section{Reading Comprehension}

The Indonesian curriculum expects students to have skills in reading comprehension so as to comprehend international textbooks or journals. In an English classroom, teaching reading ca be challenging if students have to sit quietly in order to comprehend a text and then answer questions. One student reported:

I do not like reading because it is very difficult to understand a text. It is very boring when the teacher asks us to read a text and then answer comprehension questions. How can I answer the questions if I do not understand the text? (Focus group, 10/2/2012).

Yuke said that a problem faced by her students in reading comprehension was their lack of vocabulary. Students found it hard to understand a text that uses academic or low frequency words (Interview, /1/2/2012). She speculated:

I think reading is not really interesting for my students because they need to understand a text in order to answer the questions. They have problems with reading due to lack of both vocabulary and reading comprehension strategies (Interview, 27/1/2012).

Yuke understood that she needed to teach reading comprehension strategies to her students. Comprehension is a crucial skill in English, requiring a lot of practice. She reported that she trains her students to use contextual clues as a reading comprehension strategy.

I know that my students need to be taught how to read and comprehend a text. But you know, sometimes I just run out of time. I find that, besides vocabulary, many 
students have a problem with reading strategies, especially reading strategies to aid comprehension. So I give them questions and then ask them to find the answers in the text (Interview, 27/1/2012).

Yuke also commented:

I use two different texts when I teach, one for exercise and one for the post-test. When they practise, I teach them how to comprehend and answer questions, and the second text I use for the post-test. I also allow them to work alone or in pairs. For pair work they cannot discuss with other pairs (Interview, 27/1/2012).

Yuke realised that reading skills are important and one of the focuses in the English curriculum. She helped her students to comprehend texts by teaching them reading strategies.

\section{Practising English}

Yuke stated that most of her students are motivated to learn when they are given the opportunity to practise their English. Yuke provided plenty of opportunities for her students to use English in the classroom. She also invited her students to use English outside the classroom. She wanted to give students every opportunity to use English,

...for example by giving them time to practise speaking or using language expressions. Encouraging English could also be done by giving students a chance to read a text aloud, in turns. In our large classes I usually put them to work in pairs or in groups. Organising individual practices takes a very long time. Most of my students prefer pair work or group work (Interview, 1/2/2012).

The students indicated that they enjoyed having a lot of time to practise their English. They liked practising their English, rather than just listening to their teacher explain. A student commented:

I like using English, especially if there is someone that I can talk to. Sometimes my friends tease me if I use English. Many of them will say that I show off if I use English. I just enjoy practising my English. It is fun (Focus group, 10/2/2012). 
When I observed her class, Yuke used English a lot, but she also used English to communicate with her students outside the classroom. Her students became used to speaking English with her. Yuke tried to make English-speaking a habit. She believed that when her students used English in their daily lives they would gain English skills easier.

I want my students to use their English to communicate with me and with their friends. It will help them develop English skills. I do not oblige them to have perfect English. I just want them to use English, to make using English their habit (Interview, 27/1/2012).

Her students enjoyed the opportunity to practise their English. They tried hard to use English as much as possible, especially outside the classroom. Using English outside the classroom was encouraged to familiarise them with using English for daily communication. A student reported that:

I like speaking English. My teacher supports me using English with her and with my classmates both inside and outside the classroom (Focus group, 10/2/2012).

Before asking students to practise using English, Yuke helped the students by giving examples and requiring them to practise substituting words or expressions. She used activities such as these to challenge her students in their practice of English.

As already noted, Yuke invited her students to use English in each lesson. She discussed the consequences of not using English. She let her students decide if there should be a fine for not using English, and kept watch on this regulation in order for the class to run well. However, this strategy was only applied for half a semester (Interview, 27/1/2012). Using English was a group consensus in her classes. A group consensus is in line with Dörnyei's (2001) strategies and belief that any formal commitment should be consistently observed.

I tell them that in order to use English they have to practise. I tell them that they need to use English, or Indonesian sometimes, but that they are not allowed to use local language in the classroom. Usually, after practice, I give an exercise and then evaluate this. Sometimes I announce who is getting the best mark for that particular exercise in order to motivate everyone to reach that standard (Interview, 1 /2/2012). 
Yuke and her students agreed that they would use English as a medium of communication in the classroom. They agreed to pay a small amount of money if they did not use English. However, as this agreement was not controlled consistently by Yuke some students appeared to ignore it. Several students wanted the agreement to be enforced because they found it helped them to speak English. One reported:

\footnotetext{
We have a regulation that if we use another language in the classroom there will be a fine. We have to pay a small amount of money. The fine system worked for a time, but now my classmates are too lazy to speak English. Maybe the teacher should run this regulation again. The money paid in fines will be for us. At the end of the semester we can use the money for an excursion or other activity (Focus group A, 10/2/2012).
}

In summary, communicating in English was one of the strategies that Yuke used to help her students gain English skills. She encouraged her students to use English inside and outside the classroom.

\section{Correcting mistakes}

When students have a problem with vocabulary, they often spoke in Indonesian and Yuke repeated the words or sentences in English. I noted that students felt comfortable with this because Yuke did not show that she was correcting them; the action seemed natural (Classroom observation, 3/02/2012).

It seemed clear that Yuke and her students saw corrections not as embarrassing but as a natural part of learning a new language. I found that there were no negative responses from the students when Yuke repeated and corrected their sentences. The close relationship between the teacher and students may have helped. They talked in a relaxed atmosphere whether inside or outside the classroom (Field note, 3/2/2012).

\section{Feedback}

In Indonesian schools, the semester result is usually an accumulation of classroom participation, a block test, a mid semester test, and the semester test. Classroom participation and the block test are conducted by teachers. The mid semester test is also usually conducted by the school. The semester test is usually conducted by the 
school, but in some regions the department of education organises the semester test.

Yuke had a particular strategy which she used to evaluate her students' learning. When she gave a test, she asked her students to sit in pairs. Students could work together with their partner only, not with other students. Students were allowed to select their own pairs. However, students who could work alone were challenged to do so. They sat in a different row when they answered the test. Students had the choice of working alone or working with another student. Yuke wanted them to be consistent with their choice. She said that she wanted her students to be honest and build their self-confidence.

I do not want my students to cheat in a test. If they think that they need to get help or discuss to answer the questions in my test they can choose a friend with whom to do so. If a student thinks that he can do the test himself I give him an opportunity to do so. I just want to make it fair for them. You know that sometimes the smart students do not feel comfortable if they do not share the answer when their friends ask them (Interview, 27/1/2012).

Yuke stated that most of her students would choose their own partner, usually of a similar ability. Even in the daily learning activity, she found that students of similar ability would work together.

I find that my students usually find a friend of similar ability. The average students work with their similarly able friends and the slow students also work together (Interview, 27/1/2012).

Yuke said that she got feedback from her students about her teaching, but usually only from their facial expressions or body language. They did not usually give her feedback in person.

I get feedback from the students' responses. If they like my teaching strategy they will be motivated to learn. If I use a certain strategy and the students seem lazy and unmotivated, then the way I have taught must have been un-motivating. I find that giving them the opportunity to use or practise English is really motivating. I also realise that most of my students do not have the self-confidence to work alone. They like to work in pairs or in groups. The students are really happy and motivated to 
learn if they know that their work will be evaluated and that the mark will be a part of their semester academic result (Interview, 27/1/2012).

Yuke's way of assessing her students' learning seemed suitable for her students. The students also gave feedback on Yuke's teaching practices.

\section{Other factors}

\section{English Curriculum in Indonesia}

Yuke said that the English curriculum in Indonesia does not link well between each level of schooling. She thought that the senior high school curriculum should continue from the junior high school curriculum. She mentioned that many topics and materials were unconnected. However, she wondered why her students did not have enough basic English after studying English for three years in junior high school. Some students even started learning English when they were at elementary school. As she said:

I think the junior and senior high school English curricula do not link and match. Some points are redundant (Interview, 27/1/2012).

She also found that the curriculum for senior high school did not match well with the English curriculum at university.

It is really strange that in senior high school the curriculum is focused on English skills acquisition, while the university-entrance test and the university English refers to TOEFL. The university-entrance test and university English focus more on grammar than skills. So as a teacher of English the balance is quite hard to maintain (Interview, 27/1/2012).

Yuke felt the need to help her students pass the English final state exam but she also wanted to help her students pass the university-entrance test. She said that she could not do both at the same time because the two tests had a different focus.

I think the senior high school curriculum for English should synchronise with the university-entrance test. I do not understand why the university-entrance test requires a higher level of English (Interview, 27/1/2012). 
Yuke suggests that the curriculum of English should be revised and evaluated again. The department of education should listen to teachers who were the change agents in the school.

The government should consider teachers of English when they write a curriculum. They should involve teachers of English to design the English curriculum. How do they know how to teach the students if they have never taught students at school? Teachers are best equipped to decide on good material for students (Interview, 27/1/2012).

Yuke argued that the curriculum is not in line with what students require by way of English skills.

I realise that the curriculum is boring for students. So I have to practise many ways of teaching. I try to not be monotonous. Students do not like to keep calm. They want to practise, discuss, and walk around the class. I usually make the classroom atmosphere lively. The students feel free to practise (Interview, 27/1/2012).

It seemed that Yuke was not happy with the English curriculum. She suggested that teachers should be involved in developing the curriculum or in revising the current curriculum.

\section{Summary}

Table 6.1 below provides a short summary of the key factors that characterise Yuke's teaching. This material is used in the cross case analysis in chapter 8. 
Table 6.1: Summary of Yuke's teaching attributes and practices

\begin{tabular}{|c|c|}
\hline Attributes and practices & Illustrations \\
\hline $\begin{array}{l}\text { Attributes } \\
\text { - Warm classroom manner } \\
\text { - Using English inside and } \\
\text { outside the classroom }\end{array}$ & $\begin{array}{l}\text { Smiling, greeting students warmly. Building a close } \\
\text { relationship with students. } \\
\text { Outgoing personality garnering communication with } \\
\text { students. }\end{array}$ \\
\hline $\begin{array}{l}\text { Practices } \\
\text { - Reviewing lessons } \\
\text { - Grouping students }\end{array}$ & $\begin{array}{l}\text { Setting up students for a new lesson. } \\
\text { Placing one high achiever in each group. Walking around } \\
\text { the classroom, offering help. }\end{array}$ \\
\hline $\begin{array}{l}\text { - Implementing a range of } \\
\text { activities }\end{array}$ & Using cycle-stand activity. \\
\hline - Reading comprehension & Teaching students contextual clues. \\
\hline - Correcting mistakes & $\begin{array}{l}\text { Correcting students' mistakes naturally by repeating } \\
\text { students' sentences. }\end{array}$ \\
\hline - Practising English & $\begin{array}{l}\text { Encouraging students to use English inside and outside the } \\
\text { classroom. Consequences for not using English. }\end{array}$ \\
\hline $\begin{array}{l}\text { - Reinforcing the importance } \\
\text { of English }\end{array}$ & $\begin{array}{l}\text { Reinforcing the advantages of English skills, using her } \\
\text { experience as an example. }\end{array}$ \\
\hline - Giving feedback & Students allowed to sit tests personally or in pairs. \\
\hline $\begin{array}{l}\text { - Managing unmotivated } \\
\text { students }\end{array}$ & Setting classroom rules at the beginning of each semester. \\
\hline $\begin{array}{l}\text { Other factors } \\
\text { - English curriculum }\end{array}$ & $\begin{array}{l}\text { The curriculum does not meet the students' learning needs } \\
\text { for English skills. The curriculum is unconnected between } \\
\text { each level of school. }\end{array}$ \\
\hline
\end{tabular}




\section{CHAPTER 7 \\ Case Study 4: Arfan}

\section{Type of school}

The final school in this study is the latest high school which has been opened approximately 5 years in the town. It is a government school that has yet to become popular. The academic standing of the school is not as high as the other three high schools in the town (Field note, 16/2/2012).

In addition to its academic focus, the school specialises in sport. The school has good facilities for sports but still needs more facilities to further its students' academic achievements. The school is classified as a regular standardised school.

\section{The layout and structure of the school}

The school is located about four kilometres from the town centre. There is no regular public transport to the school except in the morning and the afternoon when the school starts and ends. Most teachers and students use their own transportation.

The school is surrounded by rice fields; residential houses are located only in front of the school. In the tea break or lunchtime, students usually leave the school area to buy food. The school has one canteen but most students prefer to buy their lunch outside the school.

The school building is only one story. The main building is in the front of the school grounds and consists of the principal's office, deputy principal's office, teachers' staffroom, and administration office. There is a sports field in the middle of the school which is surrounded by classrooms. The school area is green with plenty of trees and flowers.

The school's location is quite hilly and occupies about four acres. Some buildings are higher than others. The school consists of basic school buildings such as offices, library, canteen, and classrooms. There is no laboratory, art room or sports gym. 
The location is well away from busy traffic. The air is fresh and the atmosphere is good for teaching and learning. However, it is quite hard to reach this school since it is located in a hilly area and the road is steep. It needs extra care to drive or ride vehicles to the school. The school location is not convenient for most students and their families.

\section{English teaching in the school}

Arfan reported that it is challenging to motivate students to use English in the classroom. Their interest in English is not high. The students' ability to communicate in English is not good. Arfan spends extra time preparing and delivering lessons so that students can reach the standard of English achievement as set by the curriculum (Interview, 23/2/2012).

Arfan reported that students' English achievement in senior high school was also influenced by their English achievement at their previous junior high school. Most students who study in this school are from rural backgrounds. Generally students have entered this school because they were not accepted into other, more highly sought after high schools (Interview, 23/2/2012).

Some students were talented in English and were able to use English for classroom communication. However, there were not many students like this. In each classroom, perhaps only three to five students were able to reach the standard level of English for high school students as set in the curriculum (Interview, 23/2/2012).

The more talented students were keen to use and practise their English. They tried hard to communicate in English with their teacher in the English classes. Outside of school hours, some students enrolled in extra English courses. They realised that they needed to be able to speak English, not only for their university study but also for their future careers. They reported that their classroom learning did not give them enough knowledge and skills in English (Focus group, 14/3/2012).

Arfan recognised this situation. He looked for strategies to motivate those students whom some of his colleagues think lack ability. Arfan liked to develop or use strategies that work in his classes. For example, he argued that games and songs are fun and motivating. He was keen on finding new and innovative games and he shared ideas with his colleagues. It should be noted that teachers of English in this 
school were actively involved in the English teacher association in this town (Field work, 16/2/2012).

Some teachers of English in this school, charged with enabling students to learn English, felt helpless to do so. They felt that students were unmotivated to learn. They perceived that their students were average or low achieving students and thus their ability to gain English skills was reduced (Field work, 16/2/2012). Unlike his colleagues, however, Arfan seems optimistic that he can help his students to learn English.

\section{The teacher}

There are twelve classes of students in this school, four classes of Year 10, four classes of Year 11, and four classes of Year 12. There are four teachers of English. Each teacher teaches three classes of students. They usually teach English in parallel at the same class level. This makes it easier to prepare the lesson (Field work, 16/2/2012).

Arfan had taught English for 20 years although he was new to this school. He taught English in another town before shifting to this school. He was an experienced teacher. He had a qualification to teach in a high school as his first degree. He continued his study to obtain a Masters degree in education. He had undertaken three classroom action research projects to obtain solutions for his classroom problems. He also prepared student worksheets to suit his students' learning needs. He appeared to be an innovative and creative teacher (Field note, 16/2/2012).

Arfan was the chairman of the English teacher association in the town. He was actively involved in school management; he had been a deputy principal, a student advisor, and a school treasurer. He cared about the problems the school encounters. He was often approached for help and discussion dealing with classroom or other common problems (Field note, 16/2/2012).

Arfan liked to share his knowledge and experience with other teachers. He presented his classroom action research to the teacher association forum. He also shares his knowledge when he attends seminars or conferences relating to English teaching. He encourages other teachers of English in this town to conduct classroom action research (Field note, 16/2/2012). 
Arfan was open, understanding and has a great sense of humour. His colleagues and students appeared to like him. He had a warm personality and many colleagues discussed their problems with him. He was a popular teacher of English in the school (Field note, 16/2/2012).

\section{Teacher Attributes}

\section{Classroom behaviours}

Arfan had an interesting classroom manner. He was friendly and easy going and liked to answer his students' questions. He taught enthusiastically and this encouraged his students to be motivated to learn. He explained the lesson clearly and if his students still did not understand he would explain it again. He welcomed questions from his students (Classroom observation, 7/3/2012).

Arfan argued that a teacher's classroom manner was an important factor determining an effective teaching and learning process. He added that teachers should be able to build a strong relationship with their students:

Besides teaching strategies and teaching materials, the teacher's classroom behaviours and their emotional bond with students determine the success of the teaching and learning process (Interview, 23/2/2012).

The students in a focus group said that they like Arfan's classroom manners. He was friendly and approachable. The students could talk to him inside and outside the learning period. As one commented:

I like the teacher. He is friendly. When I have a problem and I ask him for help, he will answer my question promptly. He explains the lesson enthusiastically. This motivates us (Focus group, 14/3/2012).

Arfan showed his dedication to teaching. He discussed the problems faced by students in learning English with them (Classroom observation, 7/3/2012). One of his students commented:

$\mathrm{He}$ is always happy to explain things even if some students do not really pay attention. He just goes on. His enthusiasm motivates us (Focus group, 14/3/2012). 
Another student said that Arfan was very patient in explaining the lesson. He used a range of strategies. He gave many examples. This helped his students understand what they were being taught. One student commented:

I like the teacher's way of explaining the lesson. He has many different ways of explaining the topic and gives many examples. He is so patient answering my questions (Focus group, 14/3/2012).

Most of the students in the focus group interview said that a key factor motivating their classroom learning is the teacher. The students believed that interesting learning depended on the teacher. The way a teacher explained lessons and how the teacher created the learning atmosphere was very important. As one remarked:

I think the most important thing is the teacher. If the teacher is interesting the learning will be interesting too. But if the teacher is boring the learning will be boring too (Focus group, 14/3/2012).

One student mentioned that he likes studying with Arfan, not because of his appearance but because of his classroom behaviour. His friendliness and outgoing personality impressed his students. Another student said:

My teacher is not handsome, but we like to study with him because of his warm personality. He has a good sense of humour. The learning is so fun and relaxed. We feel free to express ideas and opinions (Focus group, 14/3/2012).

In summary, Arfan was warm and friendly to his students. The learning atmosphere was relaxed and students felt free to ask him questions. They enjoyed learning with him. He had a good sense of humour. The students could approach and talk to him inside and outside the classroom.

\section{Teacher practices}

Arfan believed that a teacher could motivate students to learn English in the classroom by providing interesting activities. He stated that a teacher should know what makes his students motivated to learn English in the classroom. He thought that a teacher has a role as a motivator in the learning process: 
We have to know what the most interesting methods are for our students, whether they enjoy games, songs, and telling jokes. Jokes are always an interesting way to arouse students' interest in learning (Interview, 23/2/2012).

Arfan seemed to enjoy his work as an English teacher. He was optimistic that he could motivate his students and help them gain English skills.

\section{Reading Comprehension}

Arfan stated that a problem most students encountered was a lack of vocabulary. He helped his students comprehend texts by discussing the main vocabulary found within them. He taught his students how to retell the main points of a text.

I give them as many opportunities as possible to ask questions in the hope that they will be motivated to get help when they need it. The problem that students mostly face is a lack of vocabulary. Sometimes they are too lazy to learn because they are overwhelmed by the number of words that they do not understand. To help them, I give them some key words that will appear in a text. After reading, I ask them to retell in their own words what they have just read (Interview, 23/2/2012).

Arfan understood his students' level of English. In the classroom observation, it was evident that he helped his students to understand a text by explaining and answering his students' questions patiently.

\section{Using audio resources}

Arfan was an innovative and creative teacher. He explored new strategies in his teaching. He reported that his students enjoy learning from videos that he downloads from the internet. Students first watched a short movie and then he asked them questions. From another video, he gave grammar exercises. A picture was presented and when students click on the answer, there was a feedback from the video. This appears to be a motivating activity for his students. However, Arfan commented that it is not easy to find videos that suit the learning topic.

Students are motivated if I use video or audio in the classroom. Watching videos is always interesting for my students. Even weak students seem motivated when I use video as the learning media. However, I find it is not easy to find appropriate videos. Sometimes I find suitable videos on the internet, but this is rare (Interview, 23/2/2012). 
His students reported that they enjoy learning by watching videos. They said it was a new learning experience for them, especially in reference to answering questions by pressing right buttons. As one said:

I like learning by using games or activities from videos. Learning this way is a new experience for me. It is fun because I know directly whether I have given the right or wrong answer (Focus group, 14/3/2012).

Arfan tried hard to find ways of motivating his students to learn and he found audio learning resources that were interesting for his students.

\section{Games}

Arfan commented that games are interesting for his students. He used games from the internet or from the English teacher association workshop in town. He was enthusiastic about finding new games. He enjoyed discussing games and other classroom activities with other teachers. He adopted games and played them in his own classroom.

We need to make students engage in learning as much as possible, for example, by using a "word chain" game, or "find someone who" game (Interview, 23/2/2012).

One student reported that he was more motivated when the teacher gave the class a challenging activity, making him think harder and motivating him to find the answer:

I like games, especially games with challenging activities. I like crossword puzzles or quiz games (Focus group, 14/3/2012).

Arfan appeared to manage his classroom teaching and learning well. His students seemed comfortable in the classroom. He used innovative and challenging strategies in his teaching. His students enjoyed the classroom teaching and learning process and he created a relaxed atmosphere so that the students felt free to ask questions or deliver their opinions. 


\section{Grouping students}

Beside the use of pair work, Arfan said that he also grouped his students for some learning tasks. The group work helps weak students to learn from their peers. Arfan noted that if he did not monitor each group, the weak students might do nothing and let their friends answer the question. He needed to make sure that each group stayed on track.

I put them in group so they can help each other. But sometimes weak students only wait for their friends to answer the questions or tasks. I have to go around the classroom and check whether they are on the right track (Interview, 23/2/2012).

Arfan knew his students well, so it was easy for him to place students with a suitable peer to work on a project together.

\section{Feedback}

Arfan believed that evaluating students from their daily learning process was more appropriate than just obtaining a mark from a test.

I tell them that their participation is important and has a connection with their mark. The way the teacher evaluates students determines students' motivation too. I emphasise to my students that I evaluate their learning process not the learning product. I like to consider their mark from their classroom participation rather than the test (Interview, 23/2/2012).

He stated that not all students are good at exams. Some students did not work well when they were under pressure and achieved low marks in exams.

I prefer to evaluate my students by their daily learning activities rather than from the test. Not all students are good at the test; most of them forget the lesson that has been discussed just a few weeks before (Interview, 23/2/2012).

He explained to his students that their classroom participation was considered in their semester result. He found that this strategy increased students' motivation. He used a particular strategy when marking students' classroom participation. He tallied each time students participate in a classroom activity. 
I tell the students since the beginning of the semester that their participation will be considered in evaluation. I reward their participation each time by giving a tick that will be counted as their mark (Interview, 23/2/2012).

Arfan got feedback from his students for activities that he conducted in the classroom. His students usually commented on activities, indicating whether they like doing them. His students felt free to express their opinions. Arfan believed that the emotional engagement of his students influenced their motivation.

I find strategies from books or the internet and I try them out in the classroom. If the students respond positively by participating enthusiastically I will use that strategy in my other classrooms. Sometimes yes, they say that a particular activity helps them learn and keeps them happy in the classroom. I seldom ask them directly; I prefer to judge from their responses. I think the teacher's emotional bond with their students really determines learning and motivation (Interview, 23/2/2012).

Arfan built a strong relationship with his students. They were comfortable discussing the learning activities they did in the classroom. He assessed students' learning through the learning process rather than by a test result alone.

\section{Homework}

He gave homework to his students and checked homework completion at the beginning of the next lesson. He considered that the homework was a part of the students' attendance. If a student did not do the homework he wrote "absent" on his attendance list book, but students could do the homework later on and show it to him at the following meeting. Homework increased students' discipline and gave them a chance to practise English outside the classroom. As Arfan explains:

I give them homework and in the next meeting I check the homework. I consider the homework as part of their attendance. If they do not complete homework, I mark this as absent but I give them the opportunity to do it again and, if they do so, I will change their attendance record in my classroom evaluation book (Interview, 23/2/2012).

Classroom attendance was important, and students were not allowed to be absent without good reason. Some teachers took students' attendance as part of the students' classroom participation mark (Field note, 16/2/2012). 


\section{The use of $L 1$}

During the observation, Arfan explained the lesson by using Indonesian more than English. He said that using Indonesian helped his students. He stated that it was still difficult for his students to understand him if he used English.

My students still have limited vocabularies. I need to explain the lesson by using more Indonesian than English otherwise they will not understand and get bored. You know when students are bored as they will do other things like drawing pictures or writing on their books. They will even play with their hand phones (Stimulated recall, 7/3/2012).

He used English at the start but explained lessons in Indonesian. His students tried to use English for simple conversation. The students also used English for daily communications, for example, if they want permission to go to the toilet or to apologise for lateness (Classroom observation, 7/3/2012).

Arfan stated that when students did not understand him, they would look at him blankly and sometimes engaged in activities unrelated to learning. He assumed that the use of L1 in the classroom makes it easier for his students to understand lessons:

If they do not understand they will not do the task and just look at me with confusion. They will do other things like drawing pictures on their books or sending messages by throwing paper notes to their friends (Interview, 23/2/2012).

However, in the focus group one of the students said that she was motivated when listening to a teacher-or someone-who could speak English fluently. She needed someone to help her practise her English.

If I hear the teacher or anyone else who can speak English fluently it motivates me to learn harder (Focus group, 14/3/2012).

This suggests that there was a different expectation in the use of $L 1$ between Arfan and one of his students. This difference occurred because Arfan was concerned about the expectations of most of his students who preferred him to explain the lesson by using L1 (Interview, 23/2/2012). 


\section{Planning the Lesson}

Arfan planed lessons to suit his students' needs. However, sometimes he changed his plans to suit the classroom situation. He said that his students' ability also influenced his way of conducting the classroom. Sometimes he prepared a game, but if he then realised that his students might not be able to play the game properly, he would not use it or he would change it with another game or activity.

I read the material from the curriculum and make a lesson plan accordingly, but if the situation in a particular classroom means it is not possible to run the plan, I change the plan. For example, if, having planned to play a game, I find that the students' ability is not up to the standard required; I will change plans and go ahead with other games or activities. The ability of the students also influences my choice of teaching strategy (Interview, 23/2/2012).

Arfan usually makes a lesson plan for each semester. It is a requirement of the school that each teacher writes a lesson plan for each semester. The lesson plan should be signed by the school principal (Field note, 16/2/2012). Arfan mentioned that planning lessons is important as this helps to ensure that the teacher is on the right path. He said that in planning the lesson the important thing to consider is the students' level of English and how to teach a topic with a suitable teaching strategy (Interview, 23/2/2012).

\section{Other factors}

\section{Peers}

Arfan said that his students were also influenced by their peers, especially the one who sat next to them. He found that a motivated student could help a neighbouring peer to be motivated. In turn, an unmotivated student was a bad influence on his neighbouring peer, distracting the latter student from the lesson.

I find that peers also influence students. If a student sits next to an unmotivated student they tend to talk to each other, so I move the unmotivated students to sit next to the more motivated ones in order to keep them learning (Interview, 23/2/2012).

Arfan would move his students to avoid the problem of a motivated student being influenced by an unmotivated peer. He manages this so that students did not feel offended. First, he reminded his students to be on track and not to talk to each other 
when he is explaining lessons. If a student still did not behave properly, he would move the student to sit with a different peer.

I also sit students with friends who are matched in ability. If I find a student talks within their pair, I sit them beside another peer. I sometimes position weak students to work with clever ones. I want them to learn (Interview, 23/2/2012).

He did not have a problem moving his students because they knew that being moved was a result of bad behaviour:

Usually they understand that if I move them, it means that there is something wrong. For instance, that they have talked out of turn or not listened to me or their peers (Interview, 23/2/2012).

His students usually sat with classmates whom they choose themselves; students usually sat with their peers with similar learning habits or ability. Arfan usually asks students to carry out tasks in pairs. On most occasions, students directly worked with a friend who sat next to them (interview, 23/2/2012).

\section{Classroom facilities}

Arfan stated that the learning context also influenced students' motivation. Students were motivated when they felt that their classroom was comfortable for learning. $\mathrm{He}$ said that his school did not yet provide students with good learning conditions. For example, his students sometimes needed to find their own chairs or borrow one from another classroom if one of the chairs is broken. Sometimes they have to share a table. He thought the physical classroom condition influenced his students' motivation.

Another thing that influences students' motivation is the classroom learning context. The physical classroom environment will influence students' motivation. If students learn in a nice classroom they will be motivated compared to the classroom with an uncomfortable environment. In this school the physical classroom condition does not really support students because sometimes the chair is not comfortable and even sometimes the student has to share the table (Interview, 23/2/2012). 
To sum up, Arfan mentioned several factors that influence students' motivation to learn English in the classroom such as the teacher/student relationship, teaching strategies, teaching materials, classmates, teaching media, and the teacher assessment strategy. He argued that the most influential factor is a supportive relationship between teacher and students. If they have a good emotional link, other benefits would follow.

\section{Summary}

Table 7.1 below provides a short summary of the key factors that characterise Arfan's teaching. This material is used in the cross case analysis in Chapter 8.

Table 7.1: Summary of Arfan's teaching attributes and practices

\begin{tabular}{|c|c|}
\hline Attributes and practices & Illustrations \\
\hline $\begin{array}{l}\text { Attributes } \\
\text { - Enthusiastic classroom } \\
\text { manners } \\
\text { - Encouraging } \\
\text { - Caring }\end{array}$ & $\begin{array}{l}\text { Appearing friendly, easy going and enthusiastic. } \\
\text { Encouraging students to use English and ask } \\
\text { questions. } \\
\text { Discussing problems faced by students in learning } \\
\text { English. }\end{array}$ \\
\hline $\begin{array}{l}\text { Practices } \\
\text { - Engaging activities } \\
\text { - Challenging activities } \\
\text { - Giving feedback } \\
\text { - Giving homework } \\
\text { - Using L1 } \\
\text { - Planning the lesson } \\
\text { - Managing unmotivated } \\
\text { students }\end{array}$ & $\begin{array}{l}\text { Adopting materials from the internet such as audio, } \\
\text { game, and grammar activities. } \\
\text { Using enjoyable games and grammar quiz from the } \\
\text { internet. } \\
\text { Assessing student's learning through a learning } \\
\text { process. } \\
\text { Homework is considered as students' attendance. } \\
\text { Using } L 1 \text { when explaining lessons. } \\
\text { Changing the lessons to suit students' needs and } \\
\text { ability. } \\
\text { Moving students to sit with a suitable partner. }\end{array}$ \\
\hline $\begin{array}{l}\text { Other factors } \\
\text { - Peers } \\
\text { - Classroom facility }\end{array}$ & $\begin{array}{l}\text { A motivated student can help their peers; unmotivated } \\
\text { student has a negative influence on their peers. } \\
\text { Learning facilities influence students' motivation. } \\
\text { Classroom should be comfortable for learning. }\end{array}$ \\
\hline
\end{tabular}




\section{CHAPTER 8}

\section{Cross Case Analysis}

The findings of this research provide evidence that the teachers in each of the four case studies use motivational teaching strategies in their classrooms but each uses them in different ways. In this chapter, the findings will be discussed in relation to Dörnyei's (2001) MTP framework, the literature review including Hall and Kidman's (2004) T-L map, and literature on motivational teaching strategies. The three research questions that frame and guide this study throughout its stages are:

1. How do Indonesian teachers of English in high schools report their perceptions of motivational teaching strategies?

2. How do teachers implement motivational teaching strategies in the Indonesian EFL classroom context?

3. How do students report their perceptions of the motivational teaching strategies used by their teachers?

To begin, I will answer the first research question, explaining how teachers report their perceptions of motivational teaching strategies. I will compare the perceptions of the four teachers and I will also discuss factors that influence teachers' perceptions of motivational teaching strategies.

Secondly, I will discuss motivational teaching strategies emerging from this study together with the impact of these strategies on students' motivation and compare them to Dörnyei's MTP framework.

Thirdly, I will discuss the implementation of Dörnyei's framework embedded within teaching and learning contexts. To do this I will use Hall and Kidman's (2004) T-L map. I argue that the two frameworks are complementary.

\section{Question one: Teachers' perceptions}

The four teachers each held different perceptions of motivational teaching strategies yet there were some common perceptions. Two of the cases had a common contextual feature in that the students were more likely to be lower achievers. The findings of this study indicate that both Harry and Arfan who taught in regular schools were of the opinion that learning should involve enjoyable learning activities such as jokes, games, or funny stories. It seems that the students' characteristics 
and the school context influenced teacher perceptions, especially of how to motivate their students. The school context and the characteristics of the students were not unrelated. Regular schools are less desirable in parents' eyes compared to national and international schools.

Harry and Arfan shared another similarity in their teaching context. They taught in schools where the use of English was mostly limited to the language classroom. In these schools English is not a medium of instruction for mathematics and sciences as in an international standardised school. The students did not experience the additional motivation of using English outside the language classroom nor experience its importance as a medium of instruction in other subjects. This meant that students in regular schools had less exposure to English and fewer opportunities to use it for real communication beyond learning it as an academic subject at school.

Harry tried to mitigate the students' lack of exposure to English beyond the language classroom by making his classes enjoyable for his students. Harry said that an expert teacher could motivate students to learn. He believed that English should be familiar for the students, rather than strange. This sense of familiarity with English was a challenging idea as these students were likely to only encounter English in the language classroom. He added that a teacher should be able to create an encouraging and engaging learning atmosphere for students, so students feel that learning is not a burden, but an enjoyable activity. He said that games, songs, jokes, and other fun activities would motivate students to learn in the classroom. His views of teaching English as a foreign language impacted on his pedagogical skills when he was selecting suitable learning activities in his classroom.

Arfan held a perception that besides implementing enjoyable learning activities, a teacher should understand students' lifestyles which were close to the digital world. He found that computer-based activities were interesting for his students. This built his perception that learning should involve entertaining but challenging activities for students. This perception corresponded to his students' opinion in the focus group interviews.

Yuke also had a unique and important way of encouraging students to use English for communication. Even though English was not a medium of instruction for learning mathematics and sciences in her school, Yuke believed that inviting her 
students to use English inside and outside the classroom would help her students gain more communication skills in English. She aimed to make English-use a habit for her students. This suggested that she valued the social uses of English rather than just the academic processes of learning a language. This would help her students build their confidence to use English.

In contrast, Moza argued that a motivating language teacher should possess correct and clear pronunciation. She believed that teachers' pronunciation served as a model for students to speak English. Clear pronunciation made English familiar and comprehensible for the students. She said that in her context students had to understand English for learning mathematics and science. Students needed to speak and listen in English in these classes as well as read and write.

There were two aspects of language teaching that all four teachers had in common, student-teacher relationships and a lack of strategies to create autonomous learning. All four teachers held a similar perception that building an encouraging relationship with their students enhanced motivation. While they had different perceptions of the use of teaching materials and classroom activities, the four teachers all valued rapport with the students.

The findings revealed that none of the four teachers felt that they motivated their students to be independent learners. They did not teach their students to build their own motivation or become self-motivated students. The Indonesian educational context may have impacted on the absence of these strategies. This will be discussed further in the section entitled National context: Indonesian educational context on page 170 .

All of the teachers in the study valued rapport with students but did not recognise the concept of student learning autonomy. The teaching context appeared to influence their different perceptions about teaching and learning English. Arfan and Harry believed that teaching should make English familiar and engaging for their students. Yuke and Moza believed that students should be able to use English outside the language classroom.

However, several factors influence teachers' perceptions of motivational teaching strategies. Teachers' perceptions of how to motivate students are influenced by their cognition, teaching experience, the curriculum, and the educational context (Palmer, 
Stough, Burdenski, \& Gonzales, 2005). The findings of this study suggest that the factors influencing teacher perceptions of motivational teaching strategies can be categorised as teacher personal factors (cognition, experience, and motivation) and the context of the teaching or what could be described as external factors beyond the classroom. The following section will discuss teacher personal factors and the external factors will be discussed in the section entitled MTP and T-L map on page 167.

\section{Teacher cognition}

Teacher cognition is what teachers know, believe and think (Borg, 2003; Borg \& AlBusadi, 2012). Cognition influences the teaching approaches used, including the way teachers motivate their students. Borg (2003) emphasises that teacher cognition is shaped by the social, psychological, and environmental context of the school and the classroom. The section of teacher perceptions above describes how the participants' teaching context may influence their cognitions. The data from the four teachers indicate that they have different knowledge and beliefs about motivating language learners.

Teacher cognition embraces the complexity of teachers' mental lives (Borg, 2003). This mental construct influences teachers' classroom practices. It indicates that a language teacher's cognition and his or her classroom practices have a mutually dependent relationship. Teachers' perceptions of motivational teaching strategies can influence their practices in motivating their students but it is important to consider this within the Indonesian high school context. This will be discussed further in the section entitled Teachers' practices on page 145.

\section{Teachers' teaching experience}

As noted, one of the factors that influence teacher perceptions of motivational teaching strategies is the teachers' experience of teaching. Borg said that experienced language teachers pay more attention to the language (Borg, 2003). They deal quickly with classroom management issues and are able to improvise in their teaching. All of the teachers in my study had considerable experience teaching in their specific situations. All of the teachers based their teaching decisions on evidence either from observing student responses, or using a more formal process of action research. This led all of them to experiment with the use of strategies outside of those provided in the textbook. 
The teacher in case one, Moza, is an experienced teacher. She has taught in her school, an international standardised school, for more than 30 years. She felt confident that she could motivate her students to learn. Harry has been a teacher for more than ten years. He showed that he was an experienced teacher by understanding his students and the school situation. Because the school was a regular school where the student population is likely to be middle to low achieving, early in each semester he had to assure his students that they could learn English successfully. He enhanced his students' motivation by telling them that English was not so difficult if they worked hard and practised the language. By doing this, Harry tried to build his students' initial self-confidence. Confidence is important, especially in learning a new language where making mistakes is very easy (Gardner, 2001). His experience in teaching English guided Harry to build his students' selfconfidence; from the beginning he assured his students that they are learning in a safe environment which considers mistakes as a part of learning a foreign language.

Yuke has been a teacher for 23 years in a national standardised school. Her experience in teaching English led her to the view that motivating students to learn should involve body language activities and that giving students a lot of time to practise in the classroom was important. Her students reported that they liked her various teaching strategies such as "cycle stand", dramas, or role plays. These activities seemed to help students build their self-confidence, in turn building their self-efficacy, the belief in their ability to perform tasks, and enhancing their learning motivation (Cummins \& Davison, 2007; Raoofi, Tan, \& Chan, 2012). Yuke had learnt how to motivate the kind of students she taught from her professional experience. This finding suggested that she was able to reflect on and improve her practice as a teacher.

Arfan has been a teacher for 20 years in a regular school, the kind of school least preferred by parents. His experience had led him to the conclusion that using the same old strategies did not motivate his students. He found that new strategies sourced from the internet were interesting for his students. He noted that his students generally enjoyed activities such as games and songs; most of his students did not like activities which made them think deeply. Arfan got this impression not only from his teaching experience but also from the students' enthusiastic responses whenever he used learning materials from the internet. 
Both Yuke and Arfan used a form of classroom action research to solve their classroom problems. They said that classroom action research not only increased their knowledge of being "teachers as researchers" but also helped them provide better classroom teaching and learning. It seems that Yuke and Arfan not only based their teaching strategies on their students' feedback, but also on research findings that identified motivational teaching practices relevant to a second/foreign language learning.

Moza said that her perceptions of effective teaching were formed by her teaching practices as a language teacher. She said that each time she taught, she noted which strategies enhanced her students' motivation and helped the students understand better. When a strategy worked well in her teaching she used it again for other groups of students, but if a strategy did not help her students understand a learning topic she did not use it anymore. This indicates that Moza was a reflective teacher. Like the other three teachers, Moza also noted the students' responses through their body language or classroom behaviours toward her teaching. However, Moza taught differently because her school context was different to those of the other three teachers. The students experienced tough competition to enter this school. The school accepts students who gain a high level of achievement in their Year 9 national standardised test. The students used English in mathematics and science. Students who entered this school were high achievers. Teaching high achievers who are likely to be motivated would be different from teaching middle to low achievers. Motivated students usually have a positive attitude towards learning so they are more likely to be fully engaged in their learning process.

Arfan said that his perception was mostly influenced by what his students' said or showed through their behaviours towards his teaching. He usually asked his students about their favourite classroom activities. He said that he could also pick up on his students' body language in the classroom. This was similar to the other teachers who obtained feedback from their students, revealing that the teachers learnt from the students' responses toward their teaching strategies.

As noted, the teaching context also influences how teachers motivate their students. Teaching high achievers, such as in an international standardised school, may not be as challenging as teaching middle to low achievers in a regular school. This is because high achievers generally take more responsibility for their learning (Lamb, 2004b). This reflects perhaps a greater motivation to learn. Harry and Arfan, besides 
motivating their students, were also challenged by their students' perception that English is daunting. They noted that it was challenging to teach their students reading comprehension since their students had limited vocabulary, and reading needs high levels of thinking skills (McNamara, Levinstein, \& Boonthum, 2004).

The findings reveal that teachers' perceptions of motivational teaching strategies are influenced by their teaching practices and experience. While the length of a teachers' teaching experience did not guarantee that a teacher was motivated to seek and implement motivational teaching strategies, I had purposively selected participants who were recognised by their schools as effective in their practices. The findings of my study indicate that the teachers' teaching experience and context may have an important role in shaping teachers' perceptions and their implementation of motivational strategies. This will be discussed further in the section entitled MTP and $T$-L map (page 167).

\section{Teacher motivation}

Teacher motivation is a very important factor in effective teaching and learning (Dörnyei \& Ushioda, 2011). Each of the teachers in my study was highly motivated. They were selected by their principals as examples of teachers who were motivated and effective in their teaching. In a foreign language context, the teacher is the model and simultaneously the motivator of language learning (Jesus \& Lens, 2005). If teachers are not motivated, they will not learn and use motivational teaching strategies in their classrooms (Dörnyei, 2001). All four teachers showed that they were motivated and they demonstrated their motivation in different ways. All were enthusiastic in their approach to teaching and learning. They were motivated to find strategies to stimulate their students learning. They attended seminars, workshops, and conducted classroom action research. They also reported that teachers should be role models for motivating students' learning.

These findings on teacher motivation concur with previous studies. Lee (2008) argues that teacher motivation has a positive influence on students' motivation and this is supported by Matsumoto's (2009) study of learners' perception of teachers' motivation. Both studies conclude that a teacher's teaching commitment has a positive effect on learners' motivation. Hardre, Huang et al. (2006), in a study of high school teachers' motivational perceptions and strategies in Taiwan, claim that teacher motivation and perceptions strongly correlate with student motivation in 
terms of learning goal orientation, student ability, instrumentality of instruction, and high teaching self-efficacy.

The data from the four teachers also found the importance of teachers acting as role models and the motivators for their students. However, the findings also indicate that teachers who taught in regular schools, which were not highly desirable, seemed to work very hard to motivate their students to achieve learning goals.

\section{Question two: Teachers' practices}

The findings indicate a relationship between teacher perceptions and motivational teaching practices. What the four teachers reported in the semi-structured interview as motivating was mostly captured in the classroom observations. This section will explore how the teachers implemented the motivational teaching strategies that emerged from the data and in the second part the findings will be compared to Dörnyei's framework. Teachers' practices from this study's findings will be grouped into two main points: teacher pedagogical practices and teacher classroom behaviours. The discussion will conclude with suggestions of how these two factors support each other.

\section{Teachers' pedagogical practices}

The findings indicate that teachers' pedagogical practices can be categorised into three main activities: the selection of learning resources and activities, classroom management, and feedback.

\section{Learning resources and activities}

The four teachers believe that the students are motivated if they have a lot of time to practise. To accommodate this, the teachers used different approaches in their teaching. Moza told stories; Harry used poems, songs, games, telling jokes, or simply engaging students in discussing interesting topics related to teenagers; Yuke used strategies such as drama and role play to give her students practice; and Arfan used learning materials from the internet.

Among the four teachers, Arfan was the only one who browsed the internet to find appropriate learning resources for his students. Arfan understood that his students enjoyed the interactive resources from the internet. The way Arfan selected his internet materials seemed to be influenced by his personal practical knowledge and teaching experience (Borg, 2003). Even though the other three teachers did not use the internet as a source of materials, they did use learning materials that were close 
to teenagers' lives and linked to the students' backgrounds. These materials helped to increase language learning motivation. The findings indicate that students were not motivated by constant use of a textbook. Teachers needed to be creative to modify the activities if textbook exercises were used. This implies that students were motivated when the learning activities were challenging, varied, contextualised, and new to them.

\section{Classroom management}

Classroom management is not necessarily a motivational teaching strategy, but it supports teachers in the implementation of motivational teaching strategies. Dörnyei (2001) argues that motivational teaching strategies collapse if a teacher does not have skills in classroom management.

Classroom management is important for teachers because they need to handle complex situations in the classroom. For example, teachers have to teach, control the lesson flow, manage student behaviour, give encouragement, and assess students' learning. It is difficult for many teachers to manage the classroom (Dörnyei, 2001).

A teacher's classroom management skills are crucial to make sure that learning takes place in a conducive environment, so students need to behave in a positive manner in the classroom (Maguire, Ball, \& Braun, 2010). The current study also highlights the important role of teachers in managing their classrooms. The four participants showed that they were effective in managing their classes.

The wider environment, such as the type of students in the school, could affect the motivation of the students and the conditions in the classroom (Sugita \& Takeuci, 2010). Since Arfan's school was the least popular with families, he had more potential challenges in managing the classroom. However the findings indicate that Arfan showed his ability to manage his classes because he was able to motivate and engage his students. This supports the view that classroom management and student motivation are contextually linked.

The four teachers practised similar strategies to handle their unmotivated students. They approached them personally and set up the classroom rules at the beginning of the semester. However, among the four teachers, Arfan had to work harder to manage his class as he was likely to have more unmotivated students. Arfan needed to find unique strategies to manage his classroom. Placing students in 
suitable pairs was one method he used as it allowed the students to interact. $\mathrm{He}$ was strategic in the way he selected pairs.

\section{Type of feedback}

The four teachers used a similar strategy for correcting speaking mistakes. They did not give direct correction but picked up some important mistakes and discussed these with their students at the end of speaking practice. They complimented their students on their performance rather than criticised them. In this way, they were able to create a balance between fluency and accuracy in language use and assisted students to see mistakes as part of the learning process. This helped their students to speak with confidence, because making a mistake was not threatening. This is important especially for regular school students who appeared to be more afraid of using English. Harry and Arfan reported that making students confident when using English was not easy.

The common practice in Indonesia is to simply give a mark or grade on students' performance instead of written feedback. Giving feedback means giving information as a consequence of a performance (Hattie \& Timperley, 2007). None of the four teachers indicated that they gave descriptive written feedback to their students. The data indicated that giving feedback on students' work orally or in writing is not a common practice in the classes under observation. However, students need formative feedback to give them directions to acquire more knowledge and perform better for their learning (Hattie \& Timperley, 2007). It is possible that the teachers expected that their students understood the meaning of a mark; a high mark means high achievement and a low mark means unsatisfactory achievement. However, students would benefit if the teachers gave them more information about how to achieve a higher grade. The students expected teachers to help them more but it seems that the teachers did not address this expectation. Two possible issues may underlie the lack of feedback. One is the custom of giving little formal formative feedback and the other, as indicated in the data from Harry and Arfan, the large number of students in each class.

The teachers conducted tests in different ways. Yuke also used her assessment activities to teach moral values such as honesty. Yuke gave her students a choice when doing the tests at the end of each section of learning. Students could do the tests with friends or alone; she explained the rules and the students decided. She wanted to teach her students to be honest, an important moral value in life. She wanted her students to understand that learning is gaining knowledge, not gaining 
marks. This indicated that Yuke valued honesty more than the students' grades. She was not only teaching English skills but also living skills that would be valuable for the students' social lives.

The teachers reported that students' classroom participation was considered a credit and added this to their test result. Another credit that students could obtain was from their classroom attendance. Although students did not get written feedback, they got a total grade from their teachers based on their learning performance during a learning process and an achievement test score. Hence, the final mark that students got on their academic report was a calculation of credits for tasks, tests, homework, classroom participation and attendance. All of the teachers assessed students during the learning process, not just on test results alone. This suggests that they were rewarding their students' engagement in the learning process as well as the students' achievement. This method provides an incentive for the students to be motivated in the classroom. However, this form of motivation may not be sustained without the external incentive of having a grade allocated to it.

It appears that choosing an appropriate assessment strategy influences students' motivation (Dörnyei, 2001). Dörnyei suggested that the assessment should be clear, giving comments or suggestions for improvement, involving students in an ongoing process, providing students with self-assessment skills, and making use of peer assessment. This kind of assessment did not emerge from the data so the students were not encouraged to develop skills of self-evaluation. This may have impacted on their ability to be autonomous learners.

Hattie and Timperley (2007) describe four levels of feedback: informing students whether their work is right or wrong; helping students to complete a task; helping students to be self-regulated learners; and giving feedback about the student's "self" as a person. The four teachers appeared to use the first level of feedback, giving information whether students have done a task correctly or not. This level of feedback does not yet guide students to the self-regulation level, self-evaluation or confidence to engage in further assignments (Hattie \& Timperley, 2007). One of the reasons why teachers used this kind of feedback is because the curriculum demands evidence of learning achievement. Actually, according to the curriculum, teachers were expected to practise formative assessment by giving effective feedback to enhance students' learning (BNSP, 2007). However, on students' academic reports, teachers were only expected to record students' learning in marks 
or scores. It should be noted that teachers were likely to have had only limited experience with formative feedback as it is a relatively new concept in Indonesia and they may not have been provided with training in this form of feedback.

The Indonesian educational system and the curriculum demands influenced the teachers in the way they assessed students' learning. It seems that the teachers might not have realised that encouraging written feedback is important for giving students direction about how to achieve better learning. Since the teachers in the study were purposively selected for their excellent motivational teaching strategies, this is possibly because of the teachers' lack of knowledge about formative assessment. Azis's study (2014) found that Indonesian teachers of English think that assessing students' achievement by giving a mark is the most effective strategy to stimulate learning.

In summary, the three components of teachers' classroom practices: selection of learning resources and activities, classroom management, and feedback, appeared to have been influenced by the school context, the Indonesian educational context, and the Indonesian curriculum for English. The selection of learning resources and classroom management were influenced by the school and the local educational context. These findings will be discussed further in the section entitled MTP and T-L map.

\section{Teachers' classroom behaviours}

The teacher classroom behaviours were related to the first stage of Dörnyei's framework: creating basic motivational conditions. The four teachers in this study demonstrated that they employed these motivational strategies. They built an encouraging relationship with their students. They created a relaxed and warm classroom atmosphere to make their students feel safe and secure in expressing their ideas in the classroom. Foreign language learning may be inhibited if students do not feel psychologically secure during the language learning process: they will not take risks when practising the target language (Dörnyei, 2001; Oxford \& Shearin, 1994). In other words, a teacher's classroom behaviour can motivate or demotivate students (Kikuchi, 2009). All of the teachers in the current study argued that the relationship with their students played an important role in achieving a successful teaching process. 
The four teachers built positive relationships with their students in different ways. Moza promoted a positive relationship with her students by frequently showing encouraging and open facial expressions such as smiling when she taught in her class. Harry used his role as a teacher to motivate students by appealing to their spiritual and moral values. He was friendly and outgoing with his students not only in the classroom, but also outside the classroom. He called his students by their nicknames and this seemed to be effective in building positive relationships with students. Similarly, the teacher in case three, Yuke, maintained a close relationship between herself and her students. She had a friendly manner with her students. She came into the classroom full of enthusiasm, smiling, and greeting her students warmly. In case four, the teacher was passionate about teaching. Arfan was patient and positive, with a friendly and easy going manner. He encouraged his students to ask questions and he was happy to answer each question enthusiastically.

These findings are different from other research findings on teacher-student relationships in an Indonesian high school context such as Lamb's (2007), Bradford's (2007), and Marcellino's (2008) studies. Those studies found that the teacher-student relationship was authoritative. There was a gap between teacher and students created by the level of authority assumed by the teacher in the classroom. In the Indonesian educational context, teachers are seen as authoritative persons in the classroom. The teachers of English are sometimes seen as irritable and impatient (Bradford, 2007; Lamb \& Coleman, 2008). If there is a large gap between teachers and students, the participants in my study showed that rapport helps bridge this gap. These teachers understood how students perceived the traditional role of teachers and they approached their students with a variety of strategies both inside and outside the classroom to reduce the gap between themselves and their students.

All four teachers said that if teachers pressure students when they are learning, there is a risk that the learning process will not run smoothly. These findings concur with the literature from a variety of countries such as Japan, Korea, Brazil, Australia, and USA which indicate that teacher behaviours, particularly teacher-student interaction, is closely related to students' motivation when learning a foreign language (Ghenghesh, 2010; Marie-José Guilloteaux, 2013; Matsumoto, 2011; Ruesch et al., 2011; Xavier, 2005). The current study's findings support the importance of rapport in teaching English in a provincial Indonesian context. 
The research indicates that regardless of the particular school context, for example, international schools or regular schools, and the Indonesian educational system, rapport seems to be fundamental to motivating students. The students mentioned that the most important influence on their motivation was the teacher's classroom behaviour, including, for instance, a warm friendly manner and the way students are challenged to learn in their lessons. The findings also show that there is a strong link between classroom behaviours, the teacher's classroom practices, and the classroom atmosphere. The following figure describes how rapport and teacher practices might be interrelated.

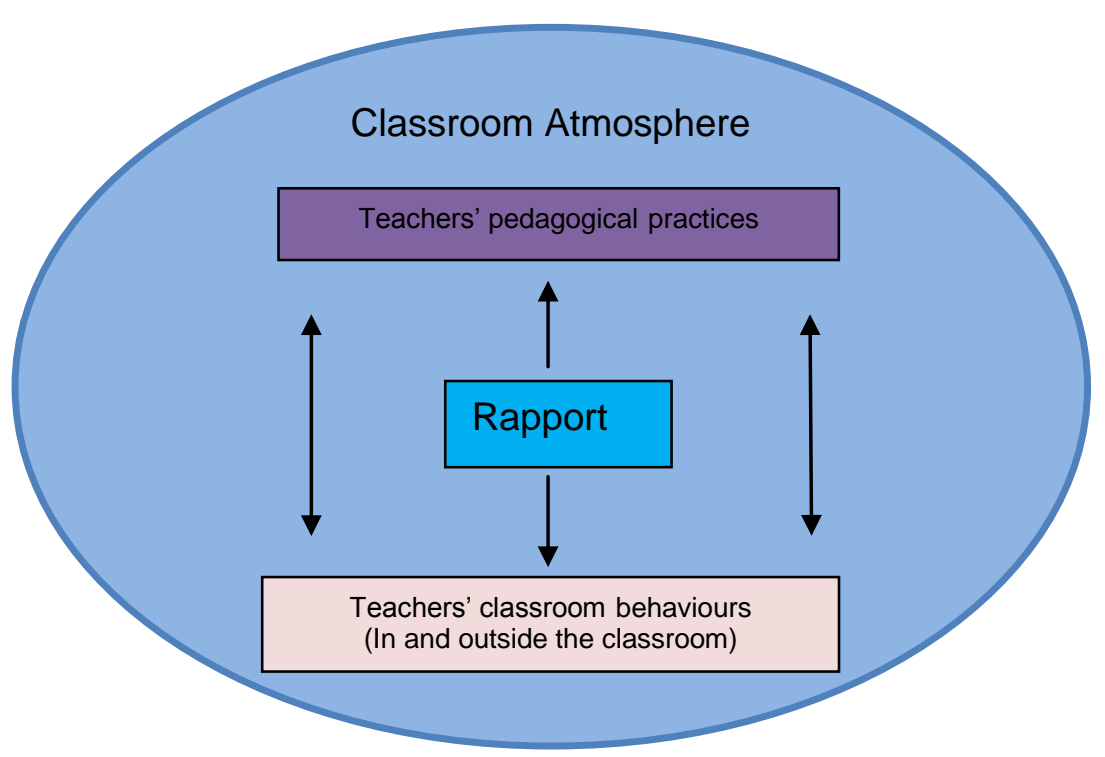

Figure 8.1: Classroom atmosphere: Main themes from the findings

Rapport helps the teachers to implement their decisions in the classroom. The positive relationship that the teachers in this study built with their students helped them select suitable learning materials, display good classroom management, and give positive feedback. Rapport is a basic condition for motivating students in the classroom, regardless of the school context, whether an international standardised, national standardised, or regular school. This is consistent with other studies such as Ruesch (2009), Xavier (2005) and Halawah (2011), which underline the importance of rapport. In addition, the success of different teaching practices also depends on rapport. Rapport helps teachers understand their students' favourite learning activities, their goals for learning English, and their level of English proficiency. This helps teachers select suitable learning resources for their students. In managing the students who were misbehaving, the teachers in this study kept their relationships with the students intact. Arfan, the teacher from the regular 
school, found no problem placing his students with a suitable partner because he knew the students well.

\section{Question three: Students' perceptions of motivational teaching strategies}

The students all held a similar perception of teacher classroom behaviours and the importance of rapport. They said that their motivation was influenced by the teachers themselves. If they liked the teacher, English became their favourite subject but when the teacher was boring, English was not an interesting subject for them. The teachers' classroom behaviours influenced students' motivation. Furthermore, and unique to this study, all the teachers maintained a close relationship with students, decreasing the traditional authority between them and their students. The encouraging relationship helped students to feel relaxed in the classroom. The students added that their teachers were motivating teachers who were approachable, friendly, and enthusiastic. This perception was stronger for the students from regular schools compared to the international and national standardised schools. Lamb (2008) also found this in Indonesian high schools and Maulana et al. (2011) in a Korean high school also confirmed that the teacher's classroom behaviour was regarded as the foundation of motivational teaching practices (Marie-Jose Guilloteaux, 2013).

In addition, the students said that learning materials and classroom activities also influenced their motivation. The teachers' motivational strategies, such as relating learning materials and content to the students' or teenagers' lives, received positive feedback from students. They enjoyed the topics with examples related to love, gadgets, information technology, and social networking. Having plenty of time to practise in the classroom was appreciated by students, especially the students in the regular schools (Harry's and Arfan's students). This was different from their counterparts in the international and national standardised schools who used English more often. These students did not value opportunities to practise as much.

This dependence on the teacher to motivate them was similar to Lamb's (2008) findings in an Indonesian high school context. However, not all strategies used by teachers were effective, especially the amount of L1 used in the classroom, the use of humour, and group work activities. This has been discussed earlier. 
Besides rapport and teacher motivational strategies, several students stated that they were motivated to learn English because of the advantages they saw in learning it. They learnt English not only to gain a good mark for their high school academic report and their university needs, but also because of the advantages of learning English as an international language.

In conclusion, the students indicated that their motivation is influenced by three factors: teacher classroom behaviours, teacher motivational strategies, and the instrumental value of learning English. Among these factors, there were no differences in the perceptions of the importance of rapport and the usefulness of English. Generally, teachers' motivational strategies influenced students' motivation positively.

\section{Teacher motivational strategies and Dörnyei's framework}

The following section analyses the data from the four teachers' and their students' perception of motivational teaching strategies in relation to the four phases of Dörnyei's framework of creating, generating, maintaining and evaluating motivation.

\section{Creating the basic motivational conditions}

\section{Table 8.1: Motivational Teaching Practice}

\begin{tabular}{|c|}
\hline MOTIVATIONAL TEACHING PRACTICE \\
\hline $\begin{array}{l}\text { Creating basic motivational conditions establishing a good teacher-student rapport, creating a } \\
\text { pleasant and supportive classroom atmosphere, and generating a cohesive learner group with } \\
\text { appropriate group norms. }\end{array}$ \\
\hline $\begin{array}{l}\text { Generating initial motivation enhancing the learners' language-related values and attitudes, } \\
\text { increasing the learners' goal-orientedness, making the teaching materials relevant for the learners, } \\
\text { and creating realistic learners' beliefs. }\end{array}$ \\
\hline $\begin{array}{l}\text { Maintaining and protecting motivation making learning stimulating, presenting tasks in a } \\
\text { motivating way, setting specific learners' goals, protecting the learners' self-esteem and increasing } \\
\text { their self-confidence, allowing learners to maintain a positive social image, promoting cooperation } \\
\text { among the learners, creating learner autonomy and promoting self-motivating learner strategies. }\end{array}$ \\
\hline $\begin{array}{l}\text { Encouraging positive retrospective self-evaluation promoting motivational attributions, providing } \\
\text { motivational feedback, increasing learner satisfaction, and offering rewards and grades in a } \\
\text { motivating manner. }\end{array}$ \\
\hline
\end{tabular}

Based on Dörnyei's (2001) framework, when creating students' motivation, at least three components are usually present: appropriate teacher behaviours and a good 
relationship with students; a pleasant and supportive classroom atmosphere; and a cohesive learner group with appropriate group norms. These three components are interrelated (Dörnyei, 2001).

In relation to the first component, Dörnyei draws attention to four important points: teacher enthusiasm; commitment to, and expectations for the students' learning; the teacher relationship with students; and the teacher relationship with students' parents (Dörnyei, 2001). All four teachers showed that they were dedicated to teaching. They were enthusiastic teachers who came to the classroom with a positive manner, for instance, smiling. They looked relaxed rather than explicitly showing their authority with a stern demeanour. This helped the students feel comfortable, an important component of the atmosphere in the teaching-learning process, especially teaching-learning English as a foreign language.

Maintaining a good relationship with their students' parents can help a teacher build a good relationship with students. For most students, parents have a big influence on their learning and play an important part in their learning motivation (Dörnyei, 2001). None of the four teachers mentioned this as part of building students' classroom motivation. In the Indonesian education context, schools appoint a class teacher/form teacher for each group of students who builds a relationship with students' parents. The purpose of this relationship is to increase students' achievement in general. Subject teachers do not have direct responsibility for building this relationship.

The second component in creating students' motivation is the provision of a pleasant and supportive classroom atmosphere. Moza, the teacher in case 1, stated that her students' motivation was also influenced by when the teaching occurred. When they studied in the morning they were more motivated than in the afternoon. Her students agreed that they preferred the morning to the afternoon period. For this reason, Moza approached the afternoon session differently to keep students on task. Instead of introducing new ideas, she used revision more in the afternoon. Harry gave his students a ten-minute break before starting the afternoon period. Yuke and Arfan did not mention that they modified their teaching for the afternoon period.

Dörnyei mentioned that humour is a tool that creates a pleasant classroom atmosphere (Dörnyei, 2001). As noted, all four teachers created an encouraging and 
relaxed atmosphere by positioning themselves as friendly, and they also displayed their sense of humour (Classroom observation, 17/2/2012). They told jokes, funny stories, life experiences, and gave religious advice as an icebreaker before starting a lesson. They acted as good models for their students to inspire them to learn English. Lamb (2012) also found that classroom learning experiences had an important role in increasing Indonesian students' motivation to learn English. Humour seemed to be an effective way to create a comfortable classroom environment.

Dörnyei argues that a classroom is both a psychological and physical environment. The classroom decoration influences students' motivation. Decoration of a classroom involves putting up posters, providing bulletin board displays, displaying flowers, or showing students' work (Dörnyei, 2001). However, the classroom physical environment in schools in Indonesia cannot be decorated for a particular subject because the classroom is a place where a group of students study all or most of their school subjects. Subject teachers do not decorate bulletin boards or display the work in their subject area. Consequently, the four teachers did not refer to the use of classroom decoration or displays of students' works as a way of influencing their students' learning motivation.

Moza and Arfan talked about classroom facilities and teaching media. Moza and Arfan considered that classroom facilities influenced their teaching. They mentioned that they needed a language laboratory, or at least a tape recorder, to teach listening skills. Moza did not have access to such a facility at her school. She used her own tape recorder or read scripts herself for listening exercises. Harry and Yuke said that they borrowed a tape recorder from their schools. Arfan said that he used his laptop in case he needed to conduct activities such as listening to a script or other internet-based activities. None of the teachers appeared to see classroom facilities as a barrier for implementing their motivational teaching strategies.

The third aspect of creating students' motivation is the establishment of a cohesive learner group. Students feel safe to say and try a new language because they are sure that they will not be blamed or teased when they make mistakes (Dörnyei, 2001). To help build a good relationship amongst their students, all four teachers implemented group-work or pair-work activities in their teaching. Their students enjoyed this kind of activity. Harry and Yuke generally organised students into mixed ability groups. Arfan, however, did not indicate that he practised mixed ability 
grouping. From the classroom observation, I found that Arfan created a group based on where the students were seated. In a pair work task, the students did a task with a friend who sat next to him/her. To form the four-person team, two students who sat in the front row turned their chairs around to face their friends who sat in the row behind (Classroom observation, 7/3/2012). However, the seating plan was not random. Arfan knew that in each group there was a motivated student who could help to run a discussion. Moza used a similar method to group her students but Yuke and Harry grouped their students based on their English ability to make sure that there was one high achiever to help their friends in each group.

Dörnyei mentioned that students' lack of motivation may be caused by the feeling of fear or being isolated by their peers. A safe learning environment is an essential part of language learning. This is the basis of classroom management. The teacher and the students should therefore negotiate rules of conduct (Dörnyei, 2001). Dörnyei mentioned that the rules should be easy to follow and explicitly discussed so that members of each group can adopt them. Moza, Harry, and Yuke stated that they set up their classroom learning rules with their students; for example, students should not laugh at their friends' mistakes, and what they say in a classroom discussion is confidential. Arfan did not mention that he established a set of classroom rules. Arfan responded to his students who were misbehaving when it occurred, such as reminding students to focus on the task if they talked on an unrelated topic to each other (Classroom observation, 7/3/2012).

Dörnyei indicated briefly how a teacher must discipline learners who break the rules. He mentioned that this is less to do with students' motivation and more a classroom management issue. However, discipline becomes a serious issue if it can damage classroom motivation (Dörnyei, 2001). As mentioned earlier, Moza and Harry dealt with their students who were unmotivated or misbehaved by talking to them personally. They mentioned that it was not necessary to discipline their students at a special time or place such as in the teacher's room. They stated that usually their unmotivated students would change their behavior after they were spoken to in person. If these students remained unmotivated or continued to misbehave, they would mostly ignore these students during class and talk to them later. Yuke and Arfan said that they directly reminded their students who were misbehaving to pay attention to the learning. They said they did not encounter any problems in reminding students while the teaching-learning process was in progress. 
In conclusion, my research findings are largely congruent with the first phase of Dörnyei's framework. However, two strategies from the framework did not emerge from the data: building a relationship with students' parents and putting learning goals or students' work on the wall. The implementation of the first of these was related to the school common practice which appointed a form teacher to build a relationship with students' parents. The second was limited by the organisation of teachers rotating through each classroom.

\section{Generating initial motivation}

Table 8.1: (repeated) Motivational Teaching Practice

\begin{tabular}{|c|}
\hline MOTIVATIONAL TEACHING PRACTICE \\
\hline $\begin{array}{l}\text { Creating basic motivational conditions } \\
\text { pleasant and supportive classroom atmosphere, and generating a cohesive learner group with } \\
\text { appropriate group norms. }\end{array}$ \\
\hline $\begin{array}{l}\text { Generating initial motivation enhancing the learners' language-related values and attitudes, } \\
\text { increasing the learners' goal-orientedness, making the teaching materials relevant for the learners, } \\
\text { and creating realistic learners' beliefs. }\end{array}$ \\
\hline $\begin{array}{l}\text { Maintaining and protecting motivation making learning stimulating, presenting tasks in a } \\
\text { motivating way, setting specific learners' goals, protecting the learners' self-esteem and } \\
\text { increasing their self-confidence, allowing learners to maintain a positive social image, promoting } \\
\text { cooperation among the learners, creating learner autonomy and promoting self-motivating learner } \\
\text { strategies. }\end{array}$ \\
\hline $\begin{array}{l}\text { Encouraging positive retrospective self-evaluation promoting motivational attributions, providing } \\
\text { motivational feedback, increasing learner satisfaction, and offering rewards and grades in a } \\
\text { motivating manner. }\end{array}$ \\
\hline
\end{tabular}

Dörnyei identifies five categories in this phase: enhancing learners' language value and attitude; increasing the learners' expectancy of success; increasing the learners' goal orientation; making the teaching material relevant to learners; and creating realistic learners' beliefs (Dörnyei, 2001).

In enhancing learner language values, Dörnyei mentioned that learners' intrinsic motivation (the excitement or enjoyment of doing an activity) can be aroused by presenting interesting materials (Dörnyei, 2001). All four teachers also made the point that promotion of interesting learning materials made their students more motivated to learn: Moza said she told stories, used her own experience, or modified materials from books to bring the lesson closer to students' lives; Harry adopted his 
teaching materials from the English Teaching Forum magazine; Yuke used the cycle-stand activity; and Arfan used the internet to find new teaching activities with his students.

Dörnyei mentioned that teachers need to vary activities and provide students with enjoyable tasks. The four teachers supported this strategy; they said that their students enjoyed a range of activities and enjoyed examples that related to their teenager lives. Their students reported a similar view. They identified that they liked examples that were related to their own, teenaged lives. Such material was easy to understand and would remain longer in their memory. They enjoyed a range of learning activities during lessons.

Another way to generate students' motivation is by emphasising the instrumental value of language, such as getting a good job, earning extra money, pursuing further study, improving one's social position, and pursuing a hobby like using a computer (Dörnyei, 2001). Moza mentioned the benefits of learning English to her students. She encouraged her students to learn by telling them that English is important for their university entrance test, their university study, and their future careers. Harry related his own learning experience. He also told his students the advantages of being competent in English; he could work at any field easily. Yuke and Arfan emphasised that in a global era the ability to use English is essential to win the competition to get good jobs.

As noted above, the learners' expectation of success and the values they hold about language learning are two influential factors in their level of motivation. There are several things that the teacher can do to support students, such as offering assistance, letting students help each other, explaining the success criteria, and considering and removing potential obstacles to learning (Dörnyei, 2001). Moza did some of these in her classroom. She walked around the class and asked if the students knew how to proceed. She offered help by giving students the opportunity to ask questions if they did not understand the task. Yuke did a similar thing; she also gave more examples when students needed help. Harry and Arfan helped their students to build their confidence to talk in English. They also helped their students to translate some Indonesian words into English words and vice versa when students spoke. All of these strategies raised students' confidence and created a more positive attitude to language learning. 
To increase learner goal orientation, a teacher may consider posting the learning goals on the classroom wall (Dörnyei, 2001). The four teachers said that they let their students know the learning goal for each of the class meetings (Interview, 18/1/2012). They usually told students the learning goals in the pre-teaching activity. Sometimes they did not identify the goals explicitly but the learning activities would reflect the direction of the learning. While the teachers did not present the goals visually, they mostly made the goals explicit to students either within the preteaching period at the start of class or within each activity.

To make teaching materials relevant to learners, the teachers said that they chose materials and examples that were relevant to a teenager's life, suitable for their English level, and they used simple sentences to explain lessons. These strategies impacted on students' understanding of lessons. Their students said that they found that the use of simple language enabled them to understand the lessons.

Both Moza and Yuke were prepared to modify the text genre and language skills mandated by the curriculum. Moza said that she had to modify her teaching materials when the texts from the textbook did not seem to match with the learning goals. However, Yuke said that emphasis on text genre in the curriculum limited the learning materials to those that were based on the text types only. She said that it seemed to be artificial that in each lesson everything should be based on a certain type of text or text genre.

In Dörnyei's model, the teacher needs to promote positive beliefs and expectations in students. Teachers also need to inform students about different ways languages are learnt in order that the students recognise a number of factors that can contribute to success. Dörnyei emphasises that learners should understand the best way of learning a foreign language for themselves. In other words, a key factor in students being successful in learning a new language is for the students to discover the methods and techniques by which they learn best (Dörnyei, 2001). Moza stated that a teacher should recognise which strategies students like or dislike. She experimented with different strategies. Harry and Arfan also mentioned that they were responsive to feedback from students about a particular activity. However, none of the teachers said that they taught their students particular learning strategies or explained to them the best way for learning a new language for themselves. 
In summary, the four teachers used a range of strategies or techniques to generate their students' motivation such as providing interesting materials, building trust with students, explaining the usefulness of English, offering help to their students, and explaining the learning goals. However, one suggested strategy in the framework did not emerge from the finding, namely, creating realistic learner beliefs.

\section{Maintaining and protecting motivation}

Table 8.1: (repeated) Motivational Teaching Practice

\begin{tabular}{|c|}
\hline MOTIVATIONAL TEACHING PRACTICE \\
\hline $\begin{array}{l}\text { Creating basic motivational conditions establishing a good teacher-student rapport, creating a } \\
\text { pleasant and supportive classroom atmosphere, and generating a cohesive learner group with } \\
\text { appropriate group norms. }\end{array}$ \\
\hline $\begin{array}{l}\text { Generating initial motivation enhancing the learners' language-related values and attitudes, } \\
\text { increasing the learners' goal-orientedness, making the teaching materials relevant for the learners, } \\
\text { and creating realistic learners' beliefs. }\end{array}$ \\
\hline $\begin{array}{l}\text { Maintaining and protecting motivation making learning stimulating, presenting tasks in a } \\
\text { motivating way, setting specific learners' goals, protecting the learners' self-esteem and } \\
\text { increasing their self-confidence, allowing learners to maintain a positive social image, promoting } \\
\text { cooperation among the learners, creating learner autonomy and promoting self-motivating learner } \\
\text { strategies. }\end{array}$ \\
\hline $\begin{array}{l}\text { Encouraging positive retrospective self-evaluation promoting motivational attributions, providing } \\
\text { motivational feedback, increasing learner satisfaction, and offering rewards and grades in a } \\
\text { motivating manner. }\end{array}$ \\
\hline
\end{tabular}

The third phase of MTP is maintaining and protecting motivation. Dörnyei divides this phase into eight categories: making learning stimulating and enjoyable; presenting tasks in a motivating way; setting specific learner goals; protecting learner self-esteem and increasing their confidence; allowing learners to maintain a positive social image; creating learner autonomy; promoting self-motivating strategies; and promoting cooperation among the learners (Dörnyei, 2001).

The data for making learning stimulating and enjoyable, and presenting tasks in a motivating way, are similar to the data in the previous stage of Dörnyei's framework for making the teaching materials relevant for the learners. These themes have been discussed in the previous section. 
All of the teachers had strategies to protect the learner's self-esteem and increase their self-confidence, all using a similar strategy of not giving direct correction when students made errors in speaking. They identified the important mistakes from the speaking activities and explained them at the end of the session. All teachers viewed mistakes as a natural aspect of learning a language. This is also one of the strategies to allow learners to maintain a positive social image about their learning (Dörnyei, 2001).

The teachers, Harry and Yuke, used mixed ability grouping to encourage students to learn from their peers. This was a strategy to promote cooperation among learners. The teachers often gave opportunity for students to choose the discussion topic. This strategy aimed to foster the students' autonomy.

Exposing students to the target language is important in order to familiarise them with the use of the target language in real life. In case 1, a weak student said that he preferred the teacher to use L1 when she was explaining the lesson, while in case 4 the students wanted their teacher to use more $\mathrm{L} 2$ to make them familiar with $\mathrm{L} 2$. Research reported in the literature suggests that L1 helps students obtain knowledge about the target language (Lightbown \& Spada, 2006).

All four teachers presented lessons in an interesting way by varying their teaching strategies. Students reported in focus groups that they enjoyed their teachers' teaching styles when they resulted in a relaxed and encouraging learning environment. This helped maintain student motivation. One student reported that the use of $L 1$ in the classroom was motivating. Research shows that L1 has an important role in communicating the content and meaning of the target language (Nation, 2003). Together with the findings of this study, the literature indicates that a judicious combination of $\mathrm{L} 1$ and $\mathrm{L} 2$ is perhaps the most productive way forward. Several studies in different L2 contexts support this notion such as Bingjun (2013), Carson and Kashira (2012), Afzal (2013), Campa and Nassaji (2009),J. H. Lee and Macaro (2013), and Pakzadian (2012).

In summary, seven out of eight strategies given by Dörnyei in this phase appeared in the data. The one strategy that did not appear was promoting self-motivation in the students. This suggests that the teachers in these cases did not encourage selfregulation. 


\section{Encouraging positive retrospective self-evaluation}

Table 8.1: (repeated) Motivational Teaching Practice

\begin{tabular}{|c|}
\hline MOTIVATIONAL TEACHING PRACTICE \\
\hline $\begin{array}{l}\text { Creating basic motivational conditions establishing a good teacher-student rapport, creating a } \\
\text { pleasant and supportive classroom atmosphere, and generating a cohesive learner group with } \\
\text { appropriate group norms. }\end{array}$ \\
\hline $\begin{array}{l}\text { Generating initial motivation enhancing the learners' language-related values and attitudes, } \\
\text { increasing the learners' goal-orientedness, making the teaching materials relevant for the learners, } \\
\text { and creating realistic learners' beliefs. }\end{array}$ \\
\hline $\begin{array}{l}\text { Maintaining and protecting motivation making learning stimulating, presenting tasks in a } \\
\text { motivating way, setting specific learners' goals, protecting the learners' self-esteem and } \\
\text { increasing their self-confidence, allowing learners to maintain a positive social image, promoting } \\
\text { cooperation among the learners, creating learner autonomy and promoting self-motivating learner } \\
\text { strategies. }\end{array}$ \\
\hline Encouraging positive retrospective self-evaluation promoting motivational attributions, providing \\
\hline $\begin{array}{l}\text { motivational feedback, increasing learner satisfaction, and offering rewards and grades in a } \\
\text { motivating manner. }\end{array}$ \\
\hline
\end{tabular}

The last phase of Dörnyei's framework involves promoting motivational attributions; providing motivational feedback; increasing learner satisfaction; and offering rewards and grades in a motivating manner (Dörnyei, 2001). Promoting motivational attribution is concerned with teaching the learner to appraise and react positively to their past learning (Dörnyei, 2001).

A teacher can help learners consider their learning achievement positively, by teaching students to explain past success and failure in constructive ways, helping them to be more satisfied with their success and progress, giving positive feedback that promotes ongoing learning, and giving rewards and grades during class (Dörnyei, 2001). The data obtained for this research did not indicate that the teachers encouraged their learners to explain past success and failures in constructive ways, or help them be more satisfied with their success and progress. The teachers from regular schools, Harry and Arfan, said that their students' low achievement in the past hindered their learning at high school. However, it should be noted that the four teachers respected students even if they were weak compared to their classmates. 
None of the four teachers in this study talked about teaching their students to evaluate their own learning. They also did not mention how they helped their students understand the best way of learning English. Perhaps, this is because of the nature of the course content, teaching methods and assessment in Indonesian schools (Bradford, 2007). Moreover, the motivational strategies employed in a language classroom may not address all the students' needs. Possibly, teachers may not pay enough attention to the students' learning motivation (Lamb, 2007).

The four teachers mentioned that they offered rewards and grades to their students. As teachers, they saw assessment as part of their role. They evaluated their students from the learning process, not just from the semester test. The students said that they liked their teachers' way of evaluating their learning.

The four teachers implemented the final phase of Dörnyei's framework by giving feedback positively to their students and offering rewards and grades in a motivating way. However, they did not mention promoting motivational attributions as a strategy to motivate their students. One aspect of this is the encouragement of students to reflect on their previous results and learn from what was not done well. The findings indicate that the students from regular schools considered that their past learning was a hindrance rather than a benefit for their learning. This raises the question of whether previous teachers had encouraged students to reflect on their learning. However, the data collected here do not deal with this question. This is an area where more understanding of strategies to promote self-reflection, as well as teacher professional development on this theme, is needed.

\section{Further discussion of the four phases}

Overall, the four teachers utilised most, but not all of the strategies suggested from Dörnyei's four-phase MTP model. Some findings appeared to fit with one particular phase of the framework while others linked with more than one phase. In addition, the data were a snapshot of motivational strategies. Some strategies may or may not have emerged when the data were collected. However, by using different data collection techniques, I endeavoured to capture a range of motivational strategies used by teachers.

Two strategies from stage one in Dörnyei's framework that did not emerge from the data in my study were the building of a good relationship with students' parents and classroom decoration. None of the teachers mentioned the building of a good 
relationship with parents, nor did they display English language materials and students' work as decorations in their classroom. This is in line with other studies which found that some strategies are culturally embedded (Cheng \& Dornyei, 2007; Marie-Jose Guilloteaux, 2013; Guilloteaux \& Dornyei, 2008). The wider context affects how schools are organised and the roles of the teachers. In Indonesian schools, subject teachers do not necessarily build relationships with parents. The school and the form/class teacher are tasked with building this relationship. The organisation of classes and spaces within the school constrains how the spaces in the classroom are used as part of the teaching process because many subjects are taught in the same classroom in Indonesia.

Three strategies from the other three stages of the framework, creating realistic learner beliefs (stage two), promoting self-motivating strategies (stage three), and promoting motivational attribution (stage four) also did not emerge from the data. Dörnyei (2001) explains that when helping students to create realistic learner beliefs, the teacher might explain to students various ways to learn a new language. By implementing this strategy, the students can then select suitable ways of learning English to achieve their learning goals. This means that the students are allowed choice in the classroom and that there is trust between the students and the teacher. This points to rapport between the students and the teacher.

To promote strategies that are self-motivating, Dörnyei (2001) suggested that the teacher should encourage the students to find ways to motivate themselves. Hence, a teacher needs to teach the students self-management skills so that they can understand the best way for them to learn a foreign language. The students are expected to understand which strategies suit their learning so as to achieve English language competency.

Teachers need to teach their students to look at their past learning experience positively to promote their motivational attribution. In psychology, attribution refers to an explanation as to why people are successful or have failed in the past (Dörnyei, 2001). According to Weiner (2000) attributions are the individuals' perceptions regarding the causes of outcomes. Teachers may help students gain positive conceptions of their learning. This will enhance students' expectation of success and motivation to learn (Sahinkarakas, 2011). 
The teacher could help students by employing activities that enable their students to experience success. The four teachers have implemented strategies to promote their students' learning. They used unique combinations of motivational teaching strategies which were found effective for their own contexts.

Among these combinations of strategies, several strategies that are not included in MTP emerged from the data. Examples are the use of L1, teaching students' moral values, looking at future learning or the ideal L2 self, and shifting students' attitudes towards English. These strategies were particular to the EFL situation in these schools in Indonesia. It is difficult to learn English for Indonesian students because English is a foreign language. Learning an additional language in a foreign language context requires greater motivation from students (Maclntyre, 2002). Language learning motivation could be considered unique compared to motivation for learning other subjects because learning a second language also involves taking on elements of the target language community's culture, psychological identification with the second language community, and changes in identity (Maclntyre, 2002).

There were some clear differences amongst the students' in their reports of preferences for motivational teaching strategies from the different types of schools. Students reported that they sometimes need the teachers to use $L 1$ for difficult learning concepts. This suggestion came from students from the international standardised school, because the teacher used English almost all the time in class. On the other hand, students from the regular schools wanted their teacher to use more English to make them familiar with English. Teachers in these two regular schools often used Indonesian in the classroom, indicating that the amount of L1 used in the classroom in this study depended on the students' needs and level of English. This supports the notion that $\mathrm{L} 1$ has an important role in learning $\mathrm{L} 2$ (Hummel, 2013; J. H. Lee \& Macaro, 2013; Nation, 2003). The use of L1 cannot be totally banned from $\mathrm{L} 2$ classroom because it is an integral part of the resources that the students bring to the classroom (Macaro \& Lee, 2013).

It can be seen in Figure 8.2 that some strategies are unique to this study. Use of L1 in the classroom was one of the motivational strategies in this study. This finding is line with studies in the area of L2 teaching and learning which found that L1 supported L2 learning (Al-Nofaie, 2010; Bingjun, 2013; Campa \& Nassaji, 2009; Carson \& Kashira, 2012; Ellis, 2008; Pakzadian, 2012). Unlike the other studies, this study's findings emphasised that the use of L1 is not only considered as a tool to 
support the learning of $\mathrm{L} 2$ but also as one of the motivational strategies used by the teachers. The data indicate that L1 use helped to motivate students when the teachers told jokes, gave advice, taught moral values, and explained difficult lessons. L1 was mostly used as the warm up of the lesson at the start, to make students feel comfortable and ready to learn. Teachers used it not only as a motivating strategy but also to build rapport with students. By having an encouraging relationship with students, the teachers tried to shift students' view of English as a difficult language. This strategy is not included in Dörnyei's (2001) framework. The findings of this study suggest that the use of L1 in an L2 classroom could be included in Dörnyei's (2001) framework.

Having a vision for learning English is likely to increase students' motivation since they can see advantages from mastering English for their future study and careers. It helps them to have a vision of their future language learning. This strategy is viewed as part of the L2 motivational self-system (Dörnyei, 2009a) which was discussed earlier on page 29. The ideal L2 self represents the learners' image of what they aspire to be in the future.

The teachers in regular schools, Harry and Arfan, stated that changing the students' mind-set towards English was important. Most students in these schools reported that English was daunting for them. To change this point of view, the teachers attempted to make English easier to use and to learn. To achieve this goal, the teachers created an accepting and supportive classroom atmosphere, built a positive relationship with students, and selected appropriate learning resources for students.

The comparison between Dörnyei's MTP and the findings in this research can be seen in the following figure. 


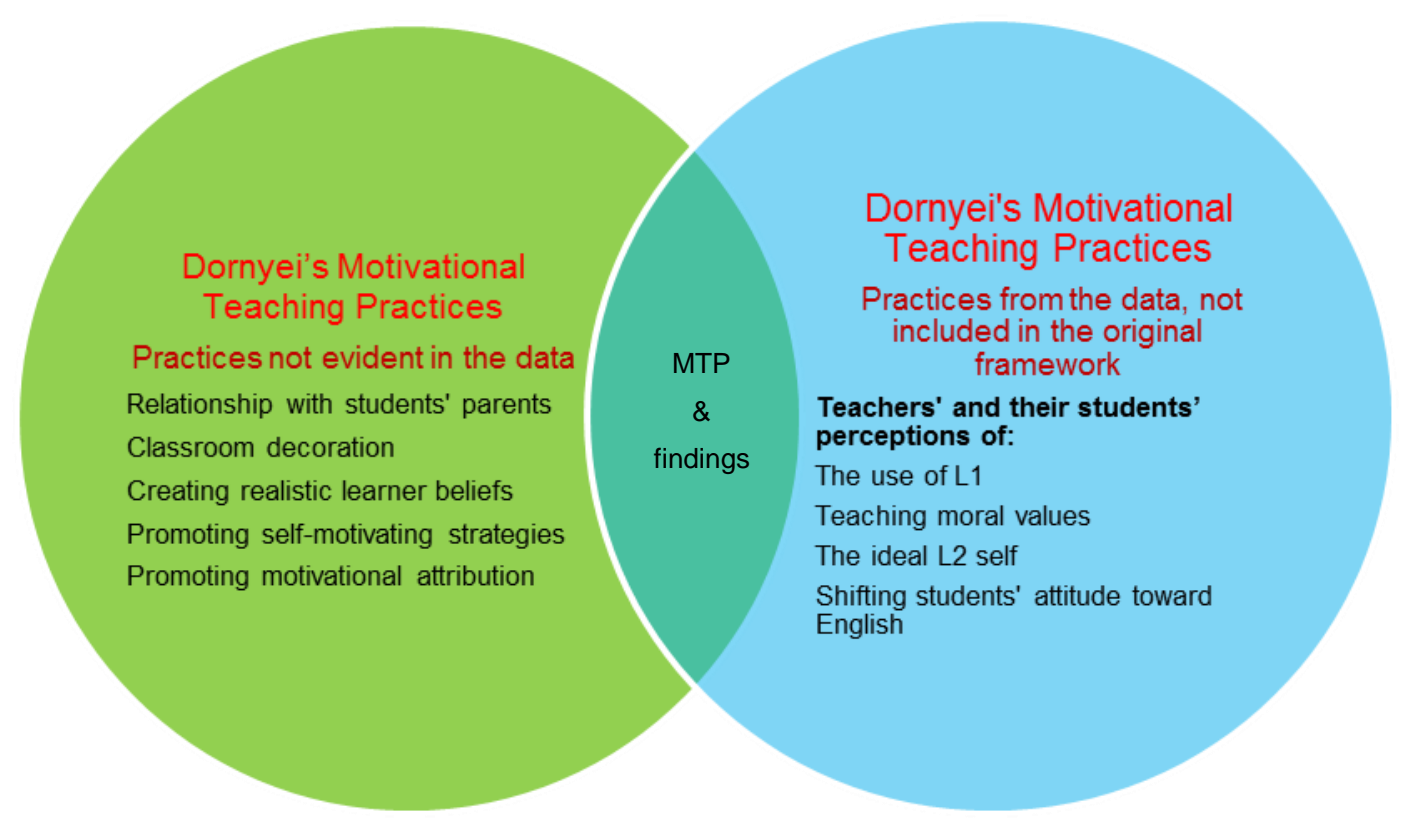

Figure 8.2: Comparison of Dörnyei's framework with the findings

The comparison of Dörnyei's framework and the findings indicate that not all strategies are applied across different teaching contexts. Some strategies are effective in all contexts but some strategies are contextually bound. This analysis using Dorynei's framework implies that the implementation of motivational strategies is embedded within a context. This will be discussed in the following section.

\section{Motivational teaching practice and the teaching-learning map}

The analysis of the findings reveals that the implementation of MTP is embedded in a particular context; one way of depicting this context is in the Hall and Kidman (2004) T-L map. The context is very important because it influences teachers' decisions in conducting their classes.

The context for this study can be represented by Hall and Kidman's (2004) T-L map. I argue that MTP and the T-L map are complementary. The findings of this study suggest that MTP can be positioned within the teaching-learning context of the T-L map. For this reason, with permission from Hall and Kidman (2004), I argue that the T-L map should be extended by putting MTP in the centre of the diagram, as shown below in Figure 8.3. 


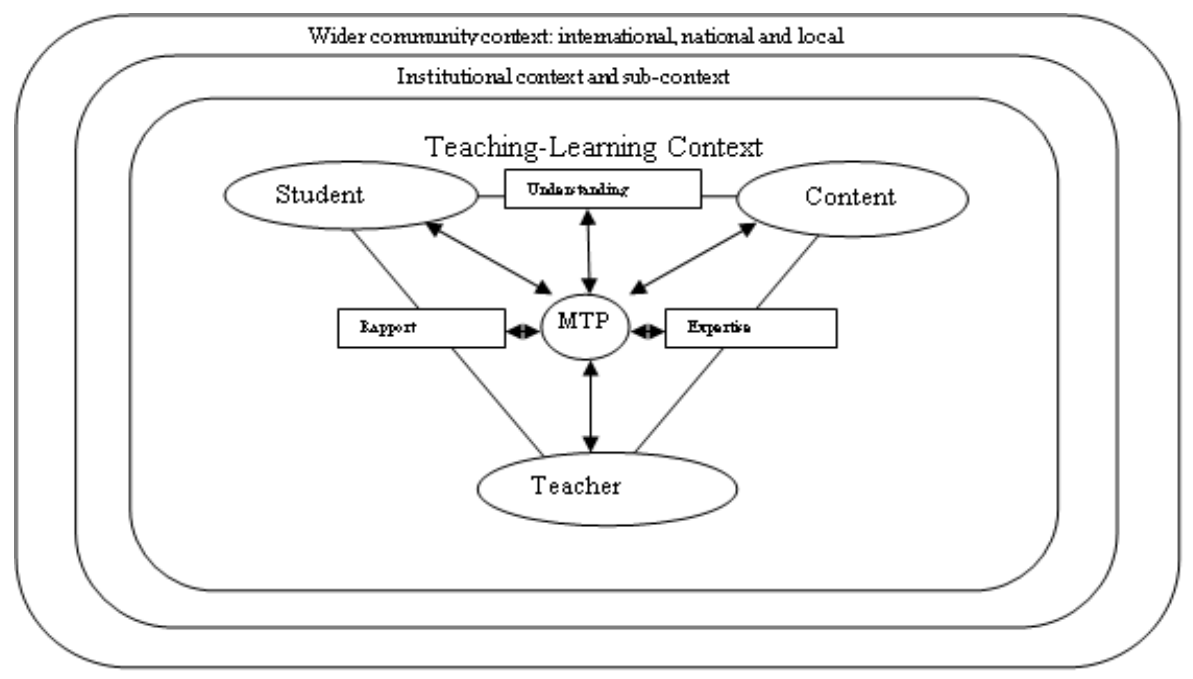

Figure 8.3: Teaching-Learning Map: The influence of context and motivation (a modified version of Hall and Kidman, 2004)

As noted in the literature review (chapter 2), Hall and Kidman emphasised the importance of context on teaching and learning; the model has a "Bronfenbrenner" structure. It is a relational map of teaching and learning within an ecological framework (see Figure 2.2 page 48 for an explanation).

The argument is made here that the MTP and T-L map are complementary. The discussion will start with the wider community context (English as a global language, the Indonesian educational system, and the local context), the institutional context (the four school contexts), and the immediate classroom teaching and learning context in relation to the teachers' and students' perception of MTP. The national or Indonesian context includes government policy and regulations and the Indonesian educational culture which influences the teaching and learning environment. The impact of these contexts on teaching and learning in the classroom will be discussed in relation to the findings of this study. 


\section{International context: English as a global language}

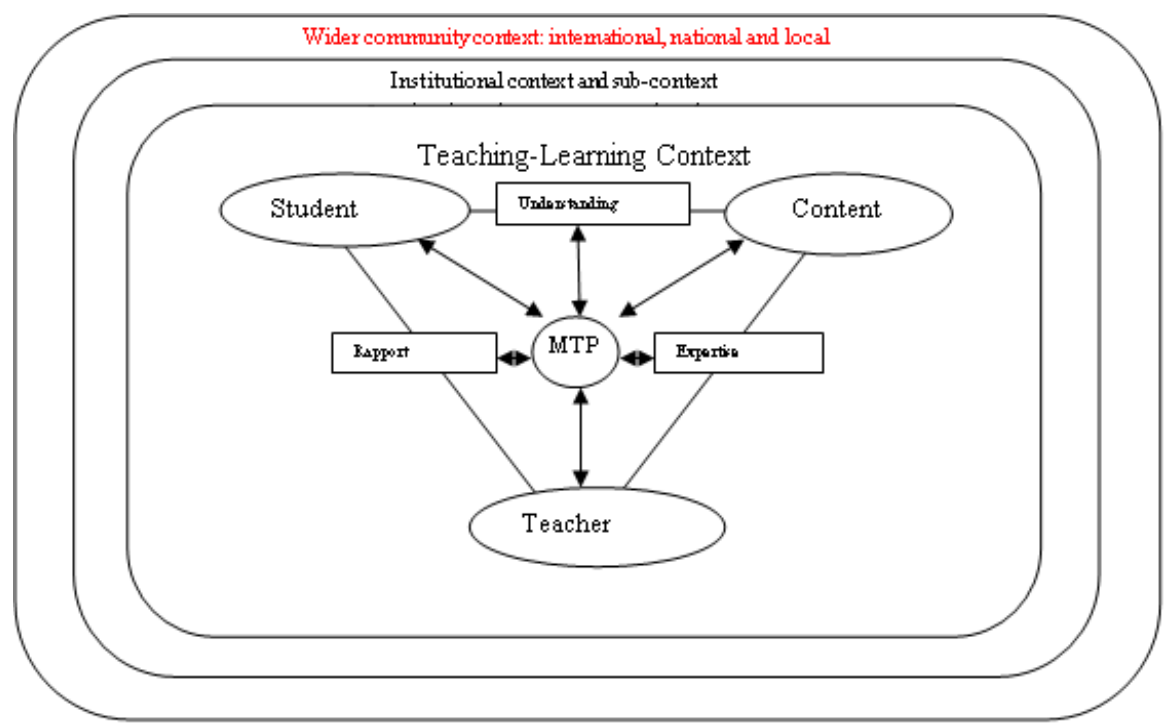

Figure 8.3: (repeated) Teaching-Learning Map: The influence of context and motivation

The wider community context includes the international context, for example, the impact of globalisation where people may work, study or trade with other people around the world. The importance of English as an international language has influenced the Indonesian government into creating a suitable curriculum for Indonesian students (Depdiknas, 2006). The high school curriculum for English aims to increase students' capability to communicate in both spoken and written English.

Both teachers and students reported that getting in touch with English native speakers motivated students' learning. This strategy fits within Dörnyei's framework. However, the teachers did not implement this strategy even though the students were keen on practising the language with English native speakers. The findings also reveal that teachers did not use internet facilities such as skype or facetime to bridge students' needs to communicate with English native speakers. Possibly, it was not easy to have English native speakers available in a small town and teachers are not used to using skype for communicating.

However, rather than aspiring to communicate with native speakers, Lamb and Budiyanto (2013) point out that Indonesian students should communicate and practise their English with their counterparts in Asia. This is because they are likely to have more communication with other Asian English speakers rather than with English native speakers from English speaking countries (Lamb \& Budiyanto, 2013). 
Arfan reported that the internet helped him greatly in his teaching. He browsed the internet to find suitable materials for his teaching. He realised that the internet is close to his students' lives. Most teenagers use the internet for communication and social networking such as facebook or twitter. However, although Arfan used the internet for his teaching, he did not use it to expose his students to English native speakers or other Indonesian proficient speakers of English. It should also be noted that the other three teachers did not mention using the internet to support their teaching or using the internet for their own social networking. These teachers did not seem to have any experience of using the internet for communication as they said that they did not have an email address or facebook account. Perhaps these teachers were not aware of media that are important to teenagers.

It seems that the teachers realised the importance of English as an international or global language. They emphasised the importance of English for obtaining a job internationally. However, it did not inspire them to utilise the internet or social networking as a medium of communication by using English. This indicates that the influence of the international context might not yet have a strong impact on teachers' classroom practices.

However, the position of English as the only compulsory foreign language in the Indonesian high school curriculum indicates that the Indonesian government is influenced by the international community. The advantages of being able to communicate in English in an international context for business, politics, and education have encouraged the Indonesian government to pay attention to English teaching and learning. This can be seen in the cycles of curriculum reform for English in order to promote students' ability to gain English proficiency so in the future they can take part in the global community. To reach this objective the government intentionally proposed the aims for learning English at Indonesian secondary school as being able to use English for communication with the international community and to learn English (the aesthetic or beauty of the language) and English culture (Depdiknas, 2008).

\section{National context: Indonesian educational context}

Within the wider community context, another important factor is the Indonesian educational context. This includes government policy, the national curriculum, and 
other related national regulations in schools in Indonesia such as teacher roles, time allocated for each subject, and official reports.

\section{Teacher roles}

According to Dörnyei (2001) teachers should be facilitators and motivators of their students' learning. However, this role has been extended by the Ministry of Education; a teacher is also required to be responsible for school discipline. For example, teachers are required to enforce the regulations endorsed by Ministry of Education ensuring that the school uniform is worn correctly.

The teachers in this study also reported that another role they have to complete is paper work and administration, which consumed a lot of their time. The paperwork covers lesson plans, constructing mid-semester and semester tests, the analysis of test results, and preparing learning assessment reports. The teachers understood that paper work was part of their job, but can find it very tiring when there was too much of it (Crookes \& Arakaki, 1999).

\section{Time for learning}

Both the teachers and the students wanted more time devoted to language learning. The Indonesian Ministry of Education allocates 180 minutes for a week to learn English at high school (Depdiknas, 2006). For students in regular schools, since English is mostly used only in the classroom, students reported that they needed more time to practice their speaking skills. It means that time allocated for English was not sufficient to address the students' desire to increase their English proficiency.

In line with the students' reports, the teachers said that the time allocated during their school year and the curriculum demands were not aligned. The learning topics to be covered in the curriculum outweighed the time allocated. This leads teachers sometimes to skip themes from the curriculum or just teach these themes quickly and provide limited time for students to practise. However, the teachers felt responsible for teaching all the themes in the curriculum since each learning topic is related to the national standardised test that students have to sit. Because of this time limitation, teachers experienced a conflict between whether to teach the curriculum or to teach students to pass the test. 


\section{Assessment}

In Indonesian schools, assessment involves both internal (within particular schools and within particular classes) and external assessment (national examinations). Student learning is assessed by teachers in the form of homework, assignments, block/unit tests, mid-semester tests, and semester tests. The homework, assignments, and unit tests varied among the teachers but the mid-semester and semester test were usually the same at each level in one school. Students who are leaving the school (Years 6, 9, and 12) sit for a school test which covers all subjects that are not tested in the National Standardised Test (Years 6, 9, and 12). During secondary school, students sit six subjects in the national standardised test which means 11 other subjects are tested by a school test. Three subjects in a national standardised test are the same for all senior high school students (Indonesian, English, and mathematics). Three other subjects are tested based on their stream. Science-stream students sit tests for physics, biology, and chemistry. The socialstream students sit economy, sociology, and geography tests. Language-stream students sit Indonesian literature, anthropology, and a foreign language other than English test. To get a certificate, students have to pass both school tests and the national standardised test. This certificate is important for students to continue their study to the next level of school. The assessment system is depicted in the following diagram:

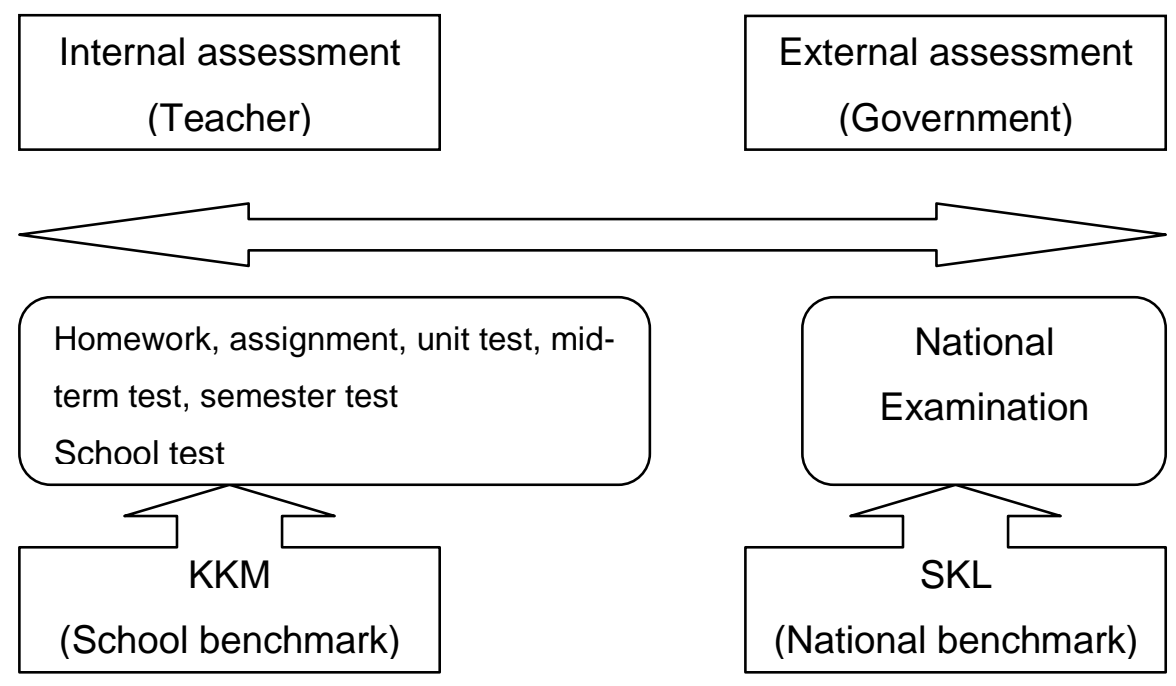

Figure 8.4: Assessment system in Indonesia (BNSP, 2007)

The school can decide the passing mark for each subject in the internal assessment. This type of assessment can be categorised as a summative assessment since it stops at a judgement (Taras, 2009). Actually, the government 
provides instructions in the national curriculum that teachers should give feedback on students' works to promote learning (BNSP, 2007). However, instead of giving written feedback on students' work, the teachers give marks. It seems that the national or external assessment practice in Indonesia influences teachers in assessing their students' learning (Azis, 2014). The teachers are not used to giving a formal formative assessment and constructive written feedback on homework, assignments, or unit/block tests.

The teachers in this study were encouraged to put marks on students' work rather than provide written feedback, because of the assessment system. English is assessed as a subject, meaning no individual marks are given for particular language skills such as listening, speaking, reading, and writing. In the national standardised test the test items generally assess students' reading with few assessing listening comprehension and only a very few items testing students' speaking ability. Writing skills are usually assessed by asking students to arrange a paragraph from jumbled sentences. In the semester academic report, teachers put a mark for English as a total of all skills that are tested with a teacher-designed test. Thus the teachers appeared to be influenced by this assessment system of giving marks on students' works/test rather than giving written academic feedback to promote students' learning.

Effective feedback is important for learning but there could be several reasons why giving full feedback is not regularly practised by Indonesian teachers of English. These reasons might include the number of students in each learning group, the assessment system in Indonesia, and the teachers' competence and experience in providing extensive written feedback. With so many students in each class, it is not easy for teachers to provide written feedback for each student. In the present study teachers often gave general feedback for their students' assignment in front of the class. After the students practised, they selected some points that they highlighted as important for students to consider.

However, for internal assessment there is a different passing grade between the different schools in this study. For the international standardised school, students required a mark of 75 while in the national standardised school and regular schools the passing marks were 68 and 70 . To some extent, the passing mark motivates teachers to help students to reach the level required. It also makes them work harder because if students do not achieve the passing mark, they have to give 
remedial teaching. This can lead teachers to teach students to answer test questions rather than teach the curriculum.

Descriptive feedback is a powerful influence on students' learning achievement (Hattie \& Timperley, 2007). Students need effective feedback to get information to improve their work. Teachers' marks on students' work or tests are therefore not likely to be as effective as descriptive feedback in helping the students reach their learning goals. Effective feedback is a bridge between what a student currently understands and what they need to understand (Hattie \& Timperley, 2007).

Regional politics and the Indonesian educational assessment system also determine the use made of assessment data. Students' achievements on the national standardised tests are used to find out which region in the country has obtained better marks or grades (BNSP, 2007). The grades influence the government's evaluation of each region. Assessment results are a political issue in Indonesia as the central government determines the resources to be given for local governments; regions with higher standardised test results usually receive more resources.

From the students' viewpoint, the English national standardised test is difficult, especially the listening section (Field note, March 2012). This is possibly because they do not have enough practice in listening. Test results are a determining factor for students' success or failure in passing their high school certificate. This certificate is one of the requirements to continue in education and study at university or to get a job.

Assessment influences students' motivation (Ghenghesh, 2010; Kikuchi, 2009; Matsumoto, 2009; Yeung et al., 2011). Kikuchi (2009) found that focussing on standardised test results decreased students' motivation. The current study found that teachers' supportive oral feedback on students' speaking practice motivated their learning and made them confident to use English. For example, Yuke was flexible in her assessment practices and gave her students choice in the assessment process.

\section{The English Curriculum}

Another influence in the wider context is the Indonesian EFL curriculum and the government policy for students' learning. Yuke reported that the curriculum did not accommodate students' communication skills; instead the curriculum provided more 
focus on literature skills for students. Teachers needed to follow what is dictated in the curriculum which is based on text-types, but at the same time, they also needed to teach students to pass the national standardised test. This national standardised test for English directs teachers to focus on teaching students how to answer the test rather than teaching the curriculum (Hadisantosa, 2010; Lie, 2007).

Teachers in the study reported that they needed to teach the characteristics of each genre since all genres were included in the national standardised test. The teachers said that how they selected teaching materials and approaches was influenced by the national curriculum which includes the national standardised assessment.

The genre approach in the current curriculum seems to limit flexibility in selecting learning resources because any language skill, grammar or language expression has to be related to a certain genre. The government intended to give more freedom to teachers to implement the curriculum based on their school context. However, since teachers were not provided with the appropriate professional development and training on how to implement the curriculum they tended to use the existing material from textbooks (Hadisantosa, 2010).

\section{National context: Indonesian educational culture}

Another influential factor is the Indonesian educational culture. The traditional Indonesian educational culture identifies teachers as the source of knowledge (Maulana et al., 2011). Teachers usually give the students direct feedback as to whether the students' answers are right or wrong. It is an absolute way of looking at knowledge that could be considered as teacher-centred. The teacher is in a position of power in the classroom. The teacher is the decision maker in the classroom and consequently learners may not be encouraged to be autonomous decision makers (Mattarima \& Hamdan, 2011b; Maulana et al., 2011). This may limit students developing their autonomous learning skills. It is not a common practice in Indonesian culture for teachers to allow students to argue or challenge their explanations. It is considered rude if students ask challenging questions or challenge a teacher's explanation.

MTP recommends that teachers promote students' autonomous learning by giving them the opportunity to evaluate their own learning. Teachers are expected to teach students to have skills in self-assessment/evaluation. The teachers in this study gave autonomy to their students to some extent such as allowing students to decide 
a discussion topic. Yuke also gave choice to her students about how they would like to do the test, alone or in pairs. However, since the Indonesian curriculum does not expect teachers to let students undertake self-evaluation or to develop selfattribution, the teachers do not think that they should include this in their teaching. This is another indication that the implementation of MTP is influenced by the culture of the wider context.

Viewing the teacher as a source of knowledge might also be influenced by passing the high stakes, national standardised test. Test results are used to evaluate school and teaching quality. Consequently, teachers focus more on teaching students to answer the test questions in Indonesia rather than on teaching the curriculum more broadly (Bradford, 2007; Lie, 2007).

Another common phenomenon in the Indonesian context is the low level of exposure to English. Low levels of exposure to English are a common phenomenon in the Indonesian high school context, except in the international standardised school. The students in the international standardised school looked more confident and fluent in English compared to students from the other schools.

The influences of school context on students' motivation to learn English will be discussed in the next section. 


\section{Institutional context: School Context}

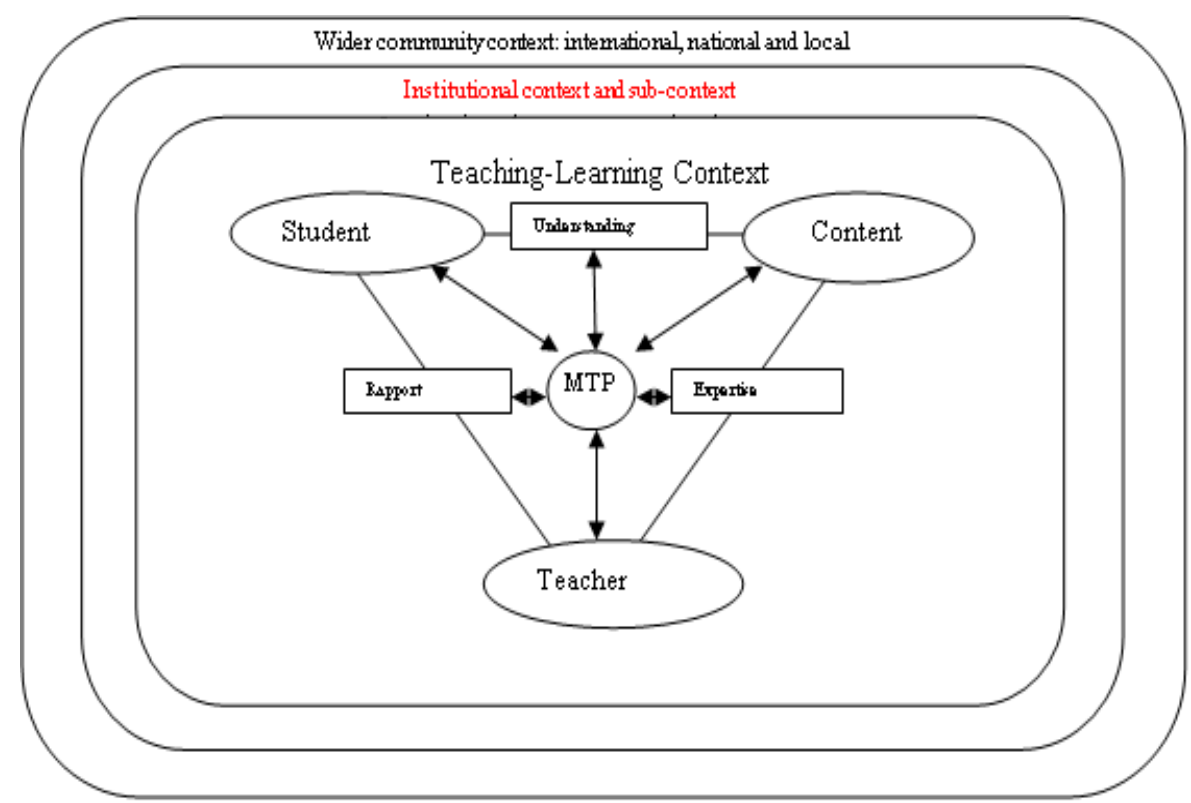

Figure 8.3: (repeated) Teaching-Learning Map: The influence of context and motivation

The next level of context in the T-L map is the institutional environment. The findings indicate that the school context influences teachers' perceptions and practices of motivational strategies. These factors include the amount of English used in the school context, the period of learning (class time), the availability of teaching and learning media such as a language laboratory or a tape recorder and data projector, and the school policy on the length of study for each day.

\section{The use of English in the school context}

Teaching other subjects by using English as a medium of instruction is known as content and language integrated learning (CLIL). This has positive influences on students' English learning motivation (Lasagabaster, 2011). In the Indonesian high school context, there is a big difference in English use between the international standardised schools and regular schools because of the amount of English the students use beyond the language classroom, for example, for mathematics and science classes.

One possible reason students seemed more motivated during English lesson is the use of English as a medium of instruction in other subjects in the international standardised school. They thought that understanding and being able to use English 
was a necessity for them. In other words, the influence of context on how much English is used may relate to students' motivation. This supports the research relating to the different motivation level associated with learning a language in second and foreign language environments (Oxford \& Shearin, 1994).

\section{The length of a school period}

The length of the school period for international and regular schools is different. In an international standardised school, students may remain until $4.00 \mathrm{pm}$, two hours longer than students from regular schools. In the morning students learn lessons from the national curriculum. This means that they are using English for two more hours each day because English is the medium of study.

Some of the students from the international standardised school stated that the additional hours motivated them to learn since in the afternoon they mostly practised what they learnt in the morning period. However, some students reported that the extended hours were too much for them. This meant that they had little time to socialise with family and friends.

\section{The timing of classes}

The timing of the class was reported as an influential factor for classroom learning motivation. Teachers and the students reported that studying in the morning was much more motivating in a hot climate since the weather was still fresh, and the students were more prepared to learn compared to study after lunch or in the last period of the school. Moza said that she adjusted her lesson and took more time to motivate her students in the afternoon periods. Mostly she reviewed the day's lessons, language expressions, and held classroom discussions rather than explaining a new difficult topic. This suggested that the context influenced both teachers' and students' motivation.

Harry said that he gave his students a short recess before he started his class in the afternoon period. He said that if he did not give time for his students to eat food or drink a glass of water, it would be hard for them to concentrate in a hot climate. The students also reported that learning in an afternoon period is more difficult. They were distracted by the hot climate, hunger, sleepiness, and noise from other classes. 


\section{Learning aids/facilities}

Moza and Arfan reported that teaching facilities also influenced students' classroom learning motivation. The availability of tape recorders, data projectors, or language laboratories supported the teaching and learning of English, especially when the students did not have access to native speakers of English. None of the four schools had a language laboratory. The teachers usually used a tape recorder in the classroom for listening exercises. Moza stated that she sometimes used her own voice by reading the script as the listening exercise for her students. Arfan utilised a programme from the internet and borrowed the data projector from the school to play the programme in his classroom.

The lack of listening and visual equipment for the classroom influenced teachers' motivation. Arfan and Yuke stated that they had to borrow and bring the tape recorder and data projector to the classroom if they wanted to use it as the teaching media. This sometimes made them unmotivated to use these teaching aids to support their teaching, even though they understood that this would motivate their students' learning.

\section{Number of students}

Teachers expressed concern about the number of students in a class. A large number of students was found to be demotivating for teaching and learning English (Marcellino, 2008). The teachers in this study said that it was not easy to manage so many students in the classroom, especially to learn a new language.

The teacher in the international school, Moza, was lucky since in an international standardised school there are only around 25 students for each class. In a regular school, a class usually consists of 40 students. This big difference in class size may have contributed to both teachers' and students' level of motivation. It also appeared to have influenced the teacher's decision-making in relation to their selection of classroom practices, such as types of activities, classroom rules, teachers' teaching approaches, and the way feedback is given.

The number of students in a class is determined not only by the school but also by local government decisions. Some schools are in high demand from students' parents. Consequently, the number of students in a class in some regular schools results in crowded classrooms compared to other schools (Field note, February 2012). The International standardised school was seen as high desirable but 
parents also paid higher fees. This was one of the reasons why this school had fewer students per class. The school also held an entrance test which limited the number of students.

\section{Teachers' perceptions of student learning achievement}

Both of the teachers from regular schools, Harry and Arfan, stated that their students' past unsuccessful language learning experiences and achievement hindered their present learning. This perception has the potential to influence the teachers' expectancy, values, emotions and beliefs (Weiner, 2000). The risk exists that teachers from a regular school might think that most of their students will not be effective learners because they were not successful in their past learning. This suggests that the school context might influence how teachers view their students' learning achievement. Such a finding corresponds with Dörnyei's L2 motivational self-system, which states that learning experience, teachers, curriculum, peers, and achievement influence students' learning motivation (Dörnyei, 2005, 2009b).

Harry and Arfan employed enjoyable learning activities to attract their students' attention such as telling jokes, using games, songs, poem or movies to stimulate the students. However, these are not activities that necessarily make students think deeply. There was clearly a difference between how Moza (in an international standardised school) and Harry and Arfan (in regular schools) approached their students. Moza usually used more activities to develop students' high level thinking while Harry and Arfan decided to use attractive activities such as games, jokes or songs. This was influenced by the school context and their perceptions of the students in the school where they teach.

The findings indicate that teachers' perceptions of their students' learning were influenced by the school context. This perception appeared to influence teachers' expectations, values, emotions, and beliefs in conducting teaching and learning in the classroom. However, regardless of the school context, the findings indicate that the four teachers have created, generated, and maintained their students' motivation. One exception is that none of the teachers taught their students to selfevaluate their achievement. Teaching the students to deal with their past learning experience in a way that promotes rather than constrains their future learning is reported as being important for students' motivation (Dörnyei, 2001). This helps them build their intrinsic motivation (Dörnyei, 1994). 


\section{Classroom context: teaching-learning context}

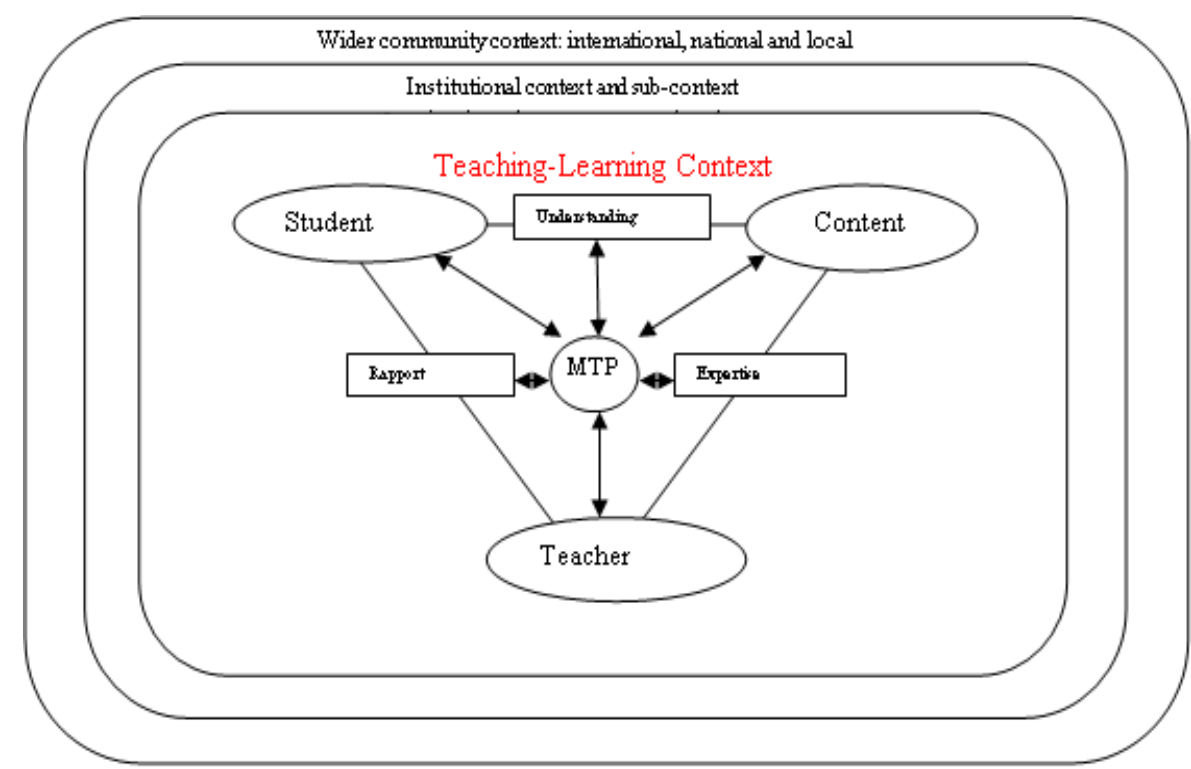

Figure 8.3: (repeated) Teaching-Learning Map: The influence of context and motivation

Lastly, there is the immediate classroom context where actual teaching and learning takes place. For my study, I situated EFL as the content. At this level, Hall and Kidman (2004) identify three aspects, the students, the content, and the teacher, in a contextual relationship. The key relationship between teachers and students is rapport, and a relationship between teachers and English is embodied in the notion of expertise. Teachers should possess two kinds of expertise: the expertise of the subject or content, and the expertise of delivering the subject or pedagogical skills (C. Hall \& Kidman, 2004). Both rapport and expertise are critically important to support students' understanding or learning achievement, that is, their English competency (C. Hall \& Kidman, 2004). According to these writers, rapport and expertise also interact to enhance or, if present negatively, limit student understanding and learning.

The two-headed arrows in the classroom teaching and learning map show the bidirectional impact of all classroom aspects on the implementation of MTP. In order to apply motivational teaching strategies, teachers need to build rapport with the students and vice versa. Similarly, one of teachers' areas of expertise is the ability to motivate students through their pedagogical expertise and classroom behaviours. The findings from this study indicate that the four teachers built a positive relationship with their students to support the success of their teaching. It was also reported by students that a warm relationship with their teachers enhanced their 
learning motivation. However, each teacher's strategies to build rapport varied according to the context.

From the literature, effective teaching is a matter of expertise as well as experience. Experience is important but is not enough without quality teaching or teaching knowledge (Palmer et al., 2005). The four teachers in my case study showed that they were expert teachers in different ways. This has been discussed in the Section Teacher practices on page 145.

In addition to psychological factors operating in the classroom, the physical classroom condition also influences students' motivation (Dörnyei, 2001). The classroom layout in the national standardised school provided more flexibility for the teacher and students to modify the classroom structure. The students sat on a chair with a little table attached to it. This made it easy for teachers to assign group work or pair work. The students also had the flexibility to select a friend to work with since they could move their chairs easily. The chairs could be arranged to form a circle with the teacher in the middle, a u-shape, or face-to-front like a common classroom. The international standardised classroom was equipped with carpet which enabled students to study on the floor. It was also equipped with an air-conditioner which is beneficial in the Indonesian hot climate. Students reported that they liked their classroom layout and conditions.

The findings of this study show that the implementation of MTP may not be effective without considering the context. The context plays an important role on how and why some strategies are implemented. The Indonesian educational context made it possible for the teachers to implement some strategies; conversely the context also made it difficult to implement other strategies. The findings suggest that the implementation of MTP is contextually dependent and the T-L map depicts the context well. These two frameworks support each other.

\section{Conclusion}

The findings show that the four teachers in my case study implemented motivational teaching strategies in their classroom. The teachers implemented strategies to make learning interesting and stimulating for their students. However, there is a missing link. The findings did not show that teachers taught their students to be aware that they should motivate themselves as learners. Creating realistic learner beliefs, promoting self-motivating strategies, and promoting motivational attribution are 
strategies that encourage students to be more independent in their learning (Dörnyei, 2001). These strategies build students' self-awareness that motivation is not created simply by outside factors such as the teacher, learning strategies, and an encouraging learning atmosphere, but also from internal factors within the students themselves. Students should be aware of this and teachers might possibly include strategies that help students promote positive self-attribution.

The findings suggest that two aspects, the building of rapport and the effectiveness of teacher's teaching practices, were crucial in motivating students to learn English. Rapport helped students feel accepted and relaxed in their classroom learning and encouraged their motivation. By using suitable learning resources, implementing appropriate classroom management strategies, and assessing students in different ways, teachers contributed to students' motivation.

The findings of this study align to a large extent with different stages of Dörnyei's MTP framework. The findings also indicate that the implementation of motivational strategies depends on the context. It reveals that to understand teachers' perceptions and practices in relation to motivational teaching strategies, the nature of an educational setting should be considered. This understanding can help teachers select motivational strategies to enhance their students' motivation.

Teachers' perceptions and practices of motivational teaching strategies were influenced by the school context and the Indonesian educational system and culture. The Indonesian educational system is influenced by the need for English as a global language. The findings indicate that MTP and the T-L map are complementary. The implications from my study indicate that the use of Dorynei's (2001) framework in analysing motivation has potential to improve learning and teaching in English language classes in Indonesia but it is important to consider contextual influences.

The following table shows how the research questions were addressed in the data. 
Table 8.2: Research questions and findings

\begin{tabular}{|c|c|}
\hline Research Questions & Findings from the data \\
\hline $\begin{array}{l}\text { Question 1: } \\
\text { How do Indonesian teachers } \\
\text { of English in high schools } \\
\text { report their perceptions of } \\
\text { motivational teaching } \\
\text { strategies? }\end{array}$ & $\begin{array}{l}\text { 1. Teachers stated that to motivate their students, they } \\
\text { need to build a positive relationship with their students. } \\
\text { 2. They understood that motivating students means using } \\
\text { interesting activities to attract students' attention to learn } \\
\text { English. } \\
\text { 3. Teachers argued that the encouraging relationship they } \\
\text { built with their students enhanced students' motivation. } \\
\text { 4. They did not mention that they taught their students to } \\
\text { build and maintain their own motivation. It appears that } \\
\text { the teachers did not think that they needed to teach their } \\
\text { students to be independent or autonomous learners. This } \\
\text { indicates that the Indonesian educational context and } \\
\text { culture influenced teachers' perceptions. }\end{array}$ \\
\hline $\begin{array}{l}\text { Question 2: } \\
\text { How do teachers implement } \\
\text { motivational teaching } \\
\text { strategies in the Indonesian } \\
\text { EFL classroom context? }\end{array}$ & $\begin{array}{l}\text { 1. Teachers implemented motivational teaching strategies } \\
\text { based on their cognition, teaching experience, curriculum } \\
\text { of English, and the context. The teachers tried to find } \\
\text { new strategies for effective teaching, using activities from } \\
\text { the internet or adopted activities from English teaching } \\
\text { forum magazines. } \\
\text { 2. Two main themes emerged from the findings: the } \\
\text { building of rapport with students, including the building of } \\
\text { an encouraging relationship with students; the influence } \\
\text { of teachers' decision making in selecting appropriate } \\
\text { learning resources, classroom management practices } \\
\text { and assessment procedures. } \\
\text { 3. The Indonesian educational context and Indonesian } \\
\text { educational culture influenced teachers' perceptions and } \\
\text { implementation of motivational teaching strategies. The } \\
\text { influences include the curriculum, learning assessments, } \\
\text { and the role of teachers in the school and society. } \\
\text { The school context influenced teachers' perception and } \\
\text { implementation of MTP. Some differences were found } \\
\text { between the international standardised school context } \\
\text { and the regular school context. These differences } \\
\text { included classroom facilities, the number of students in } \\
\text { each class, students' English achievement, and the use } \\
\text { of English in the school context. } \\
\text { The findings indicate that the MTP and T-L map are } \\
\text { complementary. The implementation of MTP is } \\
\text { influenced by the context. On the other hand, the context } \\
\text { also determined how meaningful some strategies in MTP } \\
\text { could be. The context determined that some strategies } \\
\text { are suited well and some strategies should be added to } \\
\text { MTP to fit the Indonesian high school context. }\end{array}$ \\
\hline $\begin{array}{l}\text { Question 3: } \\
\text { How do students report their } \\
\text { perceptions of the } \\
\text { motivational teaching } \\
\text { strategies used by their } \\
\text { teachers? }\end{array}$ & $\begin{array}{l}\text { 1. Students said that the teachers themselves are a } \\
\text { motivating factor for their learning. Teachers' classroom } \\
\text { behaviour was one of the key factors that influenced } \\
\text { students' motivation. Teachers' behaviours that students } \\
\text { found motivating included the teachers' warmth, their } \\
\text { enthusiasm, their caring manner, their understanding, } \\
\text { and their humour. } \\
\text { 2. The encouraging relationship that teachers built was } \\
\text { appreciated by students. The students mentioned that } \\
\text { they liked teachers who made them feel comfortable in } \\
\text { the classroom when they learn English. }\end{array}$ \\
\hline
\end{tabular}




\section{CHAPTER 9 \\ Conclusion}

\section{Introduction}

This chapter revisits the objectives of the study, discusses the contributions made by the research, and recommends directions for further research. The chapter ends with a "concluding statement" of the research as well as my personal reflections on the research overall.

\section{Summary of the research}

The findings from this research have been summarised in Table 8.2 at the end of Chapter 8. The purpose of this study was to explore the motivational teaching strategies that four teachers of English used and their impact on students' motivation in the context of learning English as a second/foreign language. The literature review identified a need to investigate teachers' motivational teaching strategies, how these strategies impact on the students' motivation, and how the social and cultural factors of the Indonesian context influence foreign language learning. To address this need, three research questions were developed to guide this study: How do teachers report their perceptions of motivational teaching strategies? How do teachers implement these strategies? How do students report the impact of these strategies on their motivation?

To answer these research questions, I used a qualitative research approach based on case study methodology. My study is situated within a social constructivist worldview that recognises that teachers' actions happen within particular contexts. Qualitative case study methodology allowed me to collect detailed, in-depth data, using multiple sources of information such as semi-structured interviews, classroom observations, stimulated recall with teachers, and focus group interviews with students, to describe cases and identify themes.

Four teachers were selected from four different high schools. Each case study was represented by a teacher (purposely selected because he/she was considered effective by the school principal) with a class of students from different types of school (an international standardised school, a national standardised school, and two regular schools). The collection of rich data allowed the context in which teachers implemented motivational teaching strategies, to be considered along with 
how their students reported the impact of these strategies. The research site was based in a small town in West Sumatera, Indonesia. I used Dörnyei's (2001) MTP to frame my study. Dörnyei's (2001) MTP framework for second and foreign language learning is believed to be comprehensive and systematic (Guilloteaux \& Dornyei, 2008). To complement this, I also used the Hall and Kidman (2004) T-L Map to provide a framework for investigating the contextual influences on teaching and learning.

The underlying assumption of Dörnyei's framework is that what teachers do to motivate their learners has a direct influence on the learners' motivation. The implementation of this framework is influenced by the context; the literature identifies that the use of motivational strategies is embedded within the teaching and learning context. The findings from the present study gave rise to an analysis of each case followed by a cross-case analysis.

The four teachers in my case study implemented a range of motivational teaching strategies to stimulate their students to learn English. There were two main themes that emerged from the data analysis: teachers' pedagogical practices and teachers' classroom behaviours, including building a positive relationship with students. Students reported that they were motivated to learn by the encouragement of their teacher, but some factors are beyond the teacher's control such as the length of classes, the curriculum for English, and national standardised tests. These factors also influence students' motivation.

This study adds to existing research in the field of motivational strategies in second and foreign language learning. In particular, four findings emerged from this study:

- Each teacher used a unique combination of motivational teaching strategies. The four teachers implemented strategies from Dörnyei's MTP, but not all the strategies were applied by the teachers. On the other hand, several strategies which are not included in MTP were used by the teachers.

- These teachers reported several factors influence them in selecting motivational teaching strategies such as the English curriculum, students' previous English achievement, students' social-economic background, and 
school context, including facilities and how much English is used in the school.

- The findings suggest that in implementing motivational teaching strategies, the context should be considered. Because of the importance of the context, this study has used an approach which blends two complementary models to embed Dörnyei's MTP in a broader conceptual framework.

- The findings indicate the use of $L 1$ can be a motivational teaching strategy. By L1, teachers can build rapport with their students and this stimulated students' engagement. The teachers also used L1 to explain difficult lessons.

These findings as well as their contributions will be elaborated in the following sections. This discussion includes a focus on the contributions of the findings to the literature and practices.

\section{The research findings}

The teachers in this study used a range of motivational strategies in the classroom. Each teacher used a unique combination of strategies from Dörnyei's MTP framework. The teachers and the students were influenced by their school context. In the international standardised school where English was the medium of instruction for mathematics and science, the students appeared to be more motivated to learn English. This may also be because most students were high achievers who gained entry to a school that was strongly preferred by parents. However, the students from regular schools (Harry's and Arfan's schools) indicated that they were impressed by the hard work of their teachers and the strategies they used to motivate them to learn. They recognised their teachers' enthusiasm for teaching.

Three strategies from Dörnyei's motivational framework did not emerge from the data: creating realistic learner beliefs; promoting self-motivating strategies; and promoting motivational attribution. These three strategies are related to students skills in motivating themselves or self-regulating their learning. The absence of strategies to encourage students' responsibility for learning suggests that in the cases of these teachers some aspects of the framework may not be implemented incompletely. This suggests that teachers could try to share their responsibility for 
motivating students with the students themselves. By sharing this responsibility, teachers might be more able to help the students become self-motivated learners. This could benefit students, not only for their high school English learning, but also for their long term learning.

Two further strategies, from the first stage of Dörnyei's framework (creating the basic motivational conditions), did not emerge from the data. These two strategies involved the building of a relationship with students' parents and the decoration of classroom. The absence of these indicated how culture and context can influence the strategies that the teachers use.

The influence of educational context and culture may explain why several strategies which are not included in Dörnyei's framework emerged from the data. These strategies are the use of $L 1$, teaching students moral values, reference to the ideal L2 self, and shifting students' attitudes toward English.

\section{Contribution of this study}

This study provides two main contributions relating to theory and practice. The findings of this study contribute to the theory of motivational teaching strategies by providing a model to understand the strategies in a wider context. The model indicates that the implementation of motivational teaching strategies is dependent not only on what happens in the classroom but also on factors outside the classroom that influence teachers' decision-making. Readers should be able to judge the applicability of the findings of this study to their own context both within Indonesia and internationally.

\section{Contribution to the field of motivational teaching strategies}

Many quantitative studies have been conducted on motivational teaching strategies around the world. This qualitative research adds to the literature. The study focussed on the implementation of motivational teaching strategies based on teachers' and students' perceptions and classroom observation. The data provided insights into the strategies that teachers' use and their impact on students' motivation.

The findings suggest that teachers should be able to select strategies to suit the curriculum demands, the school context, students' social-economic background, 
students' English achievement, and students' parents' expectations for their children's English achievement. In other words, teachers are expected to have an acute understanding of the context where they teach and the students they teach. One way to depict the influence of the educational context is provided by Hall and Kidman's (2004) T-L map.

The present study also contributes to the literature by suggesting a model of teaching and learning that may be applied to a range of educational contexts, although each context has its own specific features. A range of factors influence educational context such as curriculum, assessment, local educational policies, and the school context. This research conceptualises motivational teaching strategies and the T-L map as complementary. In this conception, the implementation of motivational strategies is contextualised within an educational map of teaching and learning. Dörnyei's (2001) MTP framework signifies a need to consider the wider educational, social, economic, and community contexts for its implementation.

The model proposed that the implementation of MTP is context-sensitive; teacher's perceptions of motivational strategies and the implementation of these strategies in the classroom depend on the supportiveness of the context. To understand the implementation of MTP, it is important to look beyond the classroom to the local, national, and international communities. Each layer portrays the educational context that relates to classroom teaching and learning. The wider contexts influence the teaching context. The findings of this study indicated that classroom teaching and learning is influenced by students' need to master English as an international language. This need influences the approach taken for the development and implementation of the Indonesian curriculum of English.

Interestingly, regardless of the school context, this study found that rapport is important and applicable to all three types of schools. This study signifies rapport between teachers and students as one of the important components for achieving successful teaching and learning. As noted in the Hall and Kidman (2004) T-L Map, rapport is a central element of the teaching and learning context. Teachers' perceptions and implementation of motivational teaching strategies are not shaped automatically. Teachers' motivation, cognitions, and teaching experience, along with the curriculum, educational context, and teachers' education at teachers' training college, all influence the teachers' perceptions and their implementation of motivational teaching strategies. 
The teacher from an international standardised school, Moza, found motivating her students less challenging. Her students understood the importance of English; additionally English is a medium of instruction for mathematics and science. The national standardised school teacher, Yuke, also did not find it hard to motivate her students. The school is one of the desirable schools so that the students who are studying at this school are more likely to have high motivation to learn. The teachers from regular schools, Harry and Arfan, found it more difficult to motivate their students. Their schools were less desired by parents and were not well-supported by good learning facilities. However, although they faced difficulties in motivating their students, these two teachers used a range of motivational teaching strategies in their classrooms. This indicates that teacher motivation and commitment to teaching influence teachers' perceptions and implementation of motivational teaching strategies.

In turn, MTP also influences the smaller unit of context, classroom teaching and learning. MTP involves cyclical stages which can be applied in most language classes. Some strategies are contextually transferable but some strategies are culturally bound. Two strategies noted by Dörnyei did not emerge from the data here: these related to the use of classroom decoration and the building of relationships with students' parents. It is not normal for most Indonesian schools to decorate the classroom walls with students' work, pictures or graphs to motivate the students' learning because the classroom is a venue for a group of students to learn all school subjects. They sit in this particular room and subject teachers come to them to teach so decoration for a particular subject may not be appropriate. Subject teachers also do not build a close relationship with parents. Parents usually build a relationship with a form or classroom teacher who is responsible for a group of students.

Another contribution from this study is the use of $L 1$ in language teaching. Appropriate use of L1 emerges as a potential motivational teaching strategy. The teachers in this study used L1, not only to support L2 learning but also to enhance students' motivation by building a positive relationship with their students. The teachers usually used L1 as an ice-breaker to make students relaxed and comfortable so they were ready to learn. L1 was usually used to tell jokes, give advice, and teach moral values. This fits in phase one and two of Dornyei's framework, creating the basic motivational condition and generating initial motivation. The teachers also used L1 to explain difficult lessons, this fits in phase 
three of the framework, maintaining and protecting motivation. Even though the use of L1 is not included as a motivational teaching strategy in Dornyei's framework, the findings indicate that the use of $L 1$ can be related to three phases of Dornyei's MTP (2001).

In summary, the analysis of data in the present research indicates that Dörnyei's (2001) MTP framework relates well, although not fully, to the contexts of each of the four schools in this study. The application of the framework, however, is limited by certain cultural practices and a curriculum limitation that may limit the way teachers helping students develop self-motivation skills and attitudes (see next paragraph). Dörnyei's (2001) framework sits well with the Hall and Kidman (2004) T-L Map for identifying the contextual influences that impact on teaching and learning; these influences may come from the wider community context, the school context, or the particular classroom environment. Examples were provided in Chapter 8.

\section{Contribution to the implementation of motivational teaching strategies in Indonesia}

The findings of this study offer a framework of motivational teaching strategies that teachers can apply in their classroom. This framework, as presented in Figure 8.3, indicates that to enhance students' motivation, the teacher needs to consider a range of factors such as rapport, teaching expertise, and context. The model in Figure 8.3 shows that motivational teaching strategies alone are not enough to motivate students to learn English. The context plays an important role. Teachers can select strategies to suit their context and the students' needs. This implies that it is crucial to consider the Indonesian educational context and culture to support the implementation of motivational teaching strategies.

\section{Understanding the Indonesian educational context}

In an Indonesian educational context teachers are still considered to be a source of knowledge and have responsibility for students' achievement. It appears that this influences teachers' perceptions and implementation of motivational teaching strategies. Teachers hold a perception that their duty is to transfer knowledge and also motivate their students to learn. In practice, they may be able to share this responsibility with their students by helping their students to gain skills in using selfmotivating strategies. 
Teachers are also expected to be responsible for enhancing their students' learning in a way that is determined by the curriculum. However, the most important way of assessing learning is a national standardised test. This may result in a conflict within the teachers' perceptions of what to teach and how to assess it. The teachers in this study reported that they assessed their students' learning through the learning process but it was still clear that the natural standardised test was a dominant component of the mix of assessment that teachers used. The risk exists that teachers will teach to the test.

As mentioned, Indonesian high schools are categorised into international, national and regular/local standardised schools. This school context also influences teachers' perceptions and implementation of motivational teaching strategies. The teacher in international and national standardised schools, Moza and Yuke, used learning activities that need more critical thinking while the teachers in regular schools, Harry and Arfan, used activities to engage their students' attention such as games, songs, poems, and short movies. Even though teachers used different approaches for learning activities, they held a similar perception that building rapport with students is a key factor for enhancing students' motivation.

\section{Understanding the Indonesian educational culture}

The Indonesian cultural value of respecting teachers and not challenging them with questions may impede interaction and maintain a distance between the teacher and students. However, Arfan encouraged his students to ask questions. The teachers in this study appeared to understand that respecting teachers does not mean just listening to teachers' explanations but also participating in an engaged and constructive way. The students seemed to realise that respect for teachers could be demonstrated by being motivated in the learning process, showing engagement in the classroom activities, or behaving well by not talking to each other when the teachers explained lessons.

The findings indicate that all four teachers were open-minded about decreasing the power/distance created by their authority over their students. This gave more opportunity for students to develop their confidence to ask critical questions or to accept different views from their teachers. This study found that teachers built a positive relationship with their students but they did not share their authority with students to any significant extent. There was still, with a few exceptions (see next 
paragraph), an authority gap between teachers and students, especially in relation to decision-making. Within the educational and sociocultural environment of Indonesia, teachers are perceived as authoritarian figures with full authority in the classroom. Teachers can decide the classroom rules that suit their classroom needs (Lamb \& Coleman, 2008). The Indonesian collectivist society perceives teachers as having high status in which students are not in a position to challenge teachers' authority. This view positions teachers as resources and students as receivers of the teachers' learning. The literature suggests that this situation limits the development of self-motivation by students. It is still a common phenomenon in many Indonesian school contexts that there is a significant gap between teachers' and students' authority. By sharing authority, teachers encourage students to take control of their own learning. Doing this may also help students shift their motivation from being extrinsic in nature to intrinsic (Ryan \& Deci, 2000).

The model in Figure 8.3 shows that students are also responsible for their own motivation. Teachers may share their authority with students by discussing each party's responsibility in the classroom for teaching and learning. For example, teachers and students may agree on how the learning is evaluated. The four teachers assessed their students' learning by judging the students' participation in class activities; assessment also included homework, attendance, and teacherdesigned tests. Yuke gave her students a choice to sit for her tests alone or in pairs. By giving choice to the students and involving students in decision-making, she attempted to share the teacher's authority with her students.

Teachers can share their authority by the language they use, for example, by focussing on students' responsibility. When a student asks questions, the teacher can ask the class to answer it, or ask students to find the answer by searching it in other resources, or discuss it in pairs or groups. This is one way to make students recognise that learning is a shared responsibility. However, one of Harry's students said that she wanted direct explanations from her teacher. In such circumstances, the teacher could help this student by telling her that learning is a process of acquiring knowledge not only from a teacher but also from peers and other sources.

The data revealed a variety of ways for teachers to share power with their students. Another way of sharing authority with students is by setting classroom rules at the beginning of each semester with the students. This indicates that teachers want their students to be involved in decision-making about teaching and learning. Moza 
and Harry gave opportunity for their students to select discussion topics and the approach they might take to tasks. Yuke offered an opportunity for her students to sit internal tests alone or in pairs.

\section{Contribution to classroom practices}

This study provides an insight into motivational teaching strategies in an Indonesian high school context. This insight may contribute to understanding the problems faced by many high school students who are attempting to achieve English competency by highlighting how the teachers perceive and implement motivational teaching strategies. The following headings cover important developments that this study has identified as gaps in current practice.

\section{Building rapport with students}

The finding of this research indicates that rapport is a core component in classroom teaching and learning. As noted in Figure 8.3, rapport influences the classroom atmosphere, and rapport enables teachers to implement effective teaching, while at the same time it also supports teachers in building positive classroom behaviours.

The four teachers fostered encouraging relationships with their students and this enhanced teaching and learning. Interestingly, regardless of the school context, rapport seemed to be a main ingredient for motivating students to learn.

\section{Teachers' classroom behaviours}

Teachers' classroom behaviours seemed to influence students' motivations. One of the students in a focus group interview stated that the most influential factor for him is the teacher; if he likes the teacher he will be motivated to learn English. The four teachers indicated that they used motivational classroom behaviours. Moza showed warm facial expressions and smiled when she taught. Harry showed his enthusiasm and caring by calling his students by their nicknames. Yuke looked enthusiastic when she greeted and interacted with her students. Arfan talked to his students in an informal way to encourage his students to practise their English and ask questions.

\section{Reducing continuous use of a textbook}

This study found that the teachers in the study modified materials from textbooks for their teaching. This indicates teachers need to be competent in evaluating when to use the materials from the textbook. The four teachers did not to use the textbook 
constantly. They modified stories to suit their students' context, so it was easy for students to understand. One of the teachers, Harry, used his students' names as the characters in stories so as to attract his students' attention.

It is clear that teachers understood their students' needs when they selected materials from textbook. They understood that their students responded in class to more lively learning materials; materials from the textbook could be learnt at home or in their own time. The reduced use of the textbook in the classroom contributed to a livelier classroom since it encouraged more interaction rather than a focus mainly on what was in the book. Moza said that her students were likely to pay less attention if she read a story from a textbook; instead they looked enthusiastic when she told stories. This suggests that teachers need to be discriminating in selecting materials for use in the class.

The findings also indicate that using learning resources from the internet motivates students to learn. Arfan's students seemed more engaged when he used learning materials from the internet especially for short movies and animated grammar games. However, Yuke's students seemed enthusiastic to practise a new learning activity which involved use of body movement such as a 'cycle-stand'.

Another approach is to source learning material from The English Teaching Forum magazine. Harry stated that this magazine contained a range of strategies for teaching English skills (listening, speaking, reading and writing), vocabulary, language expressions, poetry, dramas, and idioms. This gives teachers more options for practising the strategies that suit their teaching context.

The findings from this research indicate that students enjoy activities introduced by their teachers rather than simply reading and doing exercises from a textbook. Moza and Yuke were more likely to use activities to develop their students' critical thinking while Harry and Arfan selected activities to attract their students' attention. However, all four teachers motivated their students by adopting learning materials that were interesting for their students.

\section{Introducing learning strategies}

Only one teacher introduced students to the value of different learning strategies. The results of this study suggest that teachers may help students build their own motivation by teaching students different ways of learning a foreign language. Through an understanding of learning strategies, teachers could help students 
select and develop different ways for improving their own learning (Dörnyei, 2001). Teachers could give examples of how to use a range of learning strategies matched to particular purposes so that students are able to practise and use them individually later on. For example, as noted by both teachers and students in this study, it is hard for students to develop reading and listening comprehension skills. Teachers could teach students different contextual clues and give practice in these. This might enhance students' motivation by improving their performance and sense of success.

\section{Regarding mistakes as part of learning}

Additionally, the four teachers encouraged their students to use English to develop their speaking skills. During the development of speaking skills, they regarded mistakes as a part of the learning process. Harry even said to his students "the more mistakes, the more you learn". None of the teachers corrected mistakes publicly in class to ensure that their students did not feel embarrassed in front of their peers. It appears that the four teachers wanted to make their students feel confident to help them build their own motivation to practise the language.

\section{Improving classroom management}

Teachers often find managing a classroom is difficult, especially to manage students who are misbehaving. The four teachers from this study had a strategy to handle these difficult students. They approached students in person and talked to them individually. This seemed effective since the students were not scolded in front of their peers.

The findings indicate that managing high school students may be difficult since if teachers hurt students' feelings or disappoint them in front of their peers, the students might challenge the teacher or simply switch off from the lesson. One of Arfan's students said that she likes Arfan's way of dealing with his students. Arfan positioned himself as a "father" who advises students with appropriate words. He was also approachable outside the classroom. This aspect of rapport made it possible for Arfan to move students to a seat with a suitable partner without annoying the students.

The teachers from regular schools, Harry and Arfan, often gave advice to their students before starting their lessons. It seemed that they not only intended to build rapport with their students but used strategies that helped them manage the class. 
Also by teaching moral values through their advice, they invited their students' to behave properly.

\section{Emphasising the usefulness of English}

Another way to enhance students' motivation is by explaining the benefits of having English skills for their future lives. This approach appears to encourage students to have a vision for their future, hopefully improving their motivation to learn English. All four teachers explained to their students that English is important for their future studies and careers. Giving reasons for learning English is one strategy to motivate students.

\section{Students' perceptions}

Generally students from all the four schools held a similar perception that their teachers were the main source of motivation for them. The teachers' classroom behaviours and their decision-making about various learning resources/activities, appropriate classroom management, and how feedback was given influenced their motivation positively. However, several factors beyond the teachers' authority seemed to decrease students' motivation to some extent.

The students from the international standardised school mentioned that the long hours they spent in school did not motivate them to learn. The long hours were a burden for them because they needed time to socialise with their families and friends outside school. These students also said that they wanted their teacher to use more L1, especially when she explained a difficult learning topic. On the other hand, students from the regular school mentioned that they wanted their teacher to use more L2 because they wanted to get used to listening to English.

One of Yuke's students reported that they did not always like to work in groups. The student reported that sometimes other students were not on task or they were relying on high achievers to complete the task. Additionally, one of Harry's students mentioned that she did not like too much use of humour in the classroom especially when her friends seemed to take advantage of this opportunity to distract the teacher from the learning goals of the class. 


\section{Areas for future research}

Various studies have been conducted on motivation in learning English within an Indonesian EFL context. Future research is needed on how to encourage high school students to self-regulate so they can be autonomous learners. It is important to teach students how to develop self-motivating strategies for their future learning. This is one of the motivational strategies identified in Dörnyei's (2001) framework. A study could be undertaken initially to identify how teachers may go about encouraging independence in students and what obstacles need to be addressed.

This study has underlined the missing link of sharing responsibility between teachers and students for the cases in the study. This implies that the teacher needs to teach students that they are responsible for their own learning. It suggests that Indonesian teachers might need to lower the perception of hierarchy in the classroom, for example, by increasing rapport with students. This may be an area for further research by investigating teacher beliefs about factors that contribute to the building of rapport. This may allow the impact of teacher beliefs about rapport to be captured and linked with the achievement of learners in the Indonesian high school context.

A model of motivational teaching strategies in context has been proposed from the findings of this study. This model should be further investigated to identify the ways contextual factors-external and internal to a school-impact on teaching and learning. $A$ focus on the motivational implications of different influences should be central to this research.

\section{Recommendation for learners/teachers/stake holder}

Students need to understand that they are also responsible for their own learning. They should be able to self-regulate their learning in order to be autonomous learners eventually. Teachers have a role in this process of developing autonomy. Teachers may let learners to have choices about many aspects of the learning such as, discussion topics, strategies to accomplish tasks, or finding learning materials from internet or other resources. Teachers can also help students set realistic long and short term goals. They may teach students to self-assess their own progress towards these goals. They can help students to think about not just what they are learning but also the ways they are learning something. They can provide 
opportunities for students to use learning strategies and reflect on the effectiveness of such strategies.

Teachers can hand over various leadership/teaching roles (e.g. let students lead a discussion, teach students learning strategies, teach students various ways/resources for learning English) by adopting a role as a facilitator and letting students find out answers for some questions from their own resources/internet. Teachers should encourage learners to be more active, giving them opportunity to ask questions, encouraging them to find answers themselves. To implement those strategies teachers need to decrease their traditional authority. Building and maintaining rapport assists them to understand students. Teachers also need to understand the teaching context (students' academic background, social/cultural values, availability of teaching facilities) in order to implement motivational teaching strategies effectively.

The Ministry of Education of Indonesia should develop a curriculum for English that helps teachers to match teaching strategies and the assessment of students' learning. Specifically, when the curriculum directs teachers to increase students' language skills in listening, speaking, reading, and writing, the assessment should include all these four skills instead of only focussing on testing reading comprehension and grammar.

\section{Concluding statement}

This study contextualised the different motivational teaching strategies used by four teachers of English in an Indonesian high school context. The findings provided evidence that the implementation of motivational teaching strategies is contextually embedded. Figure 8.3 highlights that teachers' perceptions and the implementation of motivational teaching strategies are formed and influenced by several factors and contexts. The T-L map depicts the context well and how each context relates to teaching and learning. Both frameworks (MTP and the T-L map) complement each other and are able to be used for different classroom contexts. It is the role of researchers and teachers to unpack what particular influences impact on specific contexts.

As noted in the literature, motivation fluctuates and is not an automatic response from students. Consequently, the ability to self-motivate is important for keeping 
students engaged in their English learning. Teachers might consider building both students' extrinsic and intrinsic motivation. In order to do this, the four teachers used a range of strategies in their classroom to engage their students.

This study provides views from both teachers and students about what they consider motivates student learning. For example, teachers and students hold different views on the frequency of using L1. Students from an international standardised school would like their teachers to use more Indonesian while their counterparts in a regular school liked their teachers to use more English.

There appeared to be little difference between teachers' perceptions and students' perceptions of what constitutes motivational teaching strategies. Both teachers and students seemed to hold similar perceptions that it is motivating when teaching and learning involved games, songs, stories, jokes, or internet based activities. This indicated that teachers in this study were experienced and highly skilled teachers who understood ways to encourage their students to learn. Additionally, rapport between these teachers and their students helped the teachers gain information on what their students expected in the classroom learning. The teachers knew the students and drew on their experience to find ways that the students considered effective as motivational teaching strategies.

The findings also suggest that motivational strategies may be learned and improved. Hence, teachers are also part of the process to provide better classrooms for teaching and learning. This indicates that teachers will benefit from hearing their students' views about what motivates them in learning English. Involving students provides a balance to teachers' own views; this can only help teachers select or develop strategies that will enhance students' motivation to learn.

\section{Limitation of the study}

My study has a number of limitations. Some of these have been covered in Chapter three but others are addressed here:

The data was a snapshot since I just observed one classroom meeting for each teacher. However, I used methodological triangulation -data from different sources to strengthen my study. The interview and the stimulated recall aimed to capture what these teachers usually did in their classroom to motivate their students. 
Because I had taught in the same town, these teachers were my professional colleagues. I had a good relationship with them. I was able to see how representative this snapshot provided by my data might be. However, this study could be strengthened if I had conducted more than one classroom observation for each teacher.

After the interview with teachers and focus group with students, I summarised and checked with them the main points of their ideas to ensure that I understood their point of view. I did not have the opportunity to discuss the interview, stimulated recall, and focus group interviews script with them. This would have given them an opportunity to check that the data fully represented their views and maybe they wanted to add some more information. As not all of them were easily accessible by email it was difficult to send them transcripts after the interviews.

The interviews with teachers and focus group with students were in Indonesian since the participants could express their ideas appropriately and easily in their first language. I transcribed the data and then translated the data into English. I was careful to keep as close as possible to the original meaning. I used my knowledge of their context to interpret the meaning if there was any ambiguity.

The students were relaxed in answering questions. It indicates that the discussion was like an informal conversation and this allowed them more freedom to express their ideas and opinions. The focus group interviews were in a canteen; this made them feel comfortable rather than being interviewed in a school environment. The students felt secured since they were interviewed together with their peers. Additionally, their peers' answers prompted their thoughts to elaborate. The questions asked were general questions to elicit students' views of motivating classroom learning. The questions were what make them interesting to learn English in the classroom, what activities they enjoy doing in learning English in the classroom, or tell me some of the things that the teacher does that make them want to learn English.

\section{Personal reflection}

This PhD journey has been a great learning experience for me as an English teacher. It has contributed to my career as a teacher and researcher. I now see more clearly the importance of the educational contexts in the way teachers foster 
motivation in their students. My study also gave me the opportunity to listen to students' voices about the influences on their motivation. This journey has enabled me to understand myself as an English teacher in an EFL context.

I see this study as a contribution to the literature of motivation in an ESL/EFL context. This study has given me an opportunity to pay attention to teachers' strategies for motivating their students and the reasons why these strategies are used. Through the research findings, I have been able to construct a way of viewing motivation in the classroom that builds on, even though in a small way, the models that have emerged from the extensive work of researchers much as Dörnyei and Hall and Kidman.

On a personal note, this $\mathrm{PhD}$ journey has developed me not only as an EFL teacher and future researcher but as person who values the importance of life-long learning. I have learned a lot from both of my supervisors about how to motivate students from the ways they motivated me. Both of them remind me of the framework and the proposed framework that has emerged from this research; and at the same time they have given me examples of how to encourage others to teach and act in ways that are motivating to those around them.

This journey reminds me of the first ayah in the holy Qur'an: 1 إق , "Read" (96:1). This means that seeking knowledge is an obligatory for everyone. This motivates me to keep learning and spread the knowledge and compassion to others. 


\section{REFERENCES}

Afzal, S. (2013). Using the first language in English classroom as a way of scaffolding for both the students and teachers to learn and teach English. International Research Journal of Applied and Basic Science, 4(7), 18461854.

Al-Nofaie, H. (2010). The attitudes of teachers and students towards using Arabic in EFL classrooms in Saudi Public schools: A case study. Research on Youth and Language, 4(1), 64-95.

Alrabai, F. A. (2011). Motivational instruction in practice: Do EFL instructors at King Khalid University motivate their students to learn English as a foreign language? Arab World English Journal, 2(4), 257-285.

Astuti, S. P. (2013). Teachers' and students' perceptions of motivational teaching strategies in an Indonesian high school context TEFLIN Journal, 24(1), 1-18.

Azis, A. (2014). Indonesian junior secondary school teachers' conceptions of assessment: A mixed methods study. Doctor of Philosophy, Victoria University of Wellington, Wellington. Retrieved from http://hdl.handle.net/10063/3201

Bailey, F., \& Ken, P. (2003). To meet your students where they are, first you have to find them: Working with culturally and linguistically diverse at-risk students. The Reading teacher, 56(4), 370.

Bandura, A. (2001). Social cognitive theory: An agentic perspective. Annual review of psychology, 52, 1-26.

Bernaus, M., \& Gardner, R. C. (2008). Teacher motivation strategies, student perception, student motivation, and English achievement. Modern Language Journal, 8, 387-401.

Bernaus, M., Wilson, A., \& Gardner, R. C. (2009). Teachers' motivation, classroom strategy use, students' motivation, and second language achievement. Porta Linguarum, 12, 25-36.

Bingjun, M. (2013). What is the role of L1 in L2 acquisition? Studies in Literature and Language, 7(2), 31-39.

BNSP. (2007). Standar penilaian badan standar nasional pendidikan. Jakarta: National Education Standard Board.

Borg, S. (2003). Teacher cognition in language teaching: A Review of research on what language teacher think, know, believe, and do. Language Teaching, 36, 81-109. doi: 10.1017/SO261444803001903

Borg, S., \& Al-Busadi, S. (2012). Teachers' beliefs and practices regarding learner autonomy. ELT Journal, 66(3), 283-292.

Bradford, A. (2007). Motivational orientations in under-researched FLL contexts: Findings from Indonesia. SAGE Publications, 38(3), 302-323.

Bronfenbrenner, U. (1979). The ecology of human development: Experiments by nature and design. Cambrigde: Harvard University Press.

Bronfenbrenner, U. (1994). Ecological models of human development. In Oxford (Ed.), International Encyclopedia of Education (Vol. 3, pp. 1643-1647): Elsevier.

Brown, A. V. (2009). Students' and teachers' perceptions of effective foreign language teaching: A Comparison of ideals. The Modern Language Journal, 93(1), 46-60. doi: 10.1111/j.1540-4781.2009.00827.x

Bryman, A. (2008). Social research methods. Oxford: Oxford University Press.

Campa, J. C. d. I., \& Nassaji, H. (2009). The amount, purpose, and reasons for using L1 in L2 classes. Foreign Language Annals, 42(4), 742-759.

Carson, E., \& Kashira, H. (2012). Using L1 in the L2 classroom: The students speak. The Language Teacher, 36(4), 41-48.

Chang, M. (2011). Factors affecting the implementation of communicative language teaching in Taiwanese college English classes. English Language Teaching, 4(2), 3-12. 
Charmaz, K. (2006). Constructing grounded theory. London: SAGE Publications.

Cheng, H.-F., \& Dornyei, Z. (2007). The Use of motivational strategies in language instruction: The case of EFL teaching in Taiwan. Innovation in Language Learning and Teaching, 1(1), 153-174.

Creswell, J. W. (2007). Qualitative inquiry \& research design choosing among five approach. Thousand Oaks: SAGE Publications.

Creswell, J. W. (2009). Research design qualitative, quantitative, and mixed methods approaches. Los Angeles: SAGE Publications.

Crookes, G., \& Arakaki, L. (1999). Teaching idea sources and work conditions in an ESL program. TESOL Journal, 8(1), 15-19. doi: 10.1002/j.19493533.1999.tb00151.x

Csizer, K., \& Dornyei, Z. (2005). The internal structure of language learning motivation and its relationship with language choice and learning effort. The Modern Language Journal, 89, 19-36.

Cummins, J., \& Davidson, C. (2007). The global scope and politics in ELT. In J. Cummins \& C. Davidson (Eds.), International Handbook of English Language Teaching (pp. 1-11). New York: Springer.

Cummins, J., \& Davison, C. (2007). International handbook of English language teaching (Vol. 11.). New York: Springer.

Denzin, N. K., \& Lincoln, Y. S. (2008). Strategies of qualitative inquiry. Los Angeles: SAGE Publications.

Depdiknas. (2006). Pedoman kurikulum tingkat satuan pendidikan. Jakarta: Depdiknas.

Depdiknas. (2007). Pedoman penjaminan mutu sekolah/madrasah bertaraf international jenjang pendidikan dasar dan menengah. Jakarta: Direktorat Tenaga Kependidikan, Direktorat Jenderal Peningkatan Mutu Pendidik dan Tenaga Kependidikan, Departemen Pendidikan Nasional.

Depdiknas. (2008). Kurikulum tingkat satuan pendidikan. Jakarta: Indonesian Ministry of Education.

Dörnyei, Z. (1990). Conceptualizing motivation in foreign-language learning. Language Learning, 40(1), 45-78.

Dörnyei, Z. (1994). Motivation and motivating in the foreign language classroom. The Modern Language Journal, 94, 273-284.

Dörnyei, Z. (1998). Motivation in second and foreign language learning. Language Teaching, 31, 117-135.

Dörnyei, Z. (2001). Motivational strategies in language classroom. Cambridge: Cambridge University Press.

Dörnyei, Z. (2005). The psychology of the language learner individual differences in second language acquisition. New York: Lawrence Erlbaum Associates, Inc.

Dörnyei, Z. (2009a). The L2 motivational self system. In Z. Dörnyei \& E. Ushioda (Eds.), Motivation, language identity, and the L2 self (pp. 9-42). Bristol: Multilingual Matters.

Dörnyei, Z. (2009b). The psychology of second language learning. Oxford: Oxford University Press.

Dörnyei, Z. (2010a). The relationship between language aptitude and language learning motivation: Individual differences from a dynamic systems perspective. In I. E. M. (Ed.) (Ed.), Continuum companion to second language acquisition (pp. 247-267). London: Continuum.

Dörnyei, Z. (2010b). Researching motivation: from integrativeness to the ideal L2 self. In S. Hunston \& D. Oakey (Eds.), Introducing Applied Linguistics: Concepts and Skills (pp. 74-83). London: Routledge.

Dörnyei, Z. (2014). Motivation in second language learning. In M. Celce-Murcia, D. M. Brinton \& M. A. Snow (Eds.), Teaching English as a second or foreign language (pp. 518-531). Boston: National Geographic Learning/Cengage Learning. 
Dörnyei, Z., \& Ushioda, E. (2011). Teaching and researching motivation. Harlow: Pearson Education Limited.

Edstrom, A. (2007). L1 Use in the L2 classroom: One teacher's self-evaluation. The Canadian Modern Language 63(2), 275-292.

Ellis, R. (2008). The study of second language acquisition. Oxford: Oxford University Press.

Ellis, R. (2009). Task-based language teaching: Sorting out the misunderstandings. International Journal of Applied Linguistics, 19(3), 221-246. doi: 10.1111/j.1473-4192.2009.00231.x

Gardner, R. C. (1999). Correlation, causation, motivation, and second language acquisition. Canadian Psychology, 41(1), 10-24.

Gardner, R. C. (2001). Language learning motivation: The student, the teacher, and the researcher. Texas Papers in Foreign Language Education, 6(1), 1-18.

Gardner, R. C. (2007). Motivation and second language acquisition. Porta Linguarium, 8, 9-20.

Gardner, R. C., \& Lambert, W. E. (1959). Motivational variables in second language acquisition. Canadian Journal of Psychology, 13(4), 266-272.

Gardner, R. C., Masgoret, A. M., Tennant, J., \& Mihic, L. (2004). Integrative motivation: Changes during a year-long intermediate-level language. Language Learning, 54(1), 1-34.

Gardner, R. C., \& Tremblay, P. F. (1994). On motivation, research agendas, and theoretical framework. The Modern Language Journal, 78(3), 359-368.

Ghenghesh, P. (2010). The motivation of L2 learners: Does it increase with age. English Language Teaching 3(1), 128-141.

Grass, S. M., \& Mackey, A. (2000). Stimulated recall in second language research: Marwah, NJ: Lawrence Erlbaum Associates, Publisher.

Guba, E. G., \& Lincoln, Y. S. (1994). Competing paradigms in qualitative research. In N. K. Denzim \& Y. S. Lincoln (Eds.), Handbook of qualitative research (pp. 105-117). Thousand Oaks: SAGE Publications.

Guilloteaux, M.-J. (2013). Motivational strategies for the language classroom: Perceptions of Korean secondary school English teachers. ELSEVIER, 1-12.

Guilloteaux, M.-J. (2013). Motivational strategies for the language classroom: Perceptions of Korean secondary school English teachers. Elsevier, 41(1), 314. doi: http://dx.doi.org/10.1016/i.system.2012.12.002

Guilloteaux, M.-J., \& Dornyei, Z. (2008). Motivating language Learners: A classroom-oriented investigation of the effects of motivational strategies on student motivation. TESOL Journal, 42(1), 55-77.

Hadisantosa, N. (2010). Insights Indonesia. In B. Council (Ed.), Learning through English: Policies, chalenges, and prospects: British Council. Retrieved from www.britishcouncil.org/accessenglish.

Hall, C. (2007). Normative and interpretive research paradigms. School of Educaton Studies, Victoria University of Wellington, (Class handout). Wellington.

Hall, C., \& Kidman, J. (2004). Teaching and learning: Mapping the contextual influences. International Education Journal, 5(3), 331-343.

Hall, G., \& Cook, G. (2013). Own-language use in ELT: exploring global practices and attitudes. British Council, 10, 1-48.

Hardre, P. L., Huang, S.-H., Chen, C.-H., Chiang, C.-T., Jen, F.-L., \& Warden, L. (2006). High school teachers' motivational perception and strategies in an East Asian nation. Asia-Pasific Journal of Teacher Education, 34(2), 199221.

Hattie, J., \& Timperley, H. (2007). The power of feedback. Review of Educational Research, 77(1), 81-112.

Hesse-Biber, S. N., \& Leavy, P. (2006). The practice of qualitative research. Thousand Oaks: SAGE Publications.

Hullena, T. (2008). Student-teacher relationships/rapport in physical education: $A$ perspective from New Zealand secondary schools. Master of Education, 
Victoria University of Wellington. Retrieved from http://hdl.handle.net/10063/1762

Hummel, K. M. (2013). Introducing second language acquisition : Perspectives and practices Vol. 1. (pp. 267). Retrieved from http://VUW.eblib.com/patron/FullRecord.aspx?p=1582375

Jesus, S. N. d., \& Lens, W. (2005). An integrated model for the study of teacher motivation. Applied Psychology: An International Review, 54(1), 119-134.

Jindal, D. (2013, 2013/05//). Let's humanize language teaching by using L1. Language in India, 13, 221-227.

Johnson, B., \& Christensen, L. (2008). Educational research quantitative, qualitative, and mixed method approaches. Los Angeles: Sage Publications.

Kassing, R. B. (2011). Perception of motivational teaching strategies in an EFL classroom: The case of a class in a private university in Indonesia. Master Degree, Victoria University of Wellington, Wellington.

Khatib, M., \& Najafi, S. (2012). An investigation of motivational strategies used by L2 language teachers to promote English language learning: A case of Iranian high school students. Advances in English Linguistics, 1(4), 85-90.

Kikuchi, K. (2009). Listening to our learners' voices: What demotivates Japanese high school students? Language Teaching Research, 13(4), 453-471.

Kumaravadivelu, B. (2005). Understanding language teaching : From method to postmethod Retrieved from http://VUW.eblib.com/patron/FullRecord.aspx?p=261419

Lamb, M. (2004a). Integrative motivation in a globalizing world. System, 32(1), 3-19. doi: 10.1016/j.system.2003.04.002

Lamb, M. (2004b). It depends on the students themselves: Independent language learning at an Indonesian state school. Language Culture and Curriculum, $17(3), 229-245$.

Lamb, M. (2007). The impact of school on EFL learning motivation: An Indonesian case study. TESOL Quarterly, 41(4), 757-780.

Lamb, M., \& Budiyanto. (2013). Cultural challenges, identity and motivation in state school EFL. In E. U. (Ed.) (Ed.), International Perspectives on Motivation: Language Learning and Professional Challenges (pp. 18-34). Basingstoke: Palgrave Macmillan.

Lamb, M., \& Coleman, H. (2008). Literacy in English and the transformation of self and society in post-Soeharto Indonesia. The International Journal of Bilingual Education and Bilingualism, 11(2), 189-205.

Lasagabaster, D. (2011). English achievement and student motivation in CLIL and EFL setting. Innovation in Language Learning and Teaching, 5(1), 3-18.

Lauder, A. (2008). The status and function of English in Indonesia: A review of key factors. Sosial Humaniora, 12(1), 9-20.

Lee, J. H., \& Macaro, E. (2013). Investigating age in the use of L1 or English-only instruction: Vocabulary acquisition by Korean EFL learners. Modern Language Journal, 97(4), 887-901.

Lee, N. (2008). Second language teacher motivation: An exploration into classroom strategies. OnCUE Journal, 2, 133-144.

Levine, G. S. (2013). The case for a multilingual approach to language classroom communication. Language and Linguistics Compass, 7(8), 423-436. doi: 10.1111/Inc3.12036

Liando, N. V. F., Moni, K. B., \& Baldauf, J. R. B. (2005). Student motivation in learning English as a foreign language in an Indonesian context. In $\mathrm{J}$. Yamanashi \& I. Milojevic (Eds.), Researching identity, diversity, and education: Surpassing the norm (pp. 168-179).

Lie, A. (2007). Education policy and EFL curriculum in Indonesia: Between the commitment to competence and the quest for higher test score. TEFLIN Journal, 18(1), 1-14. 
Lightbown, P. M., \& Spada, N. (2006). How languages are learned. Oxford: Oxford University Press.

Lincoln, Y. S., Lynham, S. A., \& Guba, E. G. (2011). Paradigmatic controversies, contraditions, and emerging confluences, revisited. In N. K. Denzim \& Y. S. Lincoln (Eds.), The SAGE Handbook of Qualitative Research. Los Angeles: SAGE.

Littlewood, W. (2007). Communicative and task-based language teaching in East Asian classrooms. Language Teaching, 40(3), 243-249. doi: $10.1017 /$ S0261444807004363

Liu, J. (2008). L1 Use in L2 vocabulary learning: Facilitator or barrier. International Education Studies, 1(2), 65-69.

Macaro, E., \& Lee, J. H. (2013). Teacher language background, codeswitching, and English-only instruction: Does age make a difference to learners' attitudes? TESOL Quarterly, 47(4), 717-742. doi: 10.1002/tesq.74

Maclntyre, P. D. (2002). Motivation, anxiety, and emotion in second language acquisition. In P. Robinson (Ed.), Language Learning and Language Teaching. Amsterdam: John Benyamins Publishing Company.

Maguire, M., Ball, S., \& Braun, A. (2010). Behaviour, classroom management and student 'control': Enacting policy in the English secondary school. International Studies in Sociology of Education, 20(2), 153-170.

Marcellino, M. (2008). English language teaching in Indonesia: A continuous challenge in education and cultural diversity. TEFLIN Journal, 19(1), 57-69.

Matsumoto, M. (2009). Second language learner's motivation and their perceptions of teachers' motivation. Paper presented at the Teaching and Learning in Higher Education, Bond University, Australia.

Matsumoto, M. (2011). Second language learner's motivation and their perception of their teachers as an affecting factor. New Zealand Studies in Applied Linguistics, 17(2), 37-52.

Mattarima, K., \& Hamdan, A. R. (2011a). Learners' motivation and learning strategies in English foreign language in Indonesian context. Edupres, 1, 100-108.

Mattarima, K., \& Hamdan, A. R. (2011b). The teaching constraints of English as a foreign language in Indonesia: The context of school based curriculum. Sosiohumanika, 4(2), 287-300.

Maulana, R., Opdenakker, M.-C., Brok, P. d., \& Bosker, R. (2011). Teacher-student interpersonal relationships in Indonesia: Profiles and importance to student motivation. Asia-Pasific Journal of Teacher Education, 31(1), 33-49.

McDonough, S. (2007). Motivation in ELT. ELT Journal, 61(4), 369-371.

McNamara, D. S., Levinstein, I. B., \& Boonthum, C. (2004). iSTART: Interactive strategy training for active reading and thinking. Behavior Research Methods, Instruments \& Computers, 36(2), 222-233. doi: http://dx.doi.org/10.3758/BF03195567

Merriam, S. B. (1988). Case study research in education. San Fransisco: JosseyBass.

Montalvo, G. P., Mansfield, E. A., \& Miller, R. B. (2007). Liking or disliking the teacher: Student motivation, engagement, and achievement. Evaluation and Research in Education, 20(3), 144-158.

Moskovsky, C., Alrabai, F., Paolini, S., \& Racheva, S. (2013). The effect of teacher's motivational strategies on learners' motivation: A controlled investigation of second language acquisition. Language Learning, 63(1), 34-62.

Myburgh, O., Poggenpoel, M., \& Resburg, W. V. (2004). Learner's experience of teaching and learning a second or third language. Education, 124(3), 573584.

Nakata, Y. (2006). Motivation and experience in foreign language learning. Oxford: Peter Lang. 
Nation, P. (2003). The role of first language in foreign language learning. Asian EFL Journal, 1-8.

Nugroho, R. A. (2007). Motivational teaching strategies employed by English teachers in Yokyakarta. Master of Art, Ming Chuan University. Retrieved from http://vuw.summon.serialssolutions.com

Nunan, D., \& Bailey, K. M. (2009). Exploring second language classroom research: A comprehensive guide. Australia: Heinle Cengage Learning.

Oxford, R., \& Shearin, J. (1994). Language learning motivation: Expanding the theorical framework. The Modern Language Journal, 94, $12-28$.

Pakzadian, M. (2012). The effect of L1 on learning new L2 vocabulary among intermediate proficiency level students. Theory and Practice in Language Studies, 2(6), 1147-1152.

Palmer, D. J., Stough, L. M., Burdenski, T. K., \& Gonzales, M. (2005). Identiying teacher expertise: An examination of researchers' decision making. Educational Psychology, 40(1), 13-25.

Papi, M., \& Abdollahzadeh, E. (2011). Teacher motivational practice, student motivation, and possible L2 selves: An examination in the Iranian EFL context. Language Learning, 20(10), 1-24. doi: DOI: 10.1111/j.14679922.2011.00632.x

Raoofi, S., Tan, B. H., \& Chan, S. H. (2012). Self-efficacy in second/foreign language learning contexts. English Language Teaching, 5(11), 60-73. doi: 10.1016/j.sbspro.2009.01.274.

Richards, K. (2003). Qualitative inquiry in TESOL. Macmillan: Palgrave

Ruesch, A. (2012). Student and teacher perceptions of motivational strategies in the foreign language classroom. Innovation in Language Learning and Teaching, 6(1), 15-27.

Ruesch, A., Bown, J., \& Dewey, D. P. (2011). Student and teacher perceptions of motivational strategies in the foreign language classroom. Innovation in Language Learning and Teaching, 6(1), 15-27. doi: $10.1080 / 17501229.2011 .562510$

Ryan, R. M., \& Deci, E. L. (2000). Intrinsic and extrinsic motivation: Classic definitions and new direction. Contemporary Educational Psychology, 25, 5467.

Sahinkarakas, S. (2011). Young students' success and failure attributions in language learning. Social Behaviour and Personality, 39(7), 879-886.

Sakui, K., \& Cowie, N. (2012). The darkside of motivation: Teachers' perspectives on 'unmotivated'. ELT Journal, 66(2), 205-213.

Shishavan, H. B. (2010). The relationship between Iranian English language teachers' and learners' gender and their perceptions of an effective English language teacher. English Language Teaching, 3(3), 3-10.

Shishavan, H. B., \& Sadeghi, K. (2009). Characteristics of an effective English language teacher as perceived by Iranian teachers and learners of English. English Language Teaching, 2(4), 130-143.

Silverman, D. (2005). Doing qualitative research. London: SAGE Publications.

Steinhauer, H. (1994). The Indonesian language situation and linguistics: Prospects and possibilities. Bijdragen tot de Taal-, Land- en Volkenkunde, 150(4), 755784. doi: $10.2307 / 27864615$

Sugita, M., \& Takeuci, O. (2010). What can teachers do to motivate their students? A classroom research on motivational strategy use in Japanese EFL context. Innovation in Language Learning and Teaching, 4(1), 21-35. doi: DOI: 10.1080/17501220802450470

Sugita McEown, M., \& Takeuchi, O. (2012). Motivational strategies in EFL classrooms: How do teachers impact students' motivation? Innovation in Language Learning and Teaching, 8(1), 20-38. doi: $10.1080 / 17501229.2012 .741133$

Syarifah, F. (2013). Indonesian population is estimated 250 billions, Liputan 6.com. 
Taras, M. (2009). Summative assessment: The missing link for formative assessment. Journal of Further and Higher Education, 33(1), 57-69. doi: $10.1080 / 03098770802638671$

Tuan, L. T. (2012). An empirical research into EFL learner's motivation. Theory and Practice in Language Studies, 2(3), 430-439. doi: 10.4304/tpls.2.3.430-439

Ushioda, E. (2008). Motivation and good language learners. In C. Griffiths (Ed.), Lessons from good language learners. Cambridge: Cambridge University Press.

Ushioda, E., \& Dornyei, Z. (2012). Motivation. In S. Gass \& A. Mackey (Eds.), The Routledge handbook of second language acquisition (pp. 396-409). New York: Routledge.

Weiner, B. (2000). Intrapersonal and interpersonal theories of motivation from an attributional perspective. Educational Psychology Review, 12(1), 1-14.

Xavier, G. d. O. (2005). Motivational teaching strategies in Brazilian EFL school: How important are they and how frequently are they used. Master of Arts, Ohio University, Ohio.

Yeung, A. S., Lau, S., \& Nie, Y. (2011). Primary and secondary students' motivation in learning English: Grade and gender differences. Contemporary Educational Psychology, 36, 246-256.

Yin, R. K. (2003). Case study research design and methods (Vol. 5). California: SAGE Publications.

Yin, R. K. (2009). Case study research design and method. Los Angeles: SAGE Publications.

Yuwono, G. (2005). English language teaching in decentralised Indonesia: Voices from the less privileged schools. Paper presented at the International Education Research Conference, Parramatta. 


\section{APPENDICES}

\section{Appendix A: Ethical Approval Letter}

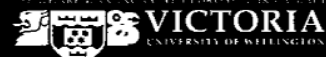 \\ FACULTY OF EDUCATION PO Box 17-310 Wellington 6012, New Zealand \\ Website www.victoria.ac.nz}

19 January 2012

Sri Puji Astuti

PhD Student

Victoria University of Wellington Faculty of Education

$\mathrm{C} /$ - School of Educational Psychology and Pedagogy

Donald Street

Wellington

Dear Sri Puji

\section{RE: Ethics application SEPP/2011/86: RM 19040}

I am pleased to advise you that your ethics application 'Teachers' and Students' Perception of Motivational Teaching Strategies in Indonesian High School Context', with requested amendments, has been approved by the Victoria University of Wellington Faculty of Education Ethics Committee. Please note that the approval for your research to commence is from the date of this letter.

Best wishes for your research.

Yours Sincerely

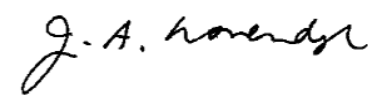

Dr Judith Loveridge

Co-Convener

Victoria University of Wellington Faculty of Education Ethics Committee 


\section{Appendix B: Teacher Interview Question}

Teachers' and students' perceptions of motivational teaching strategies in an Indonesian high school context

\section{Teacher Interview Question}

The questions are indicative. The questions are translated into the participants' home language by the researcher. The interview open-ended questions are designed to answer research questions 1 and 2 (How do Indonesian teachers of English in high schools report their perceptions of motivational teaching strategies? How do teachers implement motivational teaching strategies in the Indonesian EFL classroom context?).

1. Tell me how you make the teaching of English interesting for your students in the classroom?

2. Tell me the strategies that really work to make your students learn?

3. How do you keep your students motivated even when learning English seems difficult?

4. How do you decide which strategies to use to motivate your students to learn?

5. How do you know that your strategies are effective in motivating your students to learn? 


\section{Appendix C: Classroom Observation-Possible indicative codes}

Teachers' and students' perceptions of motivational teaching strategies in an Indonesian high school context

The classroom observation is aimed to answer research question 2 (How do teachers implement motivational teaching strategies in the Indonesian EFL classroom context?) I used MOLT as a guide (motivational orientation of language learning) observation scheme.

MOLT Part B: Post-Lesson Evaluation of the Teacher

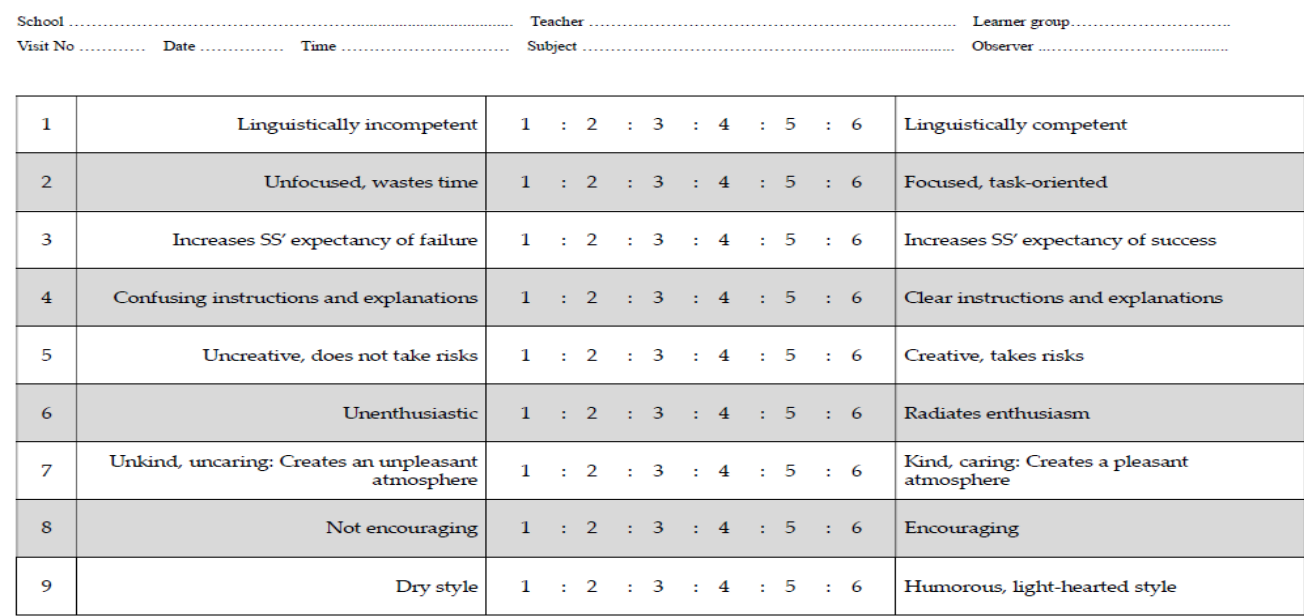

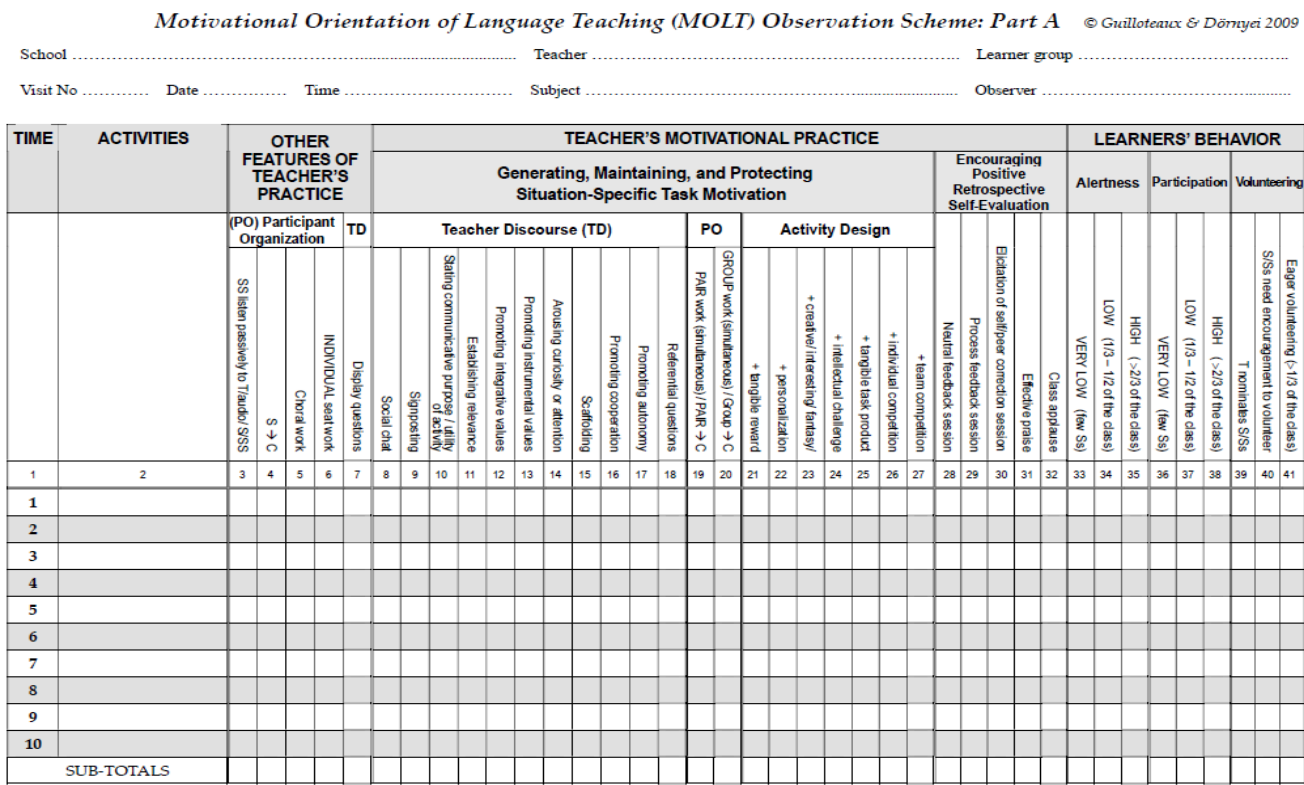




\section{Appendix D: Teacher stimulated recall}

Teachers' and students' perceptions of motivational teaching strategies in an Indonesian high school context

1. Why did you use (certain strategy e.g. jokes, songs, short stories, gesture, facial expression, stress and intonation) in your classroom?

2. Why did you use pair work/group work? 


\section{Appendix E: Student Focus Group Question}

Teachers' and students' perceptions of motivational teaching strategies in an Indonesian high school context

The focus group for students is aimed to answer research question 3 (How do students report their perception of motivational teaching strategies?). The indicative theme questions were:

1. What sort of things work for you in learning English in the classroom context?

2. What things get in your way when you are trying to learn English in the classroom?

3. What classroom activities make you want to try even harder to learn English in the classroom?

4. Tell me some of the things that the teacher does that really make you want to learn English?

5. Why are these strategies (as above) effective in motivating you to learn English 


\section{Appendix F: Student Consent}

Student Consent

Information for school student participants in the class being observed

\section{Teachers' and students' perceptions of motivational teaching strategies in an Indonesian high school context}

Dear Student,

I am a doctoral student in the Faculty of Education at Victoria University of Wellington, New Zealand. I am especially interested in how teachers of English motivate their learners in an English language classroom. I would like to invite you to participate in my study. If you agree to participate, I will observe your class. I would like your permission to:

1. Video you as part of the class during two lessons;

2. Show this video to my supervisors (two staff members of Victoria University) and to your teacher.

I will keep the video secure so that other people cannot see it. I will store it on a password protected computer system and destroy it after five years. Participating or not participating will not affect your grades in any way.

If you agree to participate but later change your mind, you can withdraw by contacting me within one week after the video recording of the class.

By observing your class, I aim to see what kind of activities in your class encourages you to learn. This may help teachers understand how their teaching motivates students. I will use the data that I gather to present at conferences, in my thesis and in other publications. You will be given another name and you will not be identified in any way in presentations or publications. You are encouraged to discuss this with your parents and should you have any questions you can contact me or my supervisors.

If you are willing to participate, please sign the attached consent form.

Yours sincerely,

Sri Puji Astuti

Sri Puji Astuti

PhD student

School of Educational Psychology and Pedagogy

Faculty of Education

Victoria University of Wellington

Email: cici.astuti@vuw.ac.nz

Carolyn Tait

School of Educational Psychology and Pedagogy

Faculty of Education

Victoria University of Wellington

Wellington, New Zealand

Email: Carolyn.tait@vuw.ac.nz
Allison Kirkman

Chair of the Victoria University of Wellington

Human Ethics Committee

Email: Allison.Kirkman@vuw.ac.nz

Emeritus Professor Cedric Hall

School of Educational Psychology and Pedagogy

Faculty of Education

Victoria University of Wellington

Wellington, New Zealand

Email: $\underline{\text { Cedric.hall@ vuw.ac.nz }}$ 


\section{Appendix G: Student consent form for classroom observation}

Student consent form for classroom observation

Teachers' and students' perceptions of motivational teaching strategies in an Indonesian high school context

Please read the following statements about your participation in this study and tick each box if you agree with the statement.

I have read the information sheet

I have talked about this study with my parents

I know I can ask the researchers questions about the research

I understand that the researchers (Sri Puji Astuti) will show the video to her supervisors and at conferences

I understand that I may withdraw from the research at any time up to one week following the completion of all recordings

I understand that the video will be destroyed five years after its completion

I agree to be filmed for this video

I give permission for the researchers to use the video in scholarly research and for educational publication

Signed:

(Student)

Date:

Thank you for agreeing to participate in our study. If you have any further questions, please email me.

Sri Puji Astuti

sripujiastuti@yahoo.com 


\title{
Appendix H: Information for student participants for focus
}

\section{group}

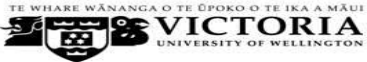 \\ Faculty of Education

\section{Information for student participants for focus group}

Teachers' and students' perceptions of motivational teaching strategies in an Indonesian high school context

Dear student,

I am a doctoral student in the Faculty of Education at Victoria University of Wellington, New Zealand. I am especially interested in how teachers of English motivate their learners in an English language classroom. I would like to invite you to participate in my study. If you agree to participate, I will conduct a group interview. I would like your permission to:

1. Audio-record you during a group interview;

2. Ask you some questions dealing with your teacher's motivational teaching strategies;

3. Write about the impact of your teacher's motivational strategies on your motivation. This will be published so that other educators can learn from it.

The interview will take about one hour and will take place outside class hours. The interview will be held at school.

If you agree to participate but later change your mind, you can withdraw by contacting me within one week after the audio recording of the interview. Participating or not participating will not affect your grades in any way.

I will keep the audio-record secure so that other people cannot listen to it. I will store it in a locked drawer and destroy it after five years.

By conducting a group interview, I aim to know what kind of activities in your class encourages you to learn. This may help teachers understand how their teaching motivates students. I will use the data that I gather to present at conferences, in my thesis and in other publications. You will be given another name and you will not be identified in any way in presentations or publications. You are encouraged to discuss this with your parents and should you have any questions you can contact me or my supervisors.

Yours sincerely,

\section{Sri Puji Astuti}

Sri Puji Astuti

PhD student

School of Educational Psychology and Pedagogy

Faculty of Education

Victoria University of Wellington

Email: cici.astuti@ vuw.ac.nz

Carolyn Tait

School of Educational Psychology and Pedagogy

Faculty of Education

Victoria University of Wellington

Wellington, New Zealand

Email: Carolyn.tait@vuw.ac.nz

\section{Allison Kirkman}

Chair of the Victoria University of Wellington

Human Ethics Committee

Email: Allison.Kirkman@ vuw.ac.nz
Emeritus Professor Cedric Hall

School of Educational Psychology and Pedagogy

Faculty of Education

Victoria University of Wellington

Wellington, New Zealand

Email: Cedric.hall@vuw.ac.nz 


\section{Appendix I: Student consent form for focus group interview}

Faculty of Education

\section{Student consent form for focus group interview}

Teachers' and students' perceptions of motivational teaching strategies in an Indonesian high school context

Please read the following statements about your participation in this study and tick each box if you agree with the statement.

I have read the information sheet

I have talked about this study with my parents

I know I can ask the researchers questions about the research

I understand that the researchers (Sri Puji Astuti) will use the group interview transcription as data and discuss it with her supervisors

I understand that I may withdraw from the research at any time up to one week following the completion of all recordings

I understand that the audio-record will be destroyed five years after its completion

I agree to be recorded in the group interview

I give permission for the researchers to use the transcript of the recording in scholarly research and for educational publication

Signed:

(Student)

Date:

Thank you for agreeing to participate in my study. If you have any further questions, please email me.

Sri Puji Astuti

sripuiiastuti@yahoo.com 


\title{
Appendix J: Information for teacher participants
}

\author{
Faculty of Education
}

\section{Information for teacher participants \\ Teachers' and students' perceptions of motivational teaching strategies in an Indonesian high school context}

Dear Teacher,

I am a doctoral student in the Faculty of Education at Victoria University of Wellington, New Zealand. I am interested in investigating teacher motivational strategies. I am especially interested in how teachers of English motivate their learners in the classroom. I would like to invite you to participate in an individual interview, two classroom observations and two interviews about these observations. All interviews will take about one hour. Each classroom observation will cover one class session. I would like your permission to:

1. Audio-record you during interviews;

2. Transcribe the recordings;

3. Video you during two lessons as you are teaching in the classroom;

4. Show this video to my supervisors;

5. Write about how you motivate your students and the impact of your teaching strategies on your students.

By interviewing and observing your teaching, I aim to see what activities in your class encourage your students to learn. This may help you and other teachers of English understand how their teaching motivates students.

I will use the data that I gather to present at conferences, in my thesis and in other publications. You will be given another name and you will not be identified in any way in presentations or publications.

If you agree to participate but later change your mind, you can withdraw by contacting me within one week after the recordings have been completed.

I will keep the recordings secure so other people cannot access them. I will store them in a locked drawer or password protected file. All recordings will be destroyed after five years.

I look forward to interviewing and videoing you as part of the data collection for my research. I hope that you will be willing to participate. If you have any questions you can contact me or my supervisors.

Yours sincerely,

Sri Puji Astuti

Sri Puji Astuti

PhD student

School of Educational Psychology and Pedagogy

Faculty of Education

Victoria University of Wellington

Email: cici.astuti@vuw.ac.nz

Carolyn Tait

School of Educational Psychology and Pedagogy

Faculty of Education

Victoria University of Wellington

Wellington, New Zealand

Email: Carolyn.tait@vuw.ac.nz
Allison Kirkman

Chair of the Victoria University of Wellington

Human Ethics Committee

Email: Allison.Kirkman@vuw.ac.nz

Emeritus Professor Cedric Hall

School of Educational Psychology and Pedagogy

Faculty of Education

Victoria University of Wellington

Wellington, New Zealand

Email: Cedric.hall@vuw.ac.nz 


\section{Appendix K: Teacher consent}

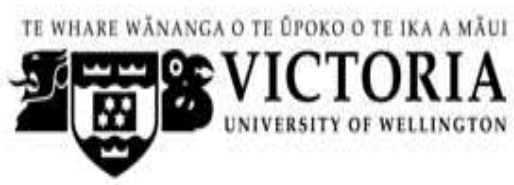

Faculty of Education

\section{Teachers' and students' perceptions of motivational teaching strategies in an Indonesian high school context}

\section{Teacher consent}

Please read the following statements about your participation in this study and tick each box if you agree with the statement.

I have read the information sheet

I know I can ask the researchers questions about the research

I understand that the researchers (Sri Puji Astuti) will show the interview transcript and the video to her supervisors

$\square$ I understand that I may withdraw from the research at any time up to one week following the completion of all recordings

] I understand that the recording of the interviews and videos will be destroyed after five years

I agree to be interviewed, and filmed during teaching

I give permission for the researcher to use the audio-record and the videorecord in scholarly research

Signed:

(Teacher)

Date:

Thank you for agreeing to participate in my study. If you have any further questions, please email me. 


\section{Appendix L: Information for the Principal}

Faculty of Education

\section{Teachers' and students' perceptions of motivational teaching strategies in an Indonesian high school context}

\section{Information for the Principal}

Dear Sir/Madam,

I am a doctoral student in the Faculty of Education at Victoria University of Wellington, New Zealand. I am interested in investigating teacher motivational strategies. I am especially interested in how teachers of English motivate their learners in the classroom. I would like to invite one of your teachers of English and one group of his/her students to participate in my research. I would like your permission to:

1. Interview one of your teachers of English;

2. Video the teacher and his/her students during two lessons;

3. Conduct a group interview with the students, about one hour, to be held at the school but outside of class hours;

4. Show the audio and video recordings to my supervisors.

If your teacher and the students agree to participate but later change their minds, they can withdraw by contacting me within one week after the recording.

In the write up of my research, or in any publications and communications arising from my research, I will not identify your school by name nor will I identify any individual participants.

I look forward to including one of your teachers of English and his/her students as participants in my research. I hope that you can give permission to your teacher and students to participate. You may ask any questions you wish at any time. My email address is below.

Yours sincerely,

\section{Sri Puji Astuti}

Sri Puji Astuti

$\mathrm{PhD}$ student

School of Educational Psychology and Pedagogy

Faculty of Education

Victoria University of Wellington

Email: cici.astuti@ vuw.ac.nz

Carolyn Tait

School of Educational Psychology and Pedagogy

Faculty of Education

Victoria University of Wellington

Wellington, New Zealand

Email: Carolyn.tait@vuw.ac.nz
Allison Kirkman

Chair of the Victoria University of Wellington

Human Ethics Committee

Email: Allison.Kirkman@vuw.ac.nz

Emeritus Professor Cedric Hall

School of Educational Psychology and Pedagogy

Faculty of Education

Victoria University of Wellington

Wellington, New Zealand

Email: Cedric.hall@vuw.ac.nz 


\section{Appendix M: Principal approval form}

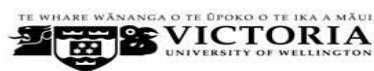

Faculty of Education

\section{Principal approval form \\ Teachers' and students' perceptions of motivational teaching strategies in an Indonesian high school context}

Please read the following statements about participating in this study and tick each box if you agree with the statement.

I have read the information sheet

I have been given an opportunity to ask questions about the research

I agree for one teacher of English and his/her students to be interviewed

I agree for one class in my school to be video-recorded twice for the purpose of the research

I understand that the researcher will allow her supervisors to view the interview transcripts and video

$\square \quad$ I understand that I may withdraw my school from the research at any time up to one week following the completion of all recordings

- I understand that the recordings will be destroyed after five years

$\square$ I give permission for the researcher (Sri Puji Astuti) to invite a teacher of Signed:

English and his/her students to participate in this research

Date:

Thank you for assisting me with my study. If you have any further questions, please email me.

Sri Puji Astuti

sripujiastuti@yahoo.com

Sri Puji Astuti

PhD student

School of Educational Psychology and Pedagogy

Faculty of Education

Victoria University of Wellington

Email: cici.astuti@vuw.ac.nz

\section{Carolyn Tait}

School of Educational Psychology and Pedagogy Faculty of Education

Victoria University of Wellington

Wellington, New Zealand

Email: Carolyn.tait@vuw.ac.nz
Allison Kirkman

Chair of the Victoria University of Wellington

Human Ethics Committee

Email: 12Allison.Kirkman@vuw.ac.nz

Emeritus Professor Cedric Hall

School of Educational Psychology and Pedagogy Faculty of Education

Victoria University of Wellington

Wellington, New Zealand

Email: Cedric.hall@vuw.ac.nz 